\title{
Emerging technologies to study glial cells
}

\author{
Héléne Hirbec ${ }^{1 *}$, Nicole Déglon ${ }^{2,3}$, Lynette C. Foo ${ }^{4}$, Inbal Goshen ${ }^{5}$, Jaime Grutzendler ${ }^{6,7}$ \\ Emilie Hangen ${ }^{8,9}$, Tirzah Kreisel $^{5}$, Linck Nathalie ${ }^{1}$, Julien Muffat ${ }^{10}$, Sara Regio ${ }^{2,3}$, Sybille Rion ${ }^{4}$, Carole \\ Escartin $8,9^{*}$
}

${ }^{*}$ Corresponding authors

\section{Affiliations}

${ }^{1}$ Institute for Functional Genomics (IGF), University of Montpellier, CNRS, INSERM, Montpellier, France.

${ }^{2}$ Lausanne University Hospital and University of Lausanne, Department of Clinical Neuroscience and University of Lausanne, Laboratory of Neurotherapies and Neuromodulation, Lausanne, Switzerland.

${ }^{3}$ Lausanne University Hospital and University of Lausanne, Neuroscience Research Center, Laboratory of Neurotherapies and Neuromodulation, Lausanne, Switzerland.

${ }^{4}$ Neuroimmunology and neurodegeneration section, The Neuroscience and Rare Diseases Discovery and Translational Area, F. Hoffman-La Roche. Basel, Switzerland.

${ }^{5}$ Edmond and Lily Safra Center for Brain Sciences, The Hebrew University of Jerusalem, Jerusalem, Israel.

6. Department of Neurology, Yale University School of Medicine, New Haven, CT, USA.

7. Department of Neuroscience, Yale University School of Medicine, New Haven, CT, USA.

${ }^{8}$ Commissariat à l'Energie Atomique et aux Energies Alternatives, Département de la Recherche Fondamentale, Institut de Biologie François Jacob, MIRCen, Fontenay-aux-Roses, France.

${ }^{9}$ Centre National de la Recherche Scientifique, Université Paris-Sud, Université Paris-Saclay, UMR 9199, Neurodegenerative Diseases Laboratory, Fontenay-aux-Roses, France.

10 Program in Neurosciences and Mental Health, The Hospital for Sick Children, and Department of Molecular Genetics, The University of Toronto, Toronto, Canada

\section{Running title}

Emerging technologies for glial cells 


\section{Acknowledgments}

This review was written by the speakers of the technical workshop held at Euroglia 2019. We thank Roche, Neuratris and SeqOne for financial support to organize the workshop. The authors are supported by CEA (CE), CNRS (CE, HH) and grants from the French National Research Agency [grants \# ANR-16-TERC-0016-01 (CE) and ANR-17-CE12-0027 (EH)], Fondation Plan-Alzheimer (HH), France Alzheimer (HH), National Institute of Health grant \# AG058257 (JG), the Swiss National Science Foundation grant \# 31003A-165834/1 (ND), the Canadian Natural Sciences and Engineering Research Council (JM), the Canada Research Chairs program (JM), European Research Council (ERC) under the European Union's Horizon 2020 research and innovation program [grant agreement No 803589 (IG)], the Israel Science Foundation [ISF grant No. 1815/18 (IG)], the Israeli Centers of Research Excellence Program [center No. 1916/12 (IG)] and the Canada-Israel grants [CIHRISF, grant No. 2591/18 (IG)].

\section{Conflict of Interest}

The authors declare no conflict of interest

\section{Word count}

Abstract: 190

Main Text: 15,773

References: 13,247

Figure \& Table Legends: 1,221

\section{Main Points}

- Many technologies are emerging to study glial cells from molecules to behaviors

- Glial cell complexity and plasticity require cell-specific, high-content and sensitive methods to study them

- Multiple techniques can be combined to provide more refined insight into glial cell (patho)physiology 


\begin{abstract}
Development, physiological functions and pathologies of the brain depend on tight interactions between neurons and different types of glial cells, such as astrocytes, microglia, oligodendrocytes, and oligodendrocyte precursor cells.

Assessing the relative contribution of different glial cell types is required for the full understanding of brain function and dysfunction. Over the recent years, several technological breakthroughs were achieved, allowing 'glio-scientists' to address new challenging biological questions. These technical developments make it possible to study the roles of specific cell types with medium or high-content workflows, and perform fine analysis of their mutual interactions in a preserved environment.

This review illustrates the potency of several cutting-edge experimental approaches (advanced cell cultures, iPSC-derived human glial cells, viral vectors, in situ glia imaging, opto- and chemo-genetic approaches and high-content molecular analysis) to unravel the role of glial cells in specific brain functions or diseases. It also illustrates the translation of some techniques to the clinics, to monitor glial cells in patients, through specific brain imaging methods. The advantages, pitfalls and future developments are discussed for each technique, and selected examples are provided to illustrate how specific 'glio-biological' questions that can now be tackled.
\end{abstract}




\section{Introduction on Glial cells}

Neurons and glial cells were first described at the same period, in the early $19^{\text {th }}$ century, using a simple microscope and the mollusk as animal model [(Dutrochet, 1824), reviewed in (Fan \& Agid, 2018)]. Virchow coined the term "neuroglia" ("Nervenkitt") in 1856 and referred it as to a type of "connective tissue" that held nervous elements together. This established the concept of "glue", which dominated the history of glial cells for a long period. About a decade later, the introduction of fixative and staining techniques allowed for a finer description of both neuronal and glial cell morphologies (Deiters, 1865; C. Golgi, 1873). By improving the "black reaction" technique implemented by Golgi, Santiago Ramon y Cajal provided the first histological evidence of the structural individuality of neurons and glial cells (Ramon y Cajal, 1888). During this period, thanks to the initial development of electrophysiology, the physiological study of nerves progressed rapidly, whereas the study of glial cells remained purely morphological. Nevertheless, careful microscopic observations suggested remarkable functions for glial cells, in particular, transport of nutrients from blood to neurons ( $\underline{\mathrm{C} \mathrm{Golgi}}$ 1875) and axon guidance in the developing brain ( $\underline{\mathrm{His}, 1888)}$. During the three following decades (1889-1921), the three main classes of glial cells of the central nervous system (CNS), namely astrocytes, oligodendrocytes and microglia, were described and the first hypotheses, regarding their roles in neurotransmission, brain function and behaviour, were put forward (reviewed in (Fan \& Agid, 2018). Pathologists also described morphological changes of glial cells under pathological conditions, and the phagocytic properties of glial cells were suggested.

In the next 30 years (1922-1950), glial research came to a standstill while the study of neurons made spectacular progress thanks to developments in cellular electrophysiology and biochemistry. Indeed, as glial cells do not generate action potentials that could be detected by the first recording techniques, and because glial cells do not directly control macroscopic body responses, such as muscle contraction, determination of their functions relied on morphological observations. Moreover, the hypotheses driven from glial cell observations could hardly be tested experimentally. In addition, the concept of "glue", inherited from the previous century, also reinforced the general dis-interest in the physiology of glial cells. Finally, in the fifties, new developments in intracellular recording methods enabled the detection of resting potential and depolarization in glial cells (Coombs, Eccles, \& Fatt, 1955; Hild, Chang, \& Tasaki, 1958). At the same time, development of histochemical techniques opened the way to biochemical studies in glial cells (Koelle, 1955).

From that point, glial research has progressed at a regular pace and changed our conceptual views of the roles of these cell types in brain function. Nowadays, glial cells are recognized to be not only support cells for neurons but active players in all important CNS processes. In brief, glial cells have a dual origin: (1) ectodermal for oligodendrocytes, oligodendrocyte progenitor cells (OPCs) and astrocytes (Allen \& Lyons, 2018), and (2) mesodermal for microglia (Prinz, Jung, \& Priller, 2019; Thion, Ginhoux, \& Garel, 2018), but all are long livedcells in the CNS. Microglia cells derived from the yolk sack invade the brain parenchyma when neural 
progenitors are actively dividing and generating the first neurons. They are the main brain immune cells, are tightly adapted to their local environment and play key roles in the surveillance and maintenance of brain homeostasis (Colonna \& Butovsky, 2017). Oligodendrocytes precursors and astrocytes are generated from neural progenitors at a later phase of fetal brain development (Bergles \& Richardson, 2015; Verkhratsky \& Nedergaard, 2018). Oligodendrocytes mature from their precursors and myelinate axons, whereas astrocytes provide trophic and metabolic support to neurons. However, over the past twenty years, it became clear that the functional role of each glial cells is much richer and complex, and that glial cells engage in many interactions not only with neurons but also among themselves. Several reviews provide a comprehensive view of how the diverse and dynamic functions of glial cells actively participate in essentially all aspects of the nervous system formation, function and dysfunction (Allen \& Barres, 2009; Allen \& Lyons, 2018; Barres, 2008). Among those, several key discoveries drastically transformed our view of glial cell roles in physiological conditions: (1) the demonstration that raising intracellular calcium $\left(\mathrm{Ca}^{2+}\right)$ concentration in astrocytes affects synaptic transmission in adjacent neurons, led to the concept of the tripartite synapse and established astrocytes as key active players in the integration of synaptic information (Araque, Parpura, Sanzgiri, \& Haydon, 1999); (2) By combining patch-clamp recording in OPC, and electron microscopy, Bergles et al. (Bergles, Roberts, Somogyi, \& Jahr, 2000) established the existence of glutamatergic synapses between neurons and OPCs. Although the physiological significance of this highly specialised form of communication is not yet clearly established, it revealed that OPCs are not solely precursors of oligodendrocytes; (3) In-vivo imaging of GFP expressing microglia revealed that they are never-resting cells that continuously move their processes, inferred a surveillance role for microglia in the brain parenchyma and opened the way to decipher microglial roles in brain physiology and pathology (Davalos et al., 2005; Nimmerjahn, Kirchhoff, \& Helmchen, 2005); (4) a lentiviral approach to knock-down the MCT1 transporter from mature myelinating oligodendrocytes revealed a key role of mature oligos in the maintenance of axonal integrity and neuronal

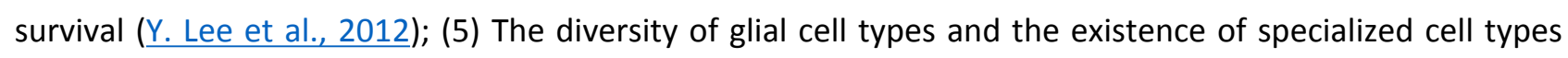
(radial glia, Schwann cells, peri-synaptic Schwann cells, etc.) was also highlighted. In addition to their physiological roles, glial cells are key drivers of neuroinflammation, which is arguably the central tenet connecting all neurodegenerative diseases (Ising \& Heneka, 2018). In many, both acute and neurodegenerative pathological conditions, glial cells undergo massive molecular and functional changes that might directly influence disease progression. Later, genetic association studies revealed that glial cells likely play important roles in the initiation and/or progression of some common neurodegenerative conditions such as Alzheimer disease (Verheijen \& Sleegers, 2018).

Application of various technologies to glial cells (i.e. electrophysiology, calcium imaging, in vivo imaging, conditional knock-out etc.), have been instrumental for further understanding of their roles in physiology and pathology. The latest technological improvements involve high-resolution and/or high-content techniques and multiparametric analyses to capture the complexity of their biological responses. In this 
review, we present a selection of in vitro, ex vivo and in vivo cutting-edge approaches that have been recently developed to study the role of glial cells in brain (dys)functions. Examples of key discoveries achieved with these approaches are presented. We also discuss the advantages, pitfalls, limitations and future developments for each of these approaches. In the near future, we believe these emerging technologies will further emphasize the importance of glial cells in brain (dys)functions. This review mainly focuses on CNS astrocytes, oligodendrocytes, OPCS and microglia, the most studied glial cells. However, some of the techniques highlighted lean on other non-neuronal cells of the brain (see (Verkhratsky, Ho, Zorec, \& Parpura, 2019) because they play important roles for brain functions.

\section{New in vitro models: opportunities and challenges}

Historically, glia were only grown to provide trophic support for cultured neurons, and therefore their isolation and culture was most certainly an after-thought. The twin realizations that glia are more than just brain-glue and that astrocytes and microglia are highly reactive cells that change their phenotype significantly when cultured have led to improved culture methods.

\section{A brief history of neural cell culture}

The development of tissue culture methods to grow neural and glial cells and their precursors was intimately linked to early work in developmental biology (Hamburger \& Levi-Montalcini, 1949). Several seminal advances allowed for the selection, purification and maintenance of primary neural and glial cultures, as well as growth and directed differentiation of tumor lines of neural and glial origin (Alliot \& Pessac, 1984; Bottenstein \& Sato, 1979; Raff, Abney, Cohen, Lindsay, \& Noble, 1983; Raff, Brockes, Fields, \& Mirsky, 1979). Enriched mixed glial cultures were initially extracted from embryonic rodent brains, by protocols relying on their staged emergence in the brain, along with selective adhesion properties (McCarthy \& de Vellis, 1980). These 'McCarthy-De Vellis' glial cultures allow for the progressive selection of highly purified OPCs and astrocytes. Later, it was determined that microglia can be harvested from the same astrocyte cultures (Giulian \& Baker, 1986).

In these cultures, serum was used as a supplement to a balanced salt and nutrient solution (Eagle, 1959) to provide an extensive cocktail of growth factors that are still difficult and expensive to generate in purified forms. As the blood-brain barrier does not allow serum entry into the brain and because serum has drastic effects on cell morphologies and functions (Figure 1A), there has been a strong effort to develop serum-free media. Minimum supplements have been defined to grow neural and glial cells without serum, allowing reproducibility and customization (Barres, 2008; Bottenstein \& Sato, 1979). In parallel, combinations of amino acid homopolymers and extracellular matrix proteins (e.g. Laminins, Fibronectin, Collagen) were used for cell attachment (Baron-Van Evercooren et al., 1982).

The more directed method of immuno-panning, which relies on the recognition of cell-surface antigens by specific antibodies, was initially developed to capture lymphocytes (Wysocki \& Sato, 1978) and was quickly 
adapted to efficiently select neurons and glia (Barres et al., 1992). Immuno-panning was then further adapted and became a precursor for successful sorting strategies such as magnetic cell sorting (Schachner, 1982; Wright, Fitzgerald, \& Colello, 1997). Later on, pure, serum-free immuno-panned cultures of retinal ganglion cells and OPCs were generated from neonatal rodents (Barres et al., 1992; Barres, Jacobson, Schmid, Sendtner, \& Raff, 1993; Meyer-Franke, Kaplan, Pfrieger, \& Barres, 1995; Meyer-Franke et al., 1998). Purified OPCs underwent apoptotic cell death in culture, highlighting their need for exogenous trophic factors, and it was then discovered that astrocytes and microglia rely on exogenous factors for survival. Identification of the crucial growth factors to culture each glial cell type in a non-reactive state without serum, has been key to refine the study of glia (Barres, Jacobson, et al., 1993; Barres, Schmid, Sendnter, \& Raff, 1993; Bohlen et al., 2017; Foo et al., 2011). These studies uncovered novel interactions between brain cells, and molecular regulation of their reactive state (Bohlen et al., 2017; Foo et al., 2011; Liddelow et al., 2017; Rothhammer et al., 2018; Scholze, Foo, Mulinyawe, \& Barres, 2014; Wheeler et al., 2019). Immuno-panning is a gentler method than other cytometry-based methods and can be implemented in any laboratory, without the need for a dedicated sorter or transgenic animals with cell type-specific fluorescent transgenes. In general, immuno-panning affords a good yield of purified cells.

The availability of murine embryonic stem cells (ESCs; (Evans \& Kaufman, 1981; Martin, 1981) soon provided another means to obtain neural and glial cells, through a deterministic in vitro process. Amphibian, avian, and eventually rodent models revealed the need for BMP antagonism, to give rise to neural precursor cells (Ang, Conlon, Jin, \& Rossant, 1994; Graff, Thies, Song, Celeste, \& Melton, 1994; Smith \& Harland, 1992). The effects of retinoic acid (Durston et al., 1989; Sive, Draper, Harland, \& Weintraub, 1990) and sonic hedgehog (Echelard et al., 1993; Riddle, Johnson, Laufer, \& Tabin, 1993) in the spatial patterning of the differentiating neural axis were also demonstrated. This led to the development of several methods to generate neural and glial precursor cells, originally identified in rodent fetal and adult brains, and thereby neurons, astrocytes and oligodendrocytes (Fraichard et al., 1995; Mujtaba et al., 1999; Okabe, Forsberg-Nilsson, Spiro, Segal, \& McKay, 1996).

\section{From rodent to human cell cultures}

Both 'McCarthy-De Vellis' and immuno-panned-based glial rodent protocols have been applied to fetal human cells. They can even be applied to adult human brain cells (Nunes et al., 2003; Sim et al., 2011; Windrem et al., 2004). However, the use of human fetal samples is naturally limited by ethical concerns and regulatory constraints, while available material from adult humans is largely restricted to abnormal tissue and pathological states.

When human ESCs and later human induced pluripotent stem cells (hiPSCs) became available, protocols similar to those implemented for rodent ESC cultures allowed the generation of human neural precursor cells (Chambers et al., 2009; Reubinoff et al., 2001; Takata et al., 2017; S. C. Zhang, Wernig, Duncan, Brustle, \& Thomson, 2001), oligodendrocytes (Douvaras et al., 2014; Hu, Du, Li, Ayala, \& Zhang, 2009); astrocytes (Brennand, 2017; Krencik \& Zhang, 2011), and eventually microglia (Abud et al., 2017; Douvaras et al., 2017; 
Muffat et al., 2016; Pandya et al., 2017). Cells of neuroectdoermal origins are obtained through inhibition of TGF $\beta$ signaling, giving rise to FGF-responsive neural progenitors. In absence of maintenance growth factors, these progenitors differentiate towards multiple neuronal and glial lineages (Figure 1B). Many of the important developmental origins of brain cells were known by the time ESCs became a model system, except for microglia whose origins were still elusive. Seminal work in the mouse showed most, if not all, microglia derive from primitive yolk sac macrophages, migrating to the brain before closure of the blood-brain barrier (Alliot, Godin, \& Pessac, 1999; Ginhoux et al., 2010; Vitry, Bertrand, Cumano, \& Dubois-Dalcq, 2003). This knowledge supported original protocols to generate microglia from hiPSCs (Abud et al., 2017; Douvaras et al., 2017; Muffat et al., 2016; Pandya et al., 2017; Takata et al., 2017). Our evolving understanding of microglial development will continue to allow differentiation protocols to improve (C. Z. W. Lee, Kozaki, \& Ginhoux, 2018) as ontogeny and cell identity become better defined (see below and Figure 1C).

Generating brain cells from iPSCs requires defining the cell type(s) of interest, an issue which is the object of emerging technologies discussed further in this review (see section 4). A cell type was historically defined by ontogeny, cytoarchitecture and physiological outputs, or by a few key expression markers identified by immunostaining or qPCR. Today, a combination of higher-resolution mapping of ontogeny and high-content multi-omics profiles, including epigenetic and full-genome expression, is available to compare cells (Arendt et al., 2016; Gokce et al., 2016; Gosselin et al., 2017; Lavin et al., 2014; Macosko et al., 2015; Tabula Muris et al., 2018; Zeng \& Sanes, 2017). We are increasingly aware of the distance separating some in vitro models from their in vivo reference counterparts. For example, one of the first thorough transcriptome-level descriptions of astrocytes in a disease-relevant context pointed out similarities between 'McCarthy-De Vellis' cultured astrocytes and post-stroke astrocytes (Cahoy et al., 2008; Zamanian et al., 2012), while immunopanned astrocytes appeared to better match the in vivo astrocyte transcriptome (Foo et al., 2011). Choice of culture methods must therefore carefully balance practical experimental needs (e.g. working with human neurons to study Alzheimer's disease) with the necessary degree of relevance of the model (e.g. a tumor line grown in diabetic conditions may be sufficient to study fundamental aspects of cell division).

Lessons learnt from rodent cell cultures, for example the discovery of factors required for glia survival and oligodendrocyte differentiation, have been integral in the development of human iPSC-derived glia (Sloan et al., 2017). The use of pluripotent stem cells (PSCs) as the source material provides a unique opportunity to work with patient cells, and to engineer the genome of the future glial cells (see section 3 ). Thanks to nuclease-based gene targeting, as CRISPR/Cas9 technology, PSCs can be targeted with fate reporters, physiological sensors, or disease-related genetic variants to perform isogenic comparisons (Y. Li et al., 2013; Omer Javed et al., 2018; Soldner et al., 2009). However, the decision to work with human cells comes with a cost: glial cells differentiation from human PSCs scales to human developmental timing, thus often requiring higher costs than similar work performed with mouse cells. Human cells should primarily be used when therapeutic translation is key, or for the study of human-specific biology such as the emergence of novel cell 
types during development, interactions with unique pathogens, or age-dependent selective neuronal vulnerability.

\section{D pure cultures for drug screening and high-content analysis}

Most of the culture systems described above are 2D culture systems that have been integral in advancing our understanding of the CNS at the molecular and cellular levels. Complex questions such as identification of key regulators of synaptic connectivity have been answered in these simplified systems (Araque et al., 1999). Primary rodent cultures, as well as neuronal and glial immortalized cell lines are used by academia and industry. They are particularly compatible with medium- and high-throughput analysis with simple readouts, for drug screening and profiling. Such tests enable proof-of-concept in vitro studies before more extensive in vivo studies of candidate drugs in small animals or non-human primates.

The information value of these cultures can be further magnified by high-content imaging, with unbiased automated imaging platforms. Coupled to powerful software and machine-learning algorithms, images can be analyzed automatically, providing multiple parameters for hundreds-to-thousands of cells per well or condition. Automatic population analysis provides the scale necessary to obtain reliable drug dose-response curves, for example. Additional sophisticated live high-content imaging machines enable the longitudinal examination of complex and important cellular behaviors such as cell division, migration, process extension and cell death. Therefore, defined, simplified 2D cell culture systems provide a high-throughput platform to obtain mechanistic information in a cost and time-effective way. They allow quick hypothesis testing and provide the backbone of more complex culture systems that better recapitulate CNS complexity.

\section{Combination of cell types and organoids}

While the reductionist approach has long attempted to fragment the nervous system into its individual components, new culture platforms for glial cells try to reverse-engineer the complex cell-cell interactions found in vivo.

Well-defined monocultures can be refined by combining them to create more complex multi-cellular culture systems to understand important questions such as the molecular mechanisms regulating reactive gliosis, myelination or synapse formation (Allen et al., 2012; Christopherson et al., 2005; Rothhammer et al., 2018; Watkins, Emery, Mulinyawe, \& Barres, 2008; Wheeler et al., 2019). Indeed, there is a growing recognition that cells cannot be what they are in isolation. Microglia are an extreme example of this problem where the tissue microenvironment adds an important layer to their identity (Gosselin et al., 2017). While microglia ontogeny has now been reasonably replicated in the dish (Abud et al., 2017; Ditadi et al., 2015; Douvaras et

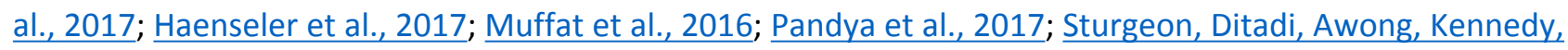
\& Keller, 2014; Takata et al., 2017), these cells are clearly particularly sensitive to in vitro perturbations (Gosselin et al., 2017). To counteract this effect, one option is to transplant them back to an in vivo setting (see conclusion) or replicate the in vivo microenvironment in vitro (Figure 1C). 
Some of these culture platforms are self-assembling, such as brain organoids or neural spheroids (Lancaster et al., 2013; Y. Li et al., 2017; Sloan et al., 2017). They allowed the study of developmental processes (Omer Javed et al., 2018), or pathology development. Other systems to study brain cells combine pre-differentiated

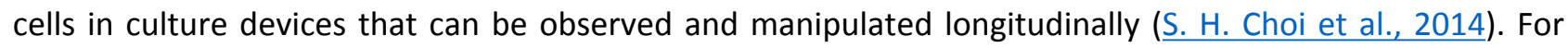
example, microglia precursors derived from hiPSCs can be embedded in cylindrical 3D cultures containing neurons, astrocytes and oligodendrocytes (Muffat et al., 2016) or in cerebral organoids (Abud et al., 2017) (Figure 1C). In these cultures, microglia adopt the ramified morphology and surveying behavior that match their in vivo counterparts more faithfully than isolated iPSC-derived microglia. These systems are not only relevant for human cells, but applicable to the mouse, where neuronal co-cultures also helps PSC-derived macrophages acquire microglial features (Takata et al., 2017). Interestingly, astrocytes grown in spheroid cultures mature to advanced developmental stages more rapidly than they would have on their own (Sloan et al., 2017). In the same line, oligodendrocytes fated inside cerebral organoids develop into myelinating cells (Madhavan et al., 2018; Marton et al., 2019; Pasca et al., 2015). In vitro and in vivo models can intersect: mouse microglial precursors and embryonic macrophages (Bennett et al., 2018), as well as human iPSCderived microglial precursors (Abud et al., 2017) have been successfully transplanted to the neonatal mouse brain. Such techniques, along with organotypic brain slice cultures, complement the 3D culture modalities available to experimentalists looking to take advantage of the plethora of mouse lines carrying relevant gene variants (Figure 1C). In these complex culture systems, we can now embed lineage tracers and physiological actuators or sensors at the pluripotent stage. Virtually all the transgenic tools described in the sections below can be delivered in vitro using viral vectors (Kiskinis et al., 2018; Weick et al., 2010), and better yet integrated in specific loci through CRISPR/Cas9 gene targeting in pluripotent cells (B. Roberts et al., 2017), to be propagated to the relevant lineages. In the process, we gain access to human neural tissue mimics that are simply not available otherwise and will contribute to the comparative study of glial biology with other species.

Although great progress has been made in glia cell culture, there are still many opportunities to improve growth conditions. Indeed, the cell culture environment is flawed: often hyperoxic or hypoxic, rarely physiological, never homeostatic. We must move past our historical reliance on media formulations designed for convenience and cost-efficiency (Barry, Coogan, \& Commins, 2016; Brewer et al., 2001; Cantor et al., 2017; Muffat et al., 2016). For example, albumin supplementation remains a convenient staple of many defined media, but is a serious source of unpredictability (Y. Chen et al., 2008) and is aberrant, considering its virtual absence in brain interstitial fluids. Glucose concentrations in generic media is essential to highly proliferative tumor lines, but is often too high for neurons and glia, placing them under extreme diabetic stress. Osmotic pressures developed to enhance viability of embryonic rodent neurons at low density have to be re-evaluated when our goal is to study human glial cultures approaching adult maturity. Improper culture conditions could easily mask some of the more important phenotypes, or doom rescue strategies to fail. Individual components of the media, normally provided by the complex tissue microenvironment, can 
be catalogued in vivo, screened and provided in vitro, to better replicate the baseline status of individual cell types (Bohlen et al., 2017) and to understand normal biology as well as disease mechanisms.

\section{New tools to study glia cells at cellular resolution}

There are now a multitude of tools to study glial cells in vivo: many transgenic mouse lines expressing fluorescent proteins, biosensors, opto/chemogenetic proteins (see section 3.3), Cre recombinase, Cas9 or suicide genes under glial cell-type-specific, Cre- dependent or tetracycline-dependent promoters (Guttenplan \& Liddelow, 2019; Slezak et al., 2007), see also http://networkglia.eu/en/animal_models). For each approach involving overexpression, activation, recombination, knock-down, or ablation, there are a number of options in terms of activity and specificity of promoters, and the timing of control of their expression. There are a fewer options to target some understudied glial cells such as perisynaptic Schwann cells or satellite glial cells. However, by combining existing transgenic lines, or by a more efficient genome manipulation with the CRISPR-Cas9 system, news tools are expected to be available in the near future, as recently illustrated for pericytes (Berthiaume \& Shih, 2019). Most of these tools have been reviewed and discussed before (Guttenplan \& Liddelow, 2019; Wieghofer, Knobeloch, \& Prinz, 2015), and we will therefore focus here on emerging technologies to monitor and manipulate glial cells in vivo.

\subsection{Approaches to manipulate glia genome or modulate gene expression in glia}

Viral vectors, which are highly versatile and easy to generate offer an interesting option to modulate gene expression in mice but also in other species and to evaluate potential therapeutic strategies (Deverman, Ravina, Bankiewicz, Paul, \& Sah, 2018). Furthermore, viral vectors can be used to transduce glial cells in primary cultures, hiPSCs (․․ Chen, McCarty, Bruce, Suzuki, \& Suzuki, 1998; Jiang et al., 2018; M. Li et al., 2010; Merienne et al., 2017; Rosario et al., 2016) or human brain organoids (Amin \& Pasca, 2018). The potential and safety of viral vectors is highlighted by the ongoing CNS clinical trials (Cartier et al., 2009; $\underline{\text { Hudry \& }}$ Vandenberghe, 2019; Palfi et al., 2018) and the recent approval of Zolgensma (AAV9-SMN) for the treatment of spinal muscular atrophy (Mendell et al., 2017).

Most gene transfer experiments in the CNS of rodents or large animals rely on two delivery systems: the lentiviral (LV) and recombinant adeno-associated viral (rAAV) vectors. These replication-deficient viral vectors have been engineered to eliminate their pathogenic genes and to lead to long-term expression in large brain areas (Sakuma, Barry, \& Ikeda, 2012; D. Wang, Tai, \& Gao, 2019). Each system has specific features in terms of cloning capacity, immune response, genome integration, tropism, and diffusion (Table 1). A detailed description of these viral vectors is beyond the scope of this publication (for reviews see (Berry \& Asokan, 2016; Lundberg et al., 2008; Murlidharan, Samulski, \& Asokan, 2014; Sakuma et al., 2012; Salganik, Hirsch, \& Samulski, 2015; D. Wang et al., 2019). Viral gene transfer applications are extremely diverse, going from expression of reporter genes, biological sensors (Grienberger \& Konnerth, 2012), optogenetic probes 
(Adesnik, 2018; Almad \& Maragakis, 2018), expression of coding or non-coding genes, gene replacement for loss of function disorders (Grienberger \& Konnerth, 2012; Mendell et al., 2017), endogenous gene activation (CRISPRa), endogenous gene inactivation (CRISPR/Cas9 and CRISPRi; (Powell, Gregory, Akbarian, \& Brennand, 2017; Savell et al., 2019; Zheng et al., 2018) and silencing of target gene with small hairpin RNA (R. Ghosh \& Tabrizi, 2017) (see Figure 2A). All these tools can be used on existing transgenic mice to further improve the spatial and/or temporal control of gene expression (Dow et al., 2015; Platt et al., 2014; Zhou et al., 2018).

Most of the initial studies targeted neurons (Deglon et al., 2000; McCown, Xiao, Li, Breese, \& Samulski, 1996; Naldini et al., 1996). To shift the tropism towards glial cells, various steps in the life cycle of these viruses were considered, especially the entry of viruses and their transcriptional and post-transcriptional regulation (Figure 2B).

\section{Modulating entry of $L V$ and $r A A V$}

For enveloped vectors such as LV, heterologous proteins are used to alter the tropism but also to increase stability of viral particles. In one of the original publication, the G-protein of the vesicular stomatitis virus (VSV-G) was used for this (Naldini et al., 1996). It was shown that LV/VSV-G mainly transduces terminally differentiated neurons, an observation confirmed by other groups (Björklund et al., 2000; Deglon et al., 2000; Mitrophanous et al., 1999). To alter the tropism of LV, envelopes from the retroviridae, paramyxoviruses, rhabdoviruses, alphaviruses and orthomyxoviruses families were used (Joglekar \& Sandoval, 2017).

With regard to astrocyte targeting, glycoproteins derived from the lymphocytic choriomeningitis virus (rhabdoviruses) or amphotropic envelope of the Moloney murine leukemia virus (retroviridae) resulted in an astrocytic tropism in the substantia nigra of rats (Cannon, Sew, Montero, Burton, \& Greenamyre, 2011). However, because integration of the Moloney murine leukemia virus genome is closely dependent on mitosis, only a small proportion of astrocytes are infected (Roe, Reynolds, Yu, \& Brown, 1993). An improved astrocyte tropism was reported with the glycoprotein derived from the Mokola virus (MOK-G; rhabdoviruses) in rat hippocampus (Pertusa et al., 2008). Finally, LV pseudotyped with Chikungunya envelope (CHIKV; alphaviruses) target astrocytes effectively in vivo (60\% of transduced cells are astrocytes) and present strong astrocyte tropism in vitro (Eleftheriadou et al., 2017). It is important to note, that these vectors can suffer from limited transduction and low viral titers and, that they can also have inflammatory/toxic effects.

The rAAV2 was the first serotype used for CNS gene transfer and its injection in the rat hippocampus leads to a largely neuronal transduction pattern (Bartlett, Samulski, \& McCown, 1998; Rabinowitz \& Samulski, 1998). In recent years, more than 100 rAAV serotypes have been discovered and a substantial number of variants have been created (Asokan, Schaffer, \& Samulski, 2012; S. L. Hammond, Leek, Richman, \& Tjalkens, 2017; Z. Wu, Asokan, \& Samulski, 2006). The cellular entry of AAV is mediated by interaction with specific surface glycans and receptor/co-receptor(s). Identified glycan moieties include heparan sulfate proteoglycans (rAAV2, rAAV3, and rAAV6), N-terminal galactose (rAAV9); and specific N- or O-linked sialic acid moieties (rAAV1, rAAV4, rAAV5, and rAAV6) (Murlidharan et al., 2014; Shen, Bryant, Brown, Randell, \& Asokan, 2011). The preferential neuronal tropism of rAAV2 was shown to correlate with the higher heparan 
sulfate proteoglycan availability on the membrane of neurons than on glia (Hsueh \& Sheng, 1999; Hsueh et al., 1998). AAV receptor (KIAA0319L) is an essential cellular receptor required for the transduction of vectors derived from multiple AAV serotypes, including the evolutionarily distant serotypes rAAV2 and rAAV5 (Pillay et al., 2016). Fibroblast growth factor receptor 1 was identified as a co-receptor for rAAV2 (Qing et al., 1999) and platelet-derived growth factor receptor alpha for rAAV5 (Pasquale et al., 2003).

In 2009, rAAV9 was the first serotype shown to bypass the blood brain barrier and to efficiently target CNS cells following intravenous injection (Foust et al., 2009). Both neuronal and glial cells can be transduced via different injection routes, in both small and large animal models (Foust et al., 2009; Gray et al., 2011; Samaranch et al., 2013). In 2016, Schober and collaborators showed that injection in the barrel cortex of rAAV6 preferentially targets astrocytes (90\% of transduced astrocytes in the transduced areas, (Schober et al., 2016)). However, the tropism of rAAV is altered, depending on the species, targeted brain regions, developmental stages and promoter activity (Hadaczek et al., 2016; Lawlor, Bland, Mouravlev, Young, \& During, 2009; G. Liu, Martins, Chiorini, \& Davidson, 2005). In addition, the degree of purity of viral vectors also affects the profile of expression (Klein, Dayton, Tatom, Henderson, \& Henning, 2008). Three years ago, the first rAAV variant with preferential tropism for oligodendrocytes was described (Powell et al., 2016). This Olig001 serotype is a mixture of rAAV1-2-6-8-9 and is functional both in vitro and in vivo, showing a low affinity for peripheral organs. Finally, targeting microglial cells has been challenging, probably because these cells are involved in the destruction of pathogens by phagocytosis, including viruses (Maes, Colombo, Schulz, \& Siegert, 2019; Rosario et al., 2016). One study showed a selective but low in vitro and in vivo transduction of microglial cells with microglia-specific promoters (F4/80 or CD68) combined with a triple mutation in rAAV6 capsid reducing proteasome degradation (Rosario et al., 2016).

\section{Defining glial cell type-specific promoters}

The second strategy to modify viral vector tropism relies on cell-type-specific promoters. Unfortunately, the number of fully characterized glial promoters that efficiently regulate transgene expression is still extremely low. The promoter of the excitatory amino acid transporter 1 (GLAST, human Scl1a3; $2.0 \mathrm{~kb}$ ) was used in MOK-LV but the level of transgene expression was low (Colin et al., 2009). Brenner et al. made a great contribution with the characterization of the glial fibrillary acid protein (GFAP) promoter (Brenner, Kisseberth, Su, Besnard, \& Messing, 1994). However, its large size (2.2 kb for Gfa2) limits its use to small transgenes (the packaging capacity is $4.5 \mathrm{~kb}$ for rAAV and $8 \mathrm{~kb}$ for LV, see Table 1). The intra-nigral or striatal injection of an rAAV2/5-Gfa2-GFP, demonstrated very high astrocyte transduction in rats and mice (Drinkut, Tereshchenko, Schulz, Bahr, \& Kugler, 2012; Meunier, Merienne, Jolle, Deglon, \& Pellerin, 2016). A shorter version, the gfaABC1D (600bp) promoter (Y. Lee, Messing, Su, \& Brenner, 2008) was generated, to allow inclusion of larger transgenes. Finally, 3 copies of an enhancer (B3 element) were later inserted to increase transgene expression and generate the gfa2(B)3 and GfaABC1D(B)3 promoters (de Leeuw et al., 2006; $\underline{\text { Y. Lee }}$ et al., 2008). The injection of an rAAV2/5-GfaABC1D(B)3-GFP in the mouse striatum showed a strong 
expression of GFP in glutamine synthetase-positive astrocytes, and no colocalization with NeuN-positive neurons (Merienne et al., 2017).

The most commonly used oligodendrocyte-specific promoter is that of the myelin basic protein $(\underline{H}$. Chen et al., 1998). Recently, different fragments of human myelin associated glycoprotein (MAG, .2, 1.5 and $0.3 \mathrm{~kb}$ ) promoter have been characterized. The corresponding rAAV1/2-MAG-GFP vectors reached around $90 \%$ transduction of oligodendrocytes after intraparenchymal delivery in adult mice. Of note, all these MAG promoter fragments were inactive in vitro (von Jonquieres et al., 2016), which probably reflects functional differences between embryonic cultures and adult cells. Additional regulatory regions might be needed to promote transcription in vitro.

As mentioned in the previous paragraph, the $F 4 / 80, C D 68$ but also the $C D 11$ promoters restrict transgene expression to microglial cells in primary cultures and in neonatal/adult brains, when injected locally (Jiang et al., 2016; Rosario et al., 2016). However, microglia are resistant to robust AAV or lentivirus infection in vivo and the available approaches are very limited.

\section{Manipulating post-transcriptional regulation in glial cells}

The final target used to enhance viral selectivity towards specific glial cells such as astrocytes, is posttranscriptional gene expression. This 'de-targeting' strategy was initially proposed by Naldini (Brown \& Naldini, 2009; Gentner \& Naldini, 2012). It takes advantage of cell-type-specific microRNAs (Bartel \& Chen, 2004) that block transgene expression in non-targeted cells (Eulalio, Huntzinger, \& Izaurralde, 2008). To block residual expression in neurons and improve astrocyte tropism, four copies of the target sequence of the neuron-specific miR124 (miR124T) were inserted in the 3'UTR region of the transgene (Colin et al., 2009). Combining miR124T with MOK-LV increases transgene targeting in astrocytes in several mouse brain regions (striatum, hippocampus and cerebellum) (Colin et al., 2009; Pannasch et al., 2014; Petrelli et al., 2018; Taschenberger, Tereshchenko, \& Kugler, 2017). To further improve astrocyte-specific expression, the Déglon laboratory incorporated a second miRNA target sequence, the miR9*T (Ko et al., 2008) and showed that it further decreases residual activity in neurons (Merienne et al., 2017). As microglial cells also lack microRNA-9 activity, a similar strategy was used to restrict transgene expression in these cells: four target sequences of the miR-9 were inserted in a LV (Akerblom et al., 2013). After brain injection, the GFP reporter gene was only expressed in cells of non-ectodermal origin, including microglia but not in astrocytes or neurons.

\section{Glia silencing or gene inactivation}

The above examples all pertain to the overexpression of a gene of interest in glial cells, but gene silencing in glia may be achieved as well. Gene silencing with small hairpin RNA (shRNA) relies on polymerase III promoters that are active in both neurons and glial cells (Drouet et al., 2009; Mazuel et al., 2017; Toro Cabrera \& Mueller, 2016). To achieve astrocyte silencing, a de-targeting strategy is not suitable because miRT sequences are cleaved during shRNA processing and maturation. To overcome this limitation, the Déglon laboratory indirectly regulated the expression of shRNA with a tetracycline-regulated (Tet) system in LV 
(Merienne et al., 2015). As an alternative for both LV and rAAV vectors, miR-embedded shRNA located in the 3'untranlated region ( $3^{\prime}$ UTR) have been developed (Fellmann et al., 2013). The optimized miR30E backbone ensures an efficient maturation of the shRNA and increases knockdown efficacy of LV (Fellmann et al., 2013). CRISPR technology could also be used to inactivate or modulate genes in glial cells (Figure 2A). A non-viral approach called CRISPR-Gold was used to deliver the RNA-guided endonucleases Cas9 and Cpf1 into the brains of adult mice (B. Lee et al., 2018). Two weeks after stereotaxic injection, approximately $10-15 \%$ of the cells around the injection site $(1-2 \mathrm{~mm})$ were edited. In the hippocampus, half of the edited cells were astrocytes, $40 \%$ were IBA1-positive and 10\% NeuN-positive (corresponding to 33\% editing efficiency in astrocytes, $19 \%$ in microglial cells and $3 \%$ in neurons). Using LV delivery and the Kamicas9 self-inactivating system, Merienne et al. (Merienne et al., 2017) reached high editing efficiency of the huntingtin gene in primary and iPSC-derived astrocytes. In vitro studies in an immortalized microglial cell line showed that a double LV approach to provide Cas9 and the sgRNA in different vectors induced a complete deletion of glia maturation factor exon 3 (Raikwar et al., 2019). Finally, a new AAV with a synthetic surface peptide was shown to target terminally differentiated human astrocytes much more efficiently than neurons (Kunze et al., 2018). This rAAV encoding both Cas9 and sgRNA was used to deliver HIV-inhibitory genes to astrocytes and inactivate persisting HIV-1 proviruses in this reservoir.

\section{Pitfalls and future directions for glial cell tools}

As illustrated above, this first generation of cell-type specific vectors provides a large panel of tools to investigate and facilitate the analysis of glial functions. They come with some intrinsic limits (e.g. transgene size, mostly local effects, risk of inflammation and biosafety requirements), but they are extremely versatile and should further reveal the contribution of glial cells in CNS disorders and promote the development of targeted therapies. If viral vectors are very popular, they come with some intrinsic limits (e.g. cloning capacity, mostly local effects and biosafety requirements). Researchers should be aware that the experimental design is essential to avoid toxicity (massive transgene overexpression; (Klein et al., 2006) or immune / inflammatory responses (Ortinski et al., 2010)). To ensure purity, potency and safety, appropriate purification methods and quality assessment of virus batches should be considered (Schnodt \& Buning, 2017). Finally, the doses administered but also the in vivo injection procedures (volume, injection rate, cannula) are critical to avoid functional impacts and result misinterpretation (Kohro et al., 2015). Under optimal conditions, long-term expression is obtained with reactive astrocytes and microglia detected exclusively around the injection site. Beside intraparenchymal delivery, non-invasive, systemic administration has been used to promote a widespread vector distribution in the CNS (Chan et al., 2017; Saraiva, Nobre, \& Pereira de Almeida, 2016).

The second major limitations of gene transfer for the CNS is the number of glial-specific promoters, which are still extremely limited to study and target cell subpopulations. Microglial cells are difficult to transduce with viral vectors (Maes et al., 2019; Rosario et al., 2016) and few promoters of the macrophage lineage (F4/80, 
CD68 and CD11b) have been used to restrict transgene expression in primary microglial cultures and in neonatal/adult brains (Jiang et al., 2016; Rosario et al., 2016).

Single-cell mRNA sequencing studies have shown that the Zika virus entry receptor AXL is enriched in radial glia, microglia, and astrocytes in the developing human cortex (Nowakowski et al., 2016). However, the use of the Zika virus as an efficient delivery system has not been yet described. A better understanding of the intracellular mechanisms is needed to define strategies to overcome this bottleneck and design viral vectors efficiently targeting microglia. Of note, viral vectors are used extensively and efficiently in vitro, where they can display different properties in terms of transduction efficiency or tropism.

\subsection{Live imaging to monitor glial cell behavior}

The investigation of glial cells has traditionally lagged behind that of neuronal studies in part due to a dearth of methodologies to elucidate their precise functions in vivo. However, advances in optical in vivo imaging and development of genetically encoded sensors of cellular physiology have dramatically improved capabilities for glial studies in the intact brain. A few examples of these studies include: time lapse intravital imaging of microglia that revealed their rapid dynamics and response to injuries (Davalos et al., 2005; Nimmerjahn et al., 2005); visualization of OPCs showing their self-repulsive behavior during adult proliferation (Hughes, Kang, Fukaya, \& Bergles, 2013); and imaging of astrocyte processes with $\mathrm{Ca}^{2+}$ sensors demonstrating time-correlated $\mathrm{Ca}^{2+}$ responses to neuronal activation (Bindocci et al., 2017). The palette of tools has continued to blossom with refined and potent techniques such as targeted two-photon holographic activation of channelrhodopsins in individual cells (Papagiakoumou et al., 2010) and genetically encoded

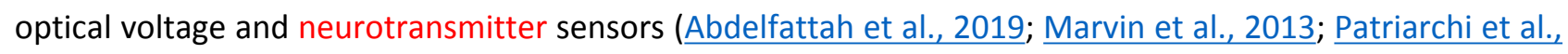
2019), which in the future will allow a more sophisticated in vivo dissection of the role of glial cells within complex neuroglial networks. Altogether, in vivo imaging techniques expand capabilities for elucidating the interactions between neuronal and non-neuronal cells in health and disease. Rather than a comprehensive review on all imaging techniques, here, we will focus on three additional examples of simple, yet powerful methodologies for in vivo imaging and experimental manipulation of glial cells.

\section{In vivo imaging to disentangle the cellular mechanisms of regulation of neurovascular coupling}

The brain has very large energetic requirements and has thus evolved a sophisticated system to precisely match regional cerebral blood flow to the constantly fluctuating activity-dependent local energetic demands. This mechanism, otherwise known as neurovascular coupling, is of great interest, not only because its disruption may be involved in a variety of cerebrovascular and neurodegenerative conditions (ladecola, 2017), but also because functional magnetic resonance imaging, a widely used technique for neuroscience research, detects increases in paramagnetic oxygen due to changes in cerebral blood flow during neurovascular coupling (Ogawa et al., 1993); see also section 5). Several recent reviews have comprehensively covered this topic (Iadecola, 2017). In this methodological review, we chose to focus on 
recent neurovascular studies from the Grutzendler laboratory that involve new imaging approaches, even if some findings remain a topic of controversy (Attwell, Mishra, Hall, O'Farrell, \& Dalkara, 2016).

While the mechanisms controlling neurovascular coupling are not well understood, previous work demonstrates the involvement of complex interactions between neurons, glia, and vascular mural cells (ladecola \& Nedergaard, 2007), which include arteriolar smooth muscle cells and capillary pericytes (Rouget, 1874). A major challenge is to study the roles of the different elements of the neurovascular unit in intact physiological states.

The precise anatomical patterns of mural cell distribution throughout the cerebral vascular tree were established using transgenic mice expressing a red fluorescent protein under the smooth muscle actin ( $\alpha$ SMA) promoter (Armstrong, Larina, Dickinson, Zimmer, \& Hirschi, 2010) and one expressing GFP under the mural cell-specific PDGFR $\beta$ promoter. There was a sharp demarcation between $\alpha$ SMA-expressing ring-like

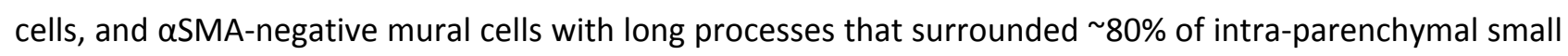
vessels (Figure 3B). The expression of $\alpha$ SMA in ring-like cells suggested that these cells are contractile, while fusiform pericytes are not. The properties of these cells were unambiguously determined by single-cell in vivo two-photon optogenetic stimulation of mural cells and intravital imaging of the microvasculature during neural activation tasks ( Hill et al., 2015). These experiments showed that increases in microvascular diameter correlated well with neuronal activation, only in vessels expressing $\alpha \mathrm{SMA}$, while capillary pericytes did not dilate as a result of different activation tasks. Expression of the genetically encoded $\mathrm{Ca}^{2+}$ sensor GCaMP6 in mural cells, showed that fluctuation of $\mathrm{Ca}^{2+}$ levels correlate with changes in vessel diameter only in aSMAexpressing ring-like mural cells. This is consistent with $\mathrm{Ca}^{2+}$ involvement in relaxation and contraction of smooth muscle cells, but not in pericytes, where $\mathrm{Ca}^{2+}$ may have different functions. The Grutzendler laboratory then implemented a single cell optogenetic approach by combining vascular imaging during twophoton optical activation of channelrhodopsins in individual mural cells (Figure 3A and section 3.3). This allowed to unambiguously determine the precise location and nature of individual contractile cells along the vascular tree. It confirmed that only aSMA-expressing cells with ring-like morphology exert contractile radial forces sufficient to alter microvascular diameter or flow. Such high-resolution mural cell imaging with fluorescent reporters, $\mathrm{Ca}^{2+}$ sensors and optogenetic single cell stimulation has also been applied to a variety of studies of neurovascular coupling and cerebral blood flow regulation in physiological conditions, ischemia, spreading depolarization and neurodegenerative conditions (Hill et al., 2015).

\section{Intravital label-free myelin imaging}

Myelin is a critical structure of the nervous system that increases the speed of propagation of action potentials and plays a role in axonal metabolic support (Simons \& Nave, 2015). The biology of myelin has been extensively studied at the molecular and ultrastructural level. However, intravital myelin imaging, has been generally restricted to early development in zebrafish (Kirby et al., 2006), primarily due to limited availability of tools for high resolution imaging of myelin in the live mammalian brain. As a result, little is 
known about rates of myelin internode formation, the stability of internodes and longevity of oligodendrocytes at various stages of life and in pathological processes.

Several methodologies for label free myelin imaging have become available over the past decade, including optical coherence microscopy (OCM), coherent anti-Stokes Raman scattering (CARS) microscopy and harmonic generation (THG) microscopy (Farrar, Wise, Fetcho, \& Schaffer, 2011; H. Wang, Fu, Zickmund, Shi, \& Cheng, 2005). These techniques have unique advantages, such as chemical sensitivity for myelin lipids with CARS ( $\underline{\text { H. Wang et al., 2005) }}$ ) and deep tissue imaging capability, that can reach subcortical white matter, with THG (Farrar et al., 2011). However, these techniques are not easy to implement, and require sophisticated equipment and setups not readily available in most laboratories (reviewed in (Hill \& Grutzendler, 2019). In contrast, spectral confocal reflectance microscopy (SCoRe) is a recently developed, simple, but yet powerful method for high-resolution intravital label free imaging of myelinated axons in the mammalian brain (Schain, Hill, \& Grutzendler, 2014). This method uses a conventional laser scanning confocal microscope to obtain reflection images of individual myelinated internodes. Contrast is generated by taking advantage of the large refractive index mismatch between highly lipidic (and thus reflective) myelin, compared to the surrounding aqueous medium in other cells and in the interstitial space. Images are generated by using multiple lasers in the visible wavelength range, as each laser generates a patchy and incomplete reflection pattern, but when all wavelengths are combined, a full axonal reconstruction can be created. Using SCoRe, it is possible to visualize axons in the cortex and to track them for hundreds of microns (Figure 3A), thus allowing the reconstruction of the internodes of individual axons and their longitudinal visualization over extended intervals of time. Because SCoRe is label-free, it is a very practical method for in vivo studies of mutant and aging mice which otherwise would require prohibitive long-term cross-breeding with fluorescent reporter mice for visualization. SCoRe can also be combined with fluorescence imaging of transgenic or virally labeled reporters in axons, oligodendrocytes or other cells, thus providing a powerful toolset for studying the biology of myelin in vivo and its interactions with neurons and other glial cells. Furthermore, because the SCoRe signal is very sensitive to changes in myelin compaction, it is uniquely able to detect areas of myelin wrapping that do not form a compact layered structure, such as the paranodal region and in pathological dysmyelinating conditions.

Using ScoRe in combination with fluorescence optical imaging, the Grutzendler laboratory recently conducted one of the first intravital longitudinal studies of myelin plasticity at singe axon resolution in the mammalian brain (Hill, Li, \& Grutzendler, 2018; Hughes, Orthmann-Murphy, Langseth, \& Bergles, 2018). These studies showed that individual axons in cortex are partially myelinated with large patches that remain unmyelinated in early adulthood, consistent with recent optical imaging (Hughes et al., 2018) and serial electron microscopy studies (Tomassy et al., 2014). However, these unmyelinated regions continue to fill in across the lifespan such that by two years of age in mice, axons were nearly fully myelinated. Modest remodeling of existing myelin internodes across the lifespan was observed, suggesting that the addition of new myelin internodes is the main mode of myelin plasticity. The precise reason for this protracted cortical 
myelination process is unclear, but the progressive addition of myelin internodes to partially myelinated axons could have significant effects on axonal conduction and neuronal spike timing-dependent plasticity, which could be critical for memory encoding (Caporale \& Dan, 2008). Furthermore, examining how these processes are altered during development, aging, neurodegeneration and other disorders is now possible by using SCoRe imaging alone or in combination with fluorescence microscopy (Jafari et al., 2019; OlmosSerrano et al., 2016). In the near future, a combination of label-free techniques such as SCoRe, CARS and THG microscopy may provide additional complementary in vivo data about myelin biology.

\section{Two-photon chemical apoptotic targeted ablation (2Phatal) of cells in the live brain}

Investigating the mechanisms and consequences of cell death and interactions with glial cells in the mammalian brain is of great importance for understanding brain development and neuropathology. However, research has been limited by the lack of methods to induce and visualize this process with cellular specificity and spatial and temporal precision in vivo. Several methods for targeted ablation of cells have become available over the years such as genetically encoded constructs for conditional expression of deathinducing signaling such as with diphtheria toxin receptor (Saito et al., 2001), Caspase 3 (Mallet et al., 2002) or the herpes simplex thymidine kinase/ganciclovir system (Moolten, 1986). These methods and others (․․ M. Roberts, Rosen, \& Casciola-Rosen, 2004) are very effective at inducing cell death but require introduction into specific cell types by viral vectors, transgenesis or in utero electroporation and it is difficult to control the location and degree of cell death. The Grutzendler laboratory recently developed an easily adoptable and robust method for targeted induction of death of single cells or small clusters of cells in living animals. This method, called 2Phatal, combines in vivo nuclear labeling by topical application of a DNA-binding dye (Hoechst 33342) followed by gentle photo-bleaching of a small area on labeled nuclei by brief (10-20 sec) focal illumination with a femtosecond-pulsed laser during two-photon microscopy leading to local production of reactive oxygen species (ROS), without causing thermal injury. This likely triggers ROS-mediated DNA damage and the subsequent induction of apoptosis (Figure 3C), but without acute cellular disruption of adjacent cells as would occur with thermal laser ablation methods (Davalos et al., 2005).

By implementing 2Phatal in mice that express fluorescent reporters in microglia and astrocytes, it is possible to visualize their reactions to adjacent dying cells at high spatio-temporal resolution. This allows precise quantification of the timing of engagement of glial processes with the dying cells, the efficiency of engulfment and the ultimate degradation of cell bodies, processes and nuclei. Using this technique on mutant mice, it is now feasible to precisely quantify in vivo the effects of candidate molecules on the death, engulfment and degradation processes, providing for the first-time dynamic data in vivo. Additional experiments that are feasible with 2Phatal include the selective elimination of cell populations of interest to assess their functional effects on neural circuits. No such study has been performed with glial cells so far, but sparse elimination of interneurons was shown to cause adjacent excitatory neurons to increase their firing frequency (Hill, Damisah, Chen, Kwan, \& Grutzendler, 2017). 
Altogether, the field of glial neurobiology is greatly benefiting from exciting neuroscience tool developments that promise to revolutionize our understanding of the diversity of non-neuronal cells in the nervous system and their interaction with neurons during development, aging and disease. Among the future developments that may further enhance glial research are super-resolution microscopy techniques that can be applied to imaging the live mammalian brain with subcellular resolution such as Stimulated Emission Depletion microscopy (Baddeley \& Bewersdorf, 2018). Methods for deep tissue imaging such as 2 and 3-Photon imaging ( Horton et al., 2013), fiber optic microscopy and miniaturized implantable scan-heads (K. K. Ghosh et al., 2011) are revolutionizing the investigation of deep brain structures in live and behaving animals. Emerging genetically encoded neurotransmitter sensors will open the possibility for investigating the functions of astrocytes within networks (Haustein et al., 2014). Further refinement of techniques for single cell manipulation will be critical for investigating with greater precision the molecular and cellular mechanisms of neuroglial interactions. Advances in optogenomics for two-photon-inducible expression of genes in single cells (Yao et al., 2019) promise to revolutionize the analysis of glial pathophysiology in their intact in vivo microenvironments.

\subsection{Chemogenetic and optogenetic tools to manipulate glia cell functions}

Classical glia research relied on two kinds of manipulations: either pharmacological or chronic genetic ones, both of which have limitations. Pharmacological manipulations provide limited temporal precision, and are rarely completely cell type-specific. Chronic genetic manipulations on the other hand, are specific to a type of glial cell, but provide low temporal precision (at the scale of days or weeks), and often no spatial specificity either. Modern optogenetic and pharmacogenetic tools developed for neuronal research can be adapted to glial cells and provide temporal and spatial precision, while avoiding side effects on neighboring cells (Figure 4A).

Importantly, both methodologies can be combined with many other investigation tools, like electrophysiology (from the single cells or cell populations in brain sections, to in vivo) and behavior, or combined with each other. Based on these clear advantages, these techniques have already revolutionized neuronal studies, and are starting to transform astrocyte research as well. This section will describe both methods, their advantages and caveats, and discuss general issues one should consider when manipulating astrocytic activity, with these tools.

\section{Chemogenetic modulation of astrocytes}

Chemogenetic (also known as pharmacogenetic) tools allow the inducible and reversible control of selected intracellular signaling pathways in genetically-defined cell populations. This goal is achieved by the expression of designer receptors engineered to be unresponsive to any innate ligands, but respond only to an otherwise inert designer drug (Roth, 2016). These receptors are known as Designer Receptors Exclusively Activated by Designer Drugs (DREADDs). DREADD expression can be achieved either by the injection of viral vectors encoding its DNA under an astrocytic promoter (see section 3.1), or by generating transgenic 
animals expressing a receptor in all astrocytes. The major disadvantage of intracranial viral infection is the surgery and its associated local immune activation. However, this drawback is compensated by significant advantages: spatial specificity (determined by the injection location), versatility (new tools can be implemented immediately), time-restricted burden of overexpression, and the possibility of combinatorial expression (e.g. receptor and indicator or two receptors targeting different populations).

Transgenic mice expressing DREADDs in astrocytes do not require intracranial injections, but their clear disadvantage is that the widespread receptor expression provides no spatial specificity, and can lead to systemic effects upon designer drug administration (see below). The designer drug is usually administered by intraperitoneal injection, but can also be delivered directly into the brain, or given in the drinking water. Several chemogenetic receptors are now available, they recruit different intracellular pathways and respondi to different ligands (Figure 4B).

Chemogenetic tools have been used on astrocytes for over a decade, with the first studies relying on transgenic mice, followed by a transition to virus-mediated expression in mice. The most commonly used tools are presently Gq-coupled DREADDs (Figure 4B). Transgenic mice expressing the Gq-coupled DREADD MrgA1R have major systemic effects when this designer receptor drug is administered, like changes in the autonomic nervous system and in motor activity globally, whereas the drug has no effect on synaptic plasticity (Agulhon et al., 2013; Agulhon, Fiacco, \& McCarthy, 2010). Local expression of a different Gq DREADD hM3Dq in dorsal CA1 induced de novo plasticity, and improved memory acquisition (Adamsky et al., 2018). Expression of this DREADD in centromedial amygdala astrocytes selectively increased inhibitory synaptic transmission, depressed excitatory transmission, and reduced fear perception (Martin-Fernandez et al., 2017). When the DREADD was targeted to astrocytes in the nucleus accumbens core, it inhibited the motivation for ethanol and cocaine seeking (Bull et al., 2014; Scofield et al., 2015). However it should be noted that the exact doses of the DREADD's ligand is crucial and different doses can even lead to opposite results ( $\underline{N}$. Chen et al., 2016; Yang, Qi, \& Yang, 2015). Furthermore, chemogenetic experiments should include control groups both for the intended effect of CNO (in DREADD-expressing animals), but also for a possible influence of CNO per-se (without DREADDs).

Transgenic mice overexpressing the Gs-coupled DREADD Rs1 were shown to have constitutive ligandindependent Gs-coupled activity, accompanied by impaired memory after prolonged expression. Ligand application dramatically impaired memory consolidation and recall (Orr et al., 2015).

The Gi DREADD hM4Di induces Ca² elevations in astrocytes (Durkee \& Araque, 2019; Nagai et al., 2019). When it was expressed in striatal astrocytes, hM4Di activation increased local excitatory synaptic transmission and induced hyperactive behavior (Nagai et al., 2019).

Whereas the effects of the different chemogenetic tools on neurons are straightforward, astrocytic modulation is harder to construe. For example, Gq-coupled receptors depolarize DREADD-expressing neurons and increase their spiking activity in response to ligand application, whereas inhibition is achieved by Gi-coupled receptors, which reduce spiking upon ligand application. The effects of astrocyte 
manipulations (using intracellular $\mathrm{Ca}^{2+}$ levels as a proxy for their activity) are harder to interpret, mainly because there is no accepted definition of astrocytic activation or inhibition. It is becoming clear that $\mathrm{Ca}^{2+}$ dynamics in different astrocyte compartments (soma vs. proximal processes) have different speed, duration and spatial spread, are mediated by different intracellular mechanisms (Bazargani \& Attwell, 2016), and may represent different kinds of information processing within astrocytes. This complexity of $\mathrm{Ca}^{2+}$ signals is exemplified by the following findings: (1) the same chemogenetic tools can differentially affect astrocytic $\mathrm{Ca}^{2+}$ dynamics in different brain regions (Chai et al., 2017); (2) when used in astrocytes, both Gq- and Gicoupled receptors induce $\mathrm{Ca}^{2+}$ elevations in these cells, despite the fact that they recruit different pathways, by mimicking different neurotransmitters (Durkee \& Araque, 2019; Nagai et al., 2019). As it is unlikely that astrocytes respond similarly to different neurotransmitters, activating different receptors, it is similarly unlikely they are identically modulated by different DREADDs. Advanced analysis methods may soon

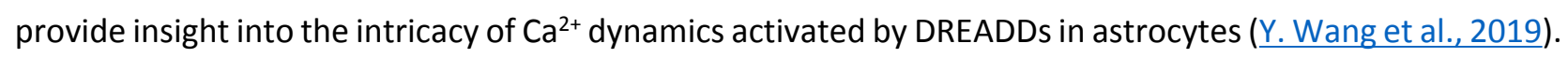

\section{Optogenetic modulation of astrocytes}

Optogenetics is a technique allowing the control of membrane potential or intracellular signaling in genetically-defined cell populations by expressing opsins (light-sensitive proteins), and stimulating them by light with high temporal accuracy [(Fenno, Yizhar, \& Deisseroth, 2011), Figure 4C]. As in chemogenetics, opsins (pumps, channels or receptors) can be either virally induced or transgenetically expressed. Light is usually delivered either ex vivo via the microscope objective, or in vivo, through the tethering to an optical fiber connected to a light source right before the experiment, which can be stressful, and thus requires appropriate control groups (Goshen, 2014). The most commonly used optogenetic tools in neuroscience are ion pumps or ion channels, directly affecting membrane potential. Whereas this kind of manipulation is intuitively fitting in neurons, the inducible changes in ionic concentration and membrane potential do not mimic any known physiological process in astrocytes. The significance of the light stimulation frequency is even more obscure when considered in the context of astrocyte manipulation.

Until recently, optogenetic manipulation in astrocytes relied mainly on Channelrhodopsin variants. Channelrhodopsin optogenetics modifies neuronal firing rate, affects respiratory responses, pupil dilation, sleep disturbance and suppresses feeding (Gourine et al., 2010; Gradinaru, Mogri, Thompson, Henderson, \& Deisseroth, 2009; Okada et al., 2012; Pelluru, Konadhode, Bhat, \& Shiromani, 2016; Perea, Yang, Boyden, \& Sur, 2014; Sasaki et al., 2012; Sweeney, Qi, Xu, \& Yang, 2016; Yamashita et al., 2014). The outwards proton pump archaerhodopsin was also used in astrocytes, to shift the oscillatory state in cortex (Poskanzer \& Yuste, 2016). It should be noted, that whereas optogenetic effects on neuronal activity are induced with millisecond precision, the change in astrocytic activity develops very slowly, on a time scale of minutes (Gourine et al., 2010; Gradinaru et al., 2009; Okada et al., 2012; Poskanzer \& Yuste, 2016). The delayed effect and the uncertainty regarding the physiological nature of the manipulation raises the possibility that the resulting phenotype (of neuronal activity or behavior) is not mediated by a precise effect mimicking astrocytic activity, but rather from some overall environmental factors. Indeed, a recent study had shown 
that the use of the most common optogenetic tool, the cation channel Channelrhodopsin caused an increase in extracellular potassium concentration and induced a non-specific excitatory effect on neuronal

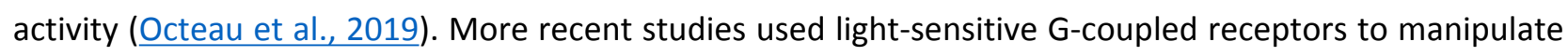
astrocytic activity, which may better mimic physiology. For example, the Gq-coupled optoGq and melanopsin in CA1 astrocytes induce de novo plasticity in neighboring neurons, and improve cognitive performance (Adamsky et al., 2018; Mederos et al., 2019).

\section{Future directions to study glia cells at cellular resolution}

Whereas chemogenetics and optogenetics are highly prevalent in neuronal research, these are early days for their use on glia. Furthermore, within the Glia field, these techniques have been used almost exclusively in astrocytes, probably because of the easy genetic access to this cell type using viral vectors (see section 3.1). In the future, with the development of effective targeting strategies of these tools to oligodendrocytes and microglia, their power could be harnessed to promote research in these cell types as well.

Optogenetics and chemogenetics have numerous advantages, but to optimally employ their power they should be used in a careful and controlled way. Especially, the major differences between glia and neurons should be kept in mind when using tools originally developed for neurons. For example, optogenetic cation channels are perfect for neuronal activation, but not for astrocytic modulation. Similarly, G-coupled receptors will recruit the same intracellular pathway, but induce very different effects in neurons and astrocytes, and can even diverge in their effects between astrocytes in different brain regions. To sum up, the use of these new tools in glia research, especially in combination with conventional tools like electrophysiology and behavior, and employing careful controls, has the potential to transform the field.

\section{$4 \quad$ High-content approaches to study glial cells at the population level}

\subsection{Sequencing approaches}

At the beginning of the 2000's, the emergence of cell isolation and high-content sequencing empowered the unsupervised analysis of the repertoire of genes expressed by specific CNS cell types. This allowed the study of changes in gene expression profiles across physio-pathological conditions, and was proved instrumental to better understand the roles of glial cells. However, it is important to note that that these methods rely on preconceived ideas of what constitutes a cell type: through cell markers for Fluorescence-activated cell sorting (FACS) or cell epitopes for immunopanning. Only single cell analysis (without sorting) does not rely on prior classification of cells (see below).

\section{Bulk genome-wide analysis of glial cells}

It really started with the pioneering work from the Barres and Wu laboratories, which expanded the initial microarray-based study (Cahoy et al., 2008) and uncovered the expression profiles of different post-natal cell types of the CNS including astrocytes, microglia, oligodendrocytes, newly-formed oligodendrocytes and OPCs (Y. Zhang et al., 2014). In several glial cell types, bulk sequencing approaches revealed that glia cells express 
specific patterns of genes across development stages [Microglia: (Matcovitch-Natan et al., 2016)], brain regions [Astrocytes: (Chai et al., 2017; John Lin et al., 2017); Microglia:(Grabert et al., 2016)], sex [Microglia: (Guneykaya et al., 2018)] and aging [Astrocytes: (Boisvert, Erikson, Shokhirev, \& Allen, 2018; Clarke et al., 2018); Microglia: (Hickman et al., 2013)]. Some of these factors were also studied in combination, as for development \& sex (Microglia: (Thion et al., 2018).

In vivo changes in gene expression profiles of glial cells have also been investigated across various pathological conditions. In general, these studies highlighted the versatility of glial cell reaction to disease conditions. These sequencing studies further characterize the loss of homeostatic functions and acquisition of new functions of reactive glial cells. In mouse microglia, the transcriptomic reaction has been thoroughly compared in various pathological conditions, leading to the identification a core reaction signature and of disease-specific profiles [for reviews (Dubbelaar, Kracht, Eggen, \& Boddeke, 2018; Hirbec, Noristani, \& Perrin, 2017)]. The pathological response of astrocytes and OPCs/oligodendrocytes, on the other hand, has been less well characterized although astrocytes do develop disease-specific molecular responses (Escartin, Guillemaud, \& Carrillo-de Sauvage, 2019; Liddelow \& Barres, 2017; Zamanian et al., 2012). Interestingly, Srinivasan et al., (Srinivasan et al., 2015) determined the concomitant remodeling of the neuronal, astrocytic and microglial transcriptome in both acute inflammation and neurodegenerative models. In endotoxemia conditions, they showed that astrocytic but not microglial transcriptomic remodeling were TNF-receptor dependent. Transcriptome remodeling of OPCs was investigated in demyelination and remyelination conditions (Moyon et al., 2015), microarray study) and morphine treatment (Avey et al., 2018).

The extreme plasticity of glial cells requires changes in the composition and structure of chromatin, through the action of epigenetic modulators. Their importance in controlling glial cell phenotypes is just starting to be unraveled, and can be assessed by studying histone modifications, DNA methylation, as well as microRNA and long non-coding RNA expression. Epigenome modifications can be studied in acutely isolated glial cells, either in bulk or at the single-cell level. Several high-throughput sequencing approaches such as Methyl-seq, Chromatin Immunoprecipitation and Assay for Transposase-Accessible Chromatin Sequencing (e.g. ChIP-Seq and ATAC-Seq) which respectively measure DNA methylation, patterns of transcription factor DNA binding and DNA accessibility to transposase can be used. Through these approaches, it was demonstrated that epigenetic regulation is instrumental in governing the differentiation of OPCs in mature oligodendrocytes (Moyon, Liang, \& Casaccia, 2016). In microglia as well, epigenetic changes play key roles for the acquisition of specific phenotypes (reviewed in (Cheray \& Joseph, 2018). In particular, alterations in microglial gene enhancers were implicated in chronic pain (Denk, Crow, Didangelos, Lopes, \& McMahon, 2016). Epigenetic mechanisms are also likely to define the immune memory of microglia, and possibly other glial cell types, a process that is thought to be involved in the differential responses of individuals to neurodegenerative conditions (Wendeln et al., 2018).

Glial cell sequencing studies have mostly been performed in mice, although some were performed in humans [(Astrocytes: (Y. Zhang et al., 2016); Microglia: (Galatro et al., 2017; Gosselin et al., 2017; Olah et al., 2018)]. 
Of note, human oligodendrocytes/OPCs transcriptome were explored either using microarrays or single-cell RNAseq. Globally, these studies highlighted that although mouse and human glial cells present largely overlapping gene expression profiles, human cells exhibit unique characteristics that should be taken into consideration for therapy design and justify the use of human models for experimental manipulation.

From these genome-wide data, we learned that each glial cell types display heterogeneous phenotypes. Such heterogeneity may reflect the tight adaptation of these cells to their local environment to best support neuronal function. The identification of such diversity also offers a great opportunity for therapeutic intervention; indeed, the existence of distinctive glial subpopulations will allow specific treatments that either promote the beneficial subpopulations and/or of inhibit the deleterious ones.

\section{From bulk to single cell analysis}

Whereas conventional/bulk RNA-seq analyses are performed on whole cell populations, single-cell RNA-seq (scRNA-seq) is a powerful method to disentangle the heterogeneity of specific glial cell populations and to investigate the diversity of individual cellular responses [for review (Hedlund \& Deng, 2018), see Table 2 and supplementary Table 1)]. Microglial heterogeneity is more pronounced in the embryonic and early-postnatal

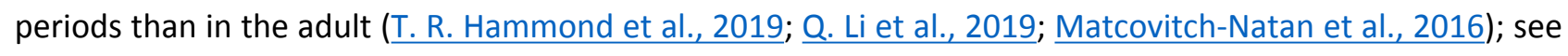
Table 2). Interestingly, by increasing the sequencing depth (T. R. Hammond et al., 2019) or the number of analyzed cells (Q. Li et al., 2019), the two most recent scRNA-seq studies identified a yet uncharacterized sub-population of microglia in the developing white matter. scRNA-seq also allowed the characterization of the mouse oligodendrocyte cell lineage in unprecedented detail. Despite being generated using different sequencing technologies the available datasets show remarkable agreement and overlap in terms of expressed genes (for review see (van Bruggen, Agirre, \& Castelo-Branco, 2017). The most comprehensive study identified twelve oligodendrocyte-related cell clusters, including six distinct mature oligodendrocyte cell states, with heterogeneity observed between ages and brain regions; it also revealed a continuous process of oligodendrocyte differentiation across age and brain regions (Jakel et al., 2019; $\underline{\text { Marques et al., }}$ 2016).

ScRNA-seq has also been used to identify cell subpopulations in pathological conditions. Disease Associated Microglia (DAM) or DAM-like microglia were identified in many different neurodegenerative conditions including Alzheimer, amyotrophic lateral sclerosis, fronto-temporal dementia and severe neurodegeneration models (Keren-Shaul et al., 2017; Mathys et al., 2017). In a different mouse model of Alzheimer's disease, Sala-Frigerio et al. recently identified activated- and interferon response microglia (Sala Frigerio et al., 2019). The activated response microglia (ARMs) partly overlap with DAMs, but by applying cell trajectory inference methods (also referred as pseudotime analyses) these authors demonstrate that ARMs were not solely present in disease conditions and are part of the normal brain ageing process. A different category of microglia associated with acute inflammation were also identified in acute inflammatory conditions as a 
heterogeneous microglia subpopulation with distinct transcriptional profile compared to DAMs (Sousa et al., 2018).

Advantages, pitfalls and future developments for glial cell sequencing:

High-content sequencing approaches are unsupervised methods that highlight the complexity of glial cell responses to their environment and allow generation of new hypothesis. Furthermore, advanced bioinformatics tools allow combining analyses from different laboratories, models and species in metaanalyses to identify common and specific features of different cell (sub)populations. scRNA-seq is still in its infancy and bioinformatics tools are regularly developed to enable the thorough analysis of the huge amount of data generated by this approach. As an example, cell trajectory inference methods can be used to study the transition of cells from one subtype to another and assess the relevance of transient subpopulations during disease progression and recovery (Masuda et al., 2019; Tay, Sagar, Dautzenberg, Grun, \& Prinz, 2018). Bioinformatics packages have also been developed to study the crosstalk between different cell types isolated from the same brain samples.

Although sequencing methods are remarkable approaches to study glial cells, there are some important pitfalls. A major issue in transcriptional profiling of dissociated cells, including scRNA-seq, is that transcriptional perturbations can occur during tissue dissociation to mask the true conditions-induced transcriptional changes (Haimon et al., 2018). Mechanical cell dissociation also breaks glial cell processes and the RNA contained in these distant processes or domains will be lost. Promising approaches based on the use of proteases working at low temperature (Adam, Potter, \& Potter, 2017) or transcription inhibitors ( $\underline{\text { Y. E. }}$ Wu, Pan, Zuo, Li, \& Hong, 2017) have emerged to reduce experimental alteration of the transcriptome. Transgenic mice in which ribosomal complexes are tagged by HA or GFP (i.e. Ribotag mice) offer an alternative approach to isolate cell-specific translatome from complex homogenates including from interesting sub-cellular domains or intricate processes, but this approach also has its weaknesses. Indeed, only RNAs being actively translated are analyzed. Furthermore, this technique may be more prone to contamination by RNA from other cells and it cannot be used at the single cell level (Sanz et al., 2009). Lasercapture microdissection prevents artefactual transcriptional changes and preserves some spatial information but is more subject to contamination, especially for small glial cells (Merienne et al., 2019; Okaty, Sugino, \& Nelson, 2011). Cell extraction protocols also influence which cell populations are being analyzed, and myelin removal steps are obviously not recommended to study mature oligodendrocytes, which may be lost or severely compromised by this procedure.

As mentioned above, in bulk RNAseq, data quality also depends on efficient methods to obtain pure cell population. Indeed, because of tight physical interactions between brain cells (e.g. mature oligodendrocytes with extensive processes unsheathing neuronal axons, fine astrocyte processes contacting synapses and blood vessels), physical isolation of glial cells is prone to contamination. 
In scRNA-seq, this issue can be theoretically overcome by sequencing all cell types present in the sample. However, such a comprehensive strategy can only currently be undertaken by large consortia, such as the Human Cell Atlas, as it implies tremendous costs to sequence sufficient cell number with adequate depth to identify small subpopulations. Even when scRNA-seq is performed on a purified cell population, the choice of the sequencing technology is important. Two main approaches are used: (1) Smart-Seq2, which is based on relatively small number of cells isolated in 384-well plates and sequenced at considerable depth and (2) droplet-based platforms such as $10 x$ Genomics $@$ which captures $50 \%$ less genes but is designed to analyze more cells (Ziegenhain et al., 2017). Pitfalls in data analysis should not be underestimated. For example, in single-cell approaches, data clustering, whose goal is to identify cell populations, is a critical initial step. Thus, comparison of different clustering algorithms is recommended to verify the robustness of identified cell clusters (G. Chen, Ning, \& Shi, 2019).

Technological developments in the field are arising at an astounding rate, offering many new opportunities. Among them single-nucleus RNA-seq [snRNA-seq; (Lacar et al., 2016) and spatial transcriptomics (Stahl et al., 2016; Strell et al., 2019)] are worth mentioning. In snRNA-seq, the cell suspension is gently lysed, nuclei are isolated by centrifugation on gradients and nuclear RNA is sequenced. The overall interest of the approach is that nuclei are more resistant to mechanical assaults and can be isolated from frozen or fixed samples such as those archived in human biobanks. Due to the low abundance of nuclear RNA, snRNA-seq detects only half of the transcripts detected by scRNA-seq. Still, high depth snRNA-seq has proved sufficient to discriminate between closely related neuronal cell types (Bakken et al., 2018). snRNA-seq was recently used to analyze no less than 80,000 nuclei isolated from the prefrontal cortex of 48 patients at different stages of Alzheimer pathology (Mathys et al., 2019). This study highlighted the complexity of neuron-glia interactions and revealed that myelination-related processes were disturbed in Alzheimer's disease. A similar approach was used to demonstrate that upper-layer excitatory neurons and microglia are the preferentially affected cells in autism patients (Velmeshev et al., 2019) (see Table 2).

Another pitfall of scRNA-seq is that potentially important spatial information is lost during cell dissociation. To overcome this issue, different transcriptomic approaches have been developed to explore gene expression profiles with high spatial resolution (for review see (Strell et al., 2019). Until recently, spatial cellular resolution was only achieved at the cost of detection efficiency. However, the recently developed STARmap (spatially-resolved transcript amplicon readout mapping, (X. Wang et al., 2018) and seqFISH+ (sequential fluorescence in situ hybridization, (Eng et al., 2019) methods allow the simultaneous detection of hundreds to thousand genes in mouse brain sections at single-cell spatial resolution with high efficiency, accuracy, and reproducibility. This technology opens the way to study glial cells in their native physiopathological context, while preserving important spatial information. This tool seems particularly adapted to study the diversity of reactive glial cells in pathological contexts in which discrete lesions are observed (e.g. amyloid plaques; dystrophic neurites; stroke infarcts; demyelinating lesions, etc.). 


\subsection{Profiling glial cells at the protein level}

Although transcriptional profiling provides useful information on the molecular status of a given cell population or subpopulation, genes and transcripts are not the cell's ultimate effectors and major discrepancies are reported between gene and protein expression (Y. Liu, Beyer, \& Aebersold, 2016; Sharma et al., 2015). Protein levels are constantly adapted to environment changes and proteomic-based studies may provide the most accurate understanding of glial cell (dys)functions (Altelaar, Munoz, \& Heck, 2013). Cell-type specific proteins can be studied by mass spectrometry-based approaches or by using specific antibodies. The first methods allows the exploration of hundreds to thousands of proteins at once, while the other approaches are targeted and focus on pre-established epitopes, but they directly provide (sub)cellular resolution [see (Levy \& Slavov, 2018)].

\section{Mass spectrometry}

Proteomics (large-scale study of proteins) has lagged behind genomics and transcriptomics, because of technical limitations imposed by our inability to amplify proteins or amino acids, contrary to nucleic acids. Protein yields required for mass spectrometry (typically tens of thousands of mammalian cells) are difficult to obtain from a pure cell-type population of non-dividing cells. With recent technical advances achieved in both mass spectroscopy accuracy and sensitivity (Altelaar et al., 2013), proteomics is now used more commonly to complement high-content genomic and transcriptomic analysis. Beyond the identification and quantification of proteins, proteomics may also support the analysis of many important proteins features, including exact sequence, state of modification, structure and interaction partners (Altelaar et al., 2013; Kitchen, Rozowsky, Gerstein, \& Nairn, 2014). Several approaches exist for proteomics analysis and quantification, but it is beyond the scope of this review to discuss them (Aebersold \& Mann, 2016; Altelaar et al., 2013). Among available proteomics methods, liquid chromatography with tandem mass-spectrometry is the most popular and widely used technology for quantitative high-throughput cell-type specific proteomics (Wilson \& Nairn, 2018; Y. Zhang, Fonslow, Shan, Baek, \& Yates, 2013).

Complex morphologies and heterogeneity of glial cells make "glioproteomics" very challenging. Most analyses are performed on primary cultures of glial cells or acutely isolated cells, which are prepared with methods that damage to fine subcellular structures and generate low protein yields. Sharma et al. recently performed an analysis of both acutely isolated and primary cultured astrocytes, oligodendrocytes and microglia in 10 major brain regions (Sharma et al., 2015). In-depth analysis identified more than 11,500 proteins in each glial cell type, of which 10,529 proteins were detected in all cell types. Parallel RNA-seq analysis demonstrated a great depth of coverage of the glioproteome. Results generated by this study constitute the largest proteomic dataset of the adult mouse brain thus far. Another recent study, assessed striatal and hippocampal proteomes from acutely isolated astrocytes. Among the 3,509 identified proteins, the authors found 18 proteins enriched in the striatal astrocytes and 12 in hippocampal astrocytes (Chai et al., 2017). These results are interesting because each of these proteins is a potential region-specific astrocyte marker. Proteomics is also crucial for therapeutic approaches, as it identifies disease-related proteins 
(Rangaraju et al., 2018) and/or early alterations that occur during prodromal stages of the disease (BozaSerrano, Yang, Paulus, \& Deierborg, 2018).

Although glial cell proteomics has been applied in animal models, it is challenging in human post mortem brain samples because of post mortem protein degradation and limited availability of human fresh samples (Mizee, Poel, \& Huitinga, 2018). The recent development of a procedure to rapidly isolate pure human microglia from autopsy tissue could improve this in the near future, but its usefulness will depend on the possibility to implement it in regular clinical practice (Mizee et al., 2018).

Advances in proteomics have also helped to characterize part of the "gliosecretome" by quantifying the expression of secreted proteins from conditioned media of cultured glial cells (Jha et al., 2018). Proteomic profiles of secreted proteins from microglia, astrocytes and other glial cells types are now well documented (Jha et al., 2013). Among the rare examples of gliosecretome analysis in human cells, the profile of cytokines and chemokines produced from normal human astrocytes derived from 15-week human fetus (Choi, Lee, Lim, Satoh, \& Kim, 2014) and the secretome of human Neural Stem Cells-derived oligodendrocytes were established (Kim et al., 2014).

\section{Mass cytometry and imaging mass cytometry}

Cytometry by time of flight (CyTOF) is a revolutionary technology merging conventional flow cytometry and mass spectrometry (for review (Brodin, 2019). The main difference with conventional flow cytometry is that fluorophore-tagged antibodies used to label cells are replaced by metal-tagged ones. Thus, after ionization of the isolated labelled cell, the specific tags are identified by time of flight of discrete masses. Low mass spectral overlap signal offers the advantage of avoiding compensation. CyTOF has also low background signal, and is thus particularly suited for high-dimension functional and phenotypic analysis at the single cell level. CyTOF was used to (1) identify different sub-populations of brain-resident macrophages in physiological conditions and (2) study the remodeling of the entire brain immune landscape in pathological conditions including Alzheimer's disease and experimental autoimmune encephalomyelitis (Mrdjen et al., 2018). As an example of the power of the CyTOF approach, these authors identified a specific microglia subpopulation associated with Alzheimer's disease and aging, which is reminiscent of DAMs identified by Keren-Shaul et al. (Keren-Shaul et al., 2017). Furthermore, by analyzing 1.8 million cells from 7 experimental conditions with a panel of 39 antibodies, 3 different CNS-resident myeloid subpopulations were identified, including a diseasespecific one (Ajami et al., 2018). Interestingly, these authors demonstrate that although defined as relatively homogeneous by cell surface markers, in pathological conditions, each subpopulation contains heterogeneous functional subsets. More recently, CyTOF, together with sophisticated bioinformatics analyses were used for a comprehensive characterization of post mortem human microglia (Bottcher et al., 2019). Of note, this study confirmed that human microglia can be phenotypically distinguished from peripheral myeloid cells and supports the notion of microglial heterogeneity in the human brain.

Also based on metal-tagged antibodies, imaging mass cytometry techniques have been developed to produce images of formalin-fixed, paraffin-embedded tissue sections (for review (Chang et al., 2017)). Two similar 
technologies have been developed: imaging mass cytometry and multiplex ion beam imaging. In brief, stained tissue sections are scanned by a $1 \mu \mathrm{m}$ diameter pulsed laser spot. Tissue vaporized on each laser spot is then analyzed by the mass cytometer. Reconstructed images from the tissue sections have a resolution comparable to light microscopy. Of note, another related approach based on the use of photo-cleavable oligonucleotide-tagged antibodies instead of metal-tagged antibodies has been developed. It can detect and quantify up to 40 different proteins in each region of interest (Blank et al., 2018). A recent study used imaging mass cytometry to explore heterogeneity of myeloid and astrocytes populations around human MS lesions (Park et al., 2019). However, the multiplexing possibilities offered by these methods will undoubtedly be useful to study the diversity of glial cells at the protein level.

\section{Advantages, pitfalls and future directions for proteomics approaches}

Mass spectrometry-based approaches are powerful unbiased methods for biomarker discovery and therapeutic strategy development as mass spectrometry allows identification of protein expression changes that can be used as markers of pathogenesis or disease progression (Bayes \& Grant, 2009; $\underline{\text { Severino, Farina, }}$ \& Chambery, 2013). Comparison of the gliosecretome with proteins found in the cerebrospinal fluid of patients provided new biomarkers for brain diseases (Suk, 2010). The upcoming challenge will now be to reach single-cell resolution while preserving wide proteome coverage (Doerr, 2019; Levy \& Slavov, 2018). A new mass spectrometry-based approach was recently developed that quantified $\sim 600$ proteins in single differentiating mouse embryonic stem cells (Budnik, Levy, Harmange, \& Slavov, 2018).

However, as mentioned for scRNA-seq approaches (section 4.1), even if proteomics sensitivity improves to the single cell level, the experimental challenge of isolating entire single glial cells remains. Indeed, cell isolation is a key primary step for mass spectrometry but also for CyTOF and can result in major artifacts and loss of important cell domains. A solution to circumvent this problem is to target protein labelling agents to specific cell types, as recently developed by the Chin and Schuman groups. The strategies are based on the cell-type specific expression (through viral vectors or in transgenic mice) of an exogenous tRNA transferase, which incorporates mass spectrometry-detectable non-canonical amino acids administered orally (AlvarezCastelao et al., 2017; Krogager et al., 2018). After isolation of labelled peptides, they were able to establish the cell-type specific proteome of the targeted cells in vivo. The importance of specialized subcellular compartment is emerging in glial research (e.g. single myelinating segments, perisynaptic or perivascular astrocyte processes, membrane subcellular microdomains). Therefore, complementary methods providing subcellular resolution, sometimes at the expense of throughput, can help illuminate this important issue. They include methods based on intact brain sections like imaging cytometry or proteomics-based methods of a specific compartment isolated through subcellular fractionation or labelling. This kind of subcellular mass spectrometry analysis was performed on axonal growth cones (Poulopoulos et al., 2019), or mitochondria tagged in specific brain cell types (Fecher et al., 2019). Alternatively, in situ proximity labeling with an exogenous biotin ligase can be used to identify protein complexes and partners in specific subcellular 
compartments (Uezu et al., 2016). However these methods are still in their early days and require more optimization (Wilson \& Nairn, 2018).

The great advantage of CyTOF and mass imaging cytometry over conventional cytometry and immunohistochemistry approaches respectively is to considerably improve the multiplexing potential. Indeed, whereas conventional cytometry is limited to staining panels of $\sim 25$ fluorophores, CyTOF uses staining panels of 35-45 metal-tagged antibodies, and the multiplexing possibilities are likely to improve in the coming years. However, these approaches still require complex, expensive instruments and analysis tools. In addition, as more markers are included or higher resolution is needed, longer acquisition times are required. For example, the rate of image acquisition with imaging mass cytometry is slow (about 0.75 $\mathrm{mm}^{2} /$ hour) and set the current limit of these approaches. High-content analysis of these data is certainly one of the greatest challenges to the effective implementation of these approaches in research. Indeed, researchers need to visualize and analyze these high-dimensional data to obtain a comprehensive picture of the different cell subpopulations within a given physio-pathological context. New clustering and dimensionality-reduction algorithms are constantly developed to resolve this issue. However, the choice among the different tools is not always straightforward.

\section{Towards the clinic: non-invasive brain imaging techniques to monitor glial cells in}

\section{Humans}

Several non-invasive brain-imaging methods linked to glial cells have been developed in pre-clinical studies and some have been translated to the clinic. They are mostly based on magnetic resonance imaging or magnetic resonance spectroscopy, which are basically sensitive to the water or proton-containing molecules present in brain tissue. They either provide images or maps or quantitative data in a voxel of interest. Other imaging techniques, such as Positron emission tomography are based on the intravenous injection of a radioactive molecule (radio-ligand) that will enter the brain, bind to a particular receptor, enzyme or cell, be detected by their emission of positons and used to assemble 3D functional images.

\subsection{Magnetic resonance imaging of myelin formed by oligodendrocytes}

Many magnetic resonance imaging modalities are used to indirectly image myelin [see (Filippi \& Agosta, 2010; Heath, Hurley, Johansen-Berg, \& Sampaio-Baptista, 2018)], Figure 5B). Classic T2-weighted images show contrast between grey and white matter and are routinely used to detect demyelinated lesions in humans. Contrast agents like gadolinium are useful to detect focal myelin loss as found in multiple sclerosis patients. Additional techniques based on water diffusion along myelinated tracks, such as diffusion tensor imaging reveal directionality and size of myelinated axons (and change thereof). Magnetization transfer ratio imaging is sensitive to the amount of macromolecules present in myelin, such as lipoproteins, allowing an indirect assessment of myelin content in situ. However, comparison of magnetic resonance imaging data in 
post mortem samples reveals that axonal damage, water content, or inflammation with accumulation of microglia and macrophages may strongly influence the MRI signals (Filippi et al., 2019; Heath et al., 2018; Vavasour, Laule, Li, Traboulsee, \& MacKay, 2011). It will thus be essential to develop more specific imaging techniques to monitor myelin loss and recovery (see section 5.3).

\subsection{Magnetic resonance spectroscopy}

Magnetic resonance spectroscopy can measure the concentration of abundant glial metabolites like myoinositol or glutamine, or quantify glial oxidative pathways, with ${ }^{13} \mathrm{C}$-labbeled metabolites such as acetate, which are metabolized preferentially in astrocytes (Escartin, Valette, Lebon, \& Bonvento, 2006; Lebon et al., 2002). Changes in metabolite concentration or metabolic fluxes in specific CNS regions can reveal ongoing disease processes or changes in brain cell metabolism.

Recently, diffusion-weighted magnetic resonance spectroscopy of glial or neuronal metabolites was used to infer morphological changes in astrocytes when they become reactive (Ligneul et al., 2019; Palombo et al., 2016). However, it is important to note that the relative distribution of several of these metabolites was assessed in vitro, in conditions where cell metabolism may be very different from in vivo, due to absence of complex cellular interactions, or vascularization and exposure to higher $\mathrm{O}_{2}$ and glucose levels (see section 2). For example, $\mathrm{N}$-acetyl-aspartate, an abundant metabolite broadly used as a neuronal marker, is in fact deeply influenced by the reactive state of astrocytes (Carrillo-de Sauvage et al., 2015). N-acetyl-aspartate is also a key intermediate in myelin production (Amaral, Meisingset, Kotter, \& Sonnewald, 2013), challenging the dogma that $\mathrm{N}$-acetyl-aspartate is a pure neuronal metabolite.

\subsection{Positron emission tomography}

Several positron emission tomography imaging approaches are based on radio-ligands targeting specific glial cell molecular targets such as translocator protein and 'translocator protein positron emission tomography imaging' (TSPO) is widely used to track microglial activation, including in patients where positive signal can be visible at early disease stages, for example in patients with Alzheimer or Huntington disease (Edison, Donat, \& Sastre, 2018; Hamelin et al., 2016; Tai et al., 2007), Figure 5A). However, reactive astrocytes also express translocator protein, and cannot be discriminated from reactive microglia with available tracers (Lavisse et al., 2012).

Efforts are ongoing to develop more specific ligands to individual cell types and, more importantly, ligands that recognize changes in cellular status in disease conditions are being sought (Aiello et al., 2018; Narayanaswami et al., 2018). For example, radio-ligands targeting monoamine oxidase B, which is induced in reactive astrocytes, may be of use, but this enzyme is also expressed in monoaminergic neurons (see (Narayanaswami et al., 2018) for references). Other specific receptors induced in reactive glial cells could provide alternative targets for positron emission tomography. Recent database describing the "sensome" of 
microglial cells, for example (Hickman et al., 2013), could help find molecular targets for positron emission tomography imaging or repurpose available radioligands. A good example of such repositioning is $\left[{ }^{11} \mathrm{C}\right]-$ Pittsburg compound, which is classically used for detection of amyloid deposits but was found to also bind myelin. The local rate of demyelination/remyelination was measured with this ligand in active lesions of relapsing-remitting multiple sclerosis patients (Bodini et al., 2016), revealing significant heterogeneity in myelin dynamics within and between patients (Figure 5C).

\section{Advantages, pitfalls and future directions for non-invasive brain imaging}

Brain imaging methods generally provide a rather coarse picture of glial cells throughout the CNS, with limited spatial resolution, well below that of the cellular imaging techniques presented in section 3.2. However, by imaging glia molecular targets, it becomes possible to indirectly monitor the global behavior of specific glial cell populations. In addition, these techniques have the major advantage of allowing longitudinal subject monitoring. This provides invaluable insight into disease evolution and potential recovery with treatment in the same subject and reduces animal use in preclinical research. Interestingly, some techniques already used in pre-clinical and clinical studies are based on functions that are strongly regulated (if not totally) by glial cells. For example, positron emission tomography imaging of [ $\left.{ }^{18} \mathrm{~F}\right]$-fluorodeoxyglucose uptake may be directly influenced by astrocytes regulating glucose uptake and lactate supply to neurons through the astrocyte-to-neuron lactate shuttle (Belanger, Allaman, \& Magistretti, 2011). Doppler-based methods, or functional magnetic resonance imaging, measure blood flow and/or brain oxygen perfusion, and blood flow is regulated by astrocytes and other non-neuronal cells (Grutzendler, Kasthuri, \& Gan, 2002; Mishra, 2017). In conclusion, imaging of glial cells is already in place in the clinics either directly or indirectly. However, developments are needed to make it more specific for a single cell type, a specific state, more sensitive and of broader applicability. Of importance, non-invasive brain-imaging methods in animal models in preclinical research and in humans in clinics use very similar equipment and techniques. These approaches are thus among the few that can really be translated to the clinic.

\section{Concluding remarks and future directions}

As illustrated in the previous sections, the glia field is blooming with many tools and techniques that provide efficient, specific and refined options to monitor and study glial cells in different experimental settings. It is important to note that glial cells encompass many different cell types with different ontogenies, molecular and morphological features or functional roles in the CNS. Therefore, some techniques are only appropriate and relevant for a given cell type, and only few of them are truly applicable to all glial cells.

Alternative animal models like zebrafish, C. Elegans or Drosophila have their own glial cells, remarkably homologous to those found in mammals. They provide great experimental opportunities, including screening with easier genetic manipulation, whole brain/body imaging and rich behavioral assessment (Coutinho-Budd \& Freeman, 2013; Freeman, 2015; Lyons \& Talbot, 2014; Shaham, 2015). On the other hand, it can be 
important to translate results obtained in rodents or in these alternative models, to non-human primates or even humans. Human glial cells are quite different from their mouse counterparts (Geirsdottir et al., 2019; Hodge et al., 2019). They may have a different morphology, gene expression profile and some of their functions may differ as well (Oberheim et al., 2009; Zeng \& Sanes, 2017; Y. Zhang et al., 2016). Analysis of glia in non-human primate models as well as human samples and cells (through iPSC cells or brain biopsies) is important. An alternative approach is to graft human glial cells in the brain of rodent models to 'humanize' these mice in an attempt to get closer to human patients (Arranz \& De Strooper, 2019), although this approach is inevitably associated with some bias of its own (e.g. need for surgery inducing mechanical injury and inflammation as well as immunodeficiency of the receiver mice). Such human-mouse chimera were used with astrocytes in Huntington disease (Benraiss et al., 2016) and microglia in Alzheimer disease models

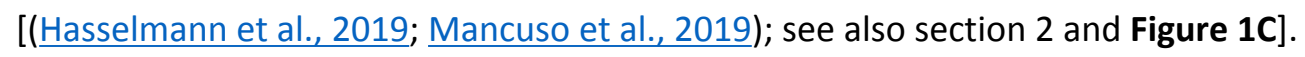

Inclusion of glial cells in the experimental arsenal for disease modelling, drug and biomarker discovery and therapeutic testing is crucial (Garden \& Campbell, 2016). It is becoming more and more evident that glial cells are central players in many brain diseases such as neurodegenerative disease, demyelinating diseases, epilepsy and brain cancer (Ben Haim et al., 2015; Priller \& Prinz, 2019; Zuchero \& Barres, 2015). It is thus important to study glial cell behaviors in these diseases as well as their response to different treatments. The development of glial cell-based therapies is in its infancy but it opens huge opportunities for the treatment of many brain diseases (Moller \& Boddeke, 2016).

Another exciting prospect for glia research is to develop research projects on overlooked glial cells, such as tanicytes, satellite glial cells, etc. There are fewer or less characterized tools and less knowledge and yet, these cells may play key roles in brain physiopathology, as it the case for tanicytes of the hypothalamus in metabolic regulation (Prevot et al., 2018), satellite glial cells in pain (Ohara et al., 2009), and enteric glial cells in gut-brain axis interactions (Grubisic \& Gulbransen, 2017). There are certainly many discoveries to be made on these glial cells. This was recently illustrated with the description of a previously unknown cutaneous glial cell that ensheathes sensory nerve terminals and is involved in noxious signal transduction (Abdo et al., 2019).

Clearly, one of the main challenges for glia research, and neuroscience in general, is to handle and make sense of the huge datasets being produced (e.g. by genomic, proteomic data, single cell profiling, electrophysiological recordings, behavioral video tracking). This calls for strong ties with other disciplines like bioinformatics, biostatistics, artificial intelligence and systems biology (Kastanenka et al., 2019). Development of multidisciplinary approaches, combining mathematics (to model complex processes for example), physics (to develop new microscopes and detectors), chemistry (to generate new probes and sensors), and informatics (to compute large and complex data), will be key to reach a better understanding of glia cell function and dysfunction. In addition, glia researchers could seek inspiration from approaches developed by immunologists to study inflammation or cell heterogeneity and by developmental biologists to study cell specification or even those implemented by endocrinologists to study cell-cell communications. 
In conclusion, the glia field has developed significantly since the seminal research papers presented in the 1850s. Many important discoveries on these cells were facilitated by methodological developments or new tools, but above all, it is the strong, growing and multi-disciplinary community of researchers that makes the glia research field so productive and exciting. 


\section{Figure legends}

\section{Figure 1: Methods to culture glial cells}

A. Left: Phase contrast images of immuno-panned astrocytes (IP-astrocytes) cultured in HBEGF, in the absence of serum display many processes. Center: IP-astrocytes cultured in the presence of $10 \%$ serum convert into flat and fibroblast-like cells. Right: Astrocytes are prepared by the traditional shake-off method and cultured in 10\% serum, as described by (McCarthy \& de Vellis, 1980), "MD astrocytes". Serum cultured IP-astrocytes resemble MD-astrocytes. B. Human PSCs can be driven exclusively towards neuroectoderm (TGF $\beta$ inhibition with dual SMAD inhibition, 15 days) into rosette-forming neural stem cells (R-NSCs). RNSCs depend on bFGF and Insulin for proliferation. Upon removal of these growth factors, multipotent RNSCs differentiate into post-mitotic neurons (>30 days) or can be steered towards glial lineages including astrocytes (in presence of CNTF and BMP4, $>45$ days), or oligodendrocytes (in presence of PDGF and T3, >60 days). Alternatively, PSCs can be driven towards the mesodermal lineage (in presence of BMP4 and activing A). CSF1R-dependent primitive macrophages/microglial precursors proliferate in response to CSF1/IL34 (>15 days). Factors such as IL34, CD200, TGFB1 or CX3CL1 can favor their maturation in microglia-like cells. C. Immature and proliferative microglial precursors can be added to various organotypic culture systems, in order to expose them to a parenchymal neural environment and complete their maturation to a homeostatic state. These include aggregated cultures of PSC-derived cells as in B, addition to PSC-derived cerebral organoids, and mouse brain slices. They may also be transplanted into neonatal mouse brains, where they will engraft. Future efforts include introduction of microglial precursors at a relevant mouse developmental stage (e.g. E8-E10). Fig1B, 1C were created with Biorender.

Figure 2: Gene transfer methods for biological and therapeutic applications and improvement of astrocyte tropism.

A. Scheme summarizing the main applications of gene transfer to (i) overexpress or silence genes of interest in the central nervous system. Recently, the CRISPR/Cas9 system were developed to (ii) activate or inactivate the expression of endogenous genes, to knockout target genes or repair mutations in disease genes. B. To improve astrocytic tropism of viral vectors, different AAV serotypes (Cearley et al., 2008; $\underline{\text { S. L. Hammond et }}$ al., 2017; Klein et al., 2008; Schober et al., 2016; Stanek, Bu, \& Shihabuddin, 2019), variants (Choudhury et al., 2016; Grimm et al., 2008; Zinn et al., 2015) or various heterologous envelopes for LV/MuLV pseudotyping (Cannon et al., 2011; Eleftheriadou et al., 2017; Pertusa et al., 2008) have been used. In addition, transcriptional regulation with astrocyte promoters and post-transcriptional regulation with miRNA detargeting (Akerblom et al., 2013; Colin et al., 2009; Fellmann et al., 2013) have been used to selectively manipulate astrocytes in vitro and in vivo. 
Figure 3: Methods to image and manipulate glial cells

A. Blood flow measurement during focal activation of channelrhodopsin-expressing mural cells (green). Channelrhodopsin expression in all mural cells allows interrogation of the contractile properties of smooth muscle cells and pericytes at different locations within the microvascular tree using single cell illumination with a two-photon laser in vivo. Vasculature is made visible by intravenous injection of a red dye. Adapted from (Hill et al., 2015). B. Myelin and oligodendrocyte imaging by SCoRe. In vivo imaging of the cortex of a PLP-DsRed reporter mouse shows a single oligodendrocyte (red) and all its internodes. SCoRe images (cyan) reveal segments of compact myelin. Notice the precise colocalization of the SCoRe signal with many DsRedlabeled processes. C. Targeted photochemical apoptotic ablation (2Phatal) of cells in the live brain. Time lapse in vivo imaging shows the induction of apoptotic cell death in a cortical neuron (red). Notice the gradual retraction of neuronal processes associated with concurrent nuclear condensation (blue) over a period of $48 \mathrm{~h}$.

Figure 4: Chemogenetic and optogenetic tools for astrocytic manipulation.

A. Genetic tools allow specific targeting of genetically-defined cell populations. For example, using viral vector injection or transgenic mice, chemogenetic or optogenetic tools can be expressed in the cell membrane of astrocytes (purple), while sparing their neighboring pyramidal excitatory neurons (orange) and GABAergic inhibitory interneurons (blue). A designer drug, or light, can then be administered to exclusively and reversibly manipulate this population. B. Chemogenetic actuators (Designer Receptors Exclusively Activated by Designer Drugs - DREADDs) are G-coupled receptors, recruiting intracellular pathways upon the application of otherwise inert designer drugs. These tools can mimic the activation of the processes induced by endogenous receptors in astrocytes. C. Optogenetic tools are light-sensitive proteins that can modulate either ionic currents in the astrocytic membrane (e.g. Ion pumps or ion channels), or intracellular processes (G-coupled opsins). The latter better mimics astrocyte physiology.

\section{Figure 5: Non-invasive imaging of glial cells in patients}

A. Translocator protein positron emission tomography imaging with $\left[{ }^{18} \mathrm{~F}\right]-\mathrm{DPA}-714$ in prodromal Alzheimer's disease patients and healthy control subjects. Sagittal, coronal and axial views of standard uptake value ratio show significant radio-ligand binding in the temporal and parietal cortex of prodromal patients. B. T1weighted magnetic resonance imaging scan (i), T2-weighted scan (ii), standard uptake value image of a $\left[{ }^{11} \mathrm{C}\right]$ PIB positron emission tomography scan (iii) from a multiple sclerosis patient. Arrows show two typical demyelinating lesions visible in all three modalities. C. Myelin dynamics monitoring by longitudinal $\left[{ }^{11} \mathrm{C}\right]-\mathrm{PIB}$ positron emission tomography imaging in a different multiple sclerosis patient. Demyelinating and remyelinating voxels appear in red and blue respectively. Adapted with permission from (Hamelin et al., 2016); A; (Bodini et al., 2016) B, C). 


\section{Table legends}

\section{Table 1: Features of lentiviral and adeno-associated vectors.}

\section{Table 2: Overview of scRNA-seq studies on glial cells}

We performed a PubMed search in Sept 2019, with key words: "(single-cell sequencing or scrna-seq or singlecell rna-seq) and (glia or glial cell or microglia or astrocyte or oligodendrocyte)", over the last 10 years. We retrieved 160 references. We only included studies performed on mammalian models, which provided substantial insight into glial cells. We did not include studies on glioma. Single-nuclei based studies were searched independently.

This table shows that single-cell/single-nuclei approaches have brought key new insights into glial cell diversity in development, health and disease (see column "Key finding" in Supplemental Table 1). The number of cells indicated is the number of cells that passed quality control and were analyzed. Note the preponderance of single cell transcriptomics on microglia or oligodendrocytes compared to other glial cells. Interestingly, some findings are validated in several studies (e.g. higher microglia heterogeneity at early developmental stages) but the exact number of cell clusters states or classes is quite variable across studies, depending on the sensitivity of the study, sequencing depths, region studied, etc.

Abbreviations used: Cells: Astro.: astrocytes; Micro.: microglia; NSC.: neuronal stem cells; Oligo.: oligodendrocytes; OPC: oligodendrocyte precursor cells. Brain regions: ACC: nucleus accombens; Amy: amygdala; Cb: cerebellum; CC: corpus callosum; CP: choroid plexus; Ctx: cortex; DG: dentate gyrus; DH: dorsal horn; FB: forebrain; FN: facial nucleus; GM: grey matter; Hpp: hippocampus; Hy: hypothalamus; LGN : lateral geniculate nucleus; MGE: medial ganglionic eminence; PFC: prefrontal cortex; SC: spinal cord; sCtx: somatosensory cortex; St: striatum; SVZ: subventricular zone; OB: olfactory bulb; vMB: ventral midbrain; VTA: ventral tegmental area; WB: whole brain; WM: white matter; ZI: zona incerta. Others: ARM: Activated response microglia; AD: Alzheimer's disease; BBB: blood brain barrier; CNS: central nervous system; DAM: disease associated microglia; FNX: unilateral facial nerve axotomy; IRM: Interferon response microglia; Identif.: identification; MS: multiple sclerosis; NS: Not specified; stim.: stimulation; TBI: traumatic brain injury; wo / mo / yo: weeks / months / years old. 


\section{References}

Abdelfattah, A. S., Kawashima, T., Singh, A., Novak, O., Liu, H., Shuai, Y., . . Schreiter, E. R. (2019). Bright and photostable chemigenetic indicators for extended in vivo voltage imaging. Science, 365(6454), 699-704. doi:10.1126/science.aav6416

Abdo, H., Calvo-Enrique, L., Lopez, J. M., Song, J., Zhang, M. D., Usoskin, D., . . Ernfors, P. (2019). Specialized cutaneous Schwann cells initiate pain sensation. Science, 365(6454), 695-699. doi:10.1126/science.aax6452

Abud, E. M., Ramirez, R. N., Martinez, E. S., Healy, L. M., Nguyen, C. H. H., Newman, S. A., . . Blurton-Jones, M. (2017). iPSC-Derived Human Microglia-like Cells to Study Neurological Diseases. Neuron, 94(2), 278-293 e279. doi:10.1016/j.neuron.2017.03.042

Adam, M., Potter, A. S., \& Potter, S. S. (2017). Psychrophilic proteases dramatically reduce single-cell RNA-seq artifacts: a molecular atlas of kidney development. Development, 144(19), 3625-3632. doi:10.1242/dev.151142

Adamsky, A., Kol, A., Kreisel, T., Doron, A., Ozeri-Engelhard, N., Melcer, T., . . . Goshen, I. (2018). Astrocytic Activation Generates De Novo Neuronal Potentiation and Memory Enhancement. Cell, 174(1), 59-71 e14. doi:10.1016/j.cell.2018.05.002

Adesnik, H. (2018). Cell Type-Specific Optogenetic Dissection of Brain Rhythms. Trends Neurosci, 41(3), $122-124$. doi:10.1016/j.tins.2018.01.001

Aebersold, R., \& Mann, M. (2016). Mass-spectrometric exploration of proteome structure and function. Nature, 537(7620), 347-355. doi:10.1038/nature19949

Agulhon, C., Boyt, K. M., Xie, A. X., Friocourt, F., Roth, B. L., \& McCarthy, K. D. (2013). Modulation of the autonomic nervous system and behaviour by acute glial cell Gq protein-coupled receptor activation in vivo. J Physiol, 591(22), 5599-5609. doi:10.1113/jphysiol.2013.261289

Agulhon, C., Fiacco, T. A., \& McCarthy, K. D. (2010). Hippocampal short- and long-term plasticity are not modulated by astrocyte Ca2+ signaling. Science, 327(5970), 1250-1254. doi:10.1126/science.1184821

Aiello, M., Cavaliere, C., Fiorenza, D., Duggento, A., Passamonti, L., \& Toschi, N. (2018). Neuroinflammation in Neurodegenerative Diseases: Current Multi-modal Imaging Studies and Future Opportunities for Hybrid PET/MRI. Neuroscience. doi:10.1016/j.neuroscience.2018.07.033

Ajami, B., Samusik, N., Wieghofer, P., Ho, P. P., Crotti, A., Bjornson, Z., . . Steinman, L. (2018). Single-cell mass cytometry reveals distinct populations of brain myeloid cells in mouse neuroinflammation and neurodegeneration models. Nat Neurosci, 21(4), 541-551. doi:10.1038/s41593-018-0100-x

Akerblom, M., Sachdeva, R., Quintino, L., Wettergren, E. E., Chapman, K. Z., Manfre, G., . . Jakobsson, J. (2013). Visualization and genetic modification of resident brain microglia using lentiviral vectors regulated by microRNA-9. Nat Commun, 4, 1770. doi:10.1038/ncomms2801

Allen, N. J., \& Barres, B. A. (2009). Neuroscience: Glia - more than just brain glue. Nature, 457(7230), 675-677.

Allen, N. J., Bennett, M. L., Foo, L. C., Wang, G. X., Chakraborty, C., Smith, S. J., \& Barres, B. A. (2012). Astrocyte glypicans 4 and 6 promote formation of excitatory synapses via GluA1 AMPA receptors. Nature, 486(7403), 410-414. doi:10.1038/nature11059

Allen, N. J., \& Lyons, D. A. (2018). Glia as architects of central nervous system formation and function. Science, 362(6411), 181-185. doi:10.1126/science.aat0473

Alliot, F., Godin, I., \& Pessac, B. (1999). Microglia derive from progenitors, originating from the yolk sac, and which proliferate in the brain. Brain Res Dev Brain Res, 117(2), 145-152. doi:10.1016/s0165-3806(99)00113-3

Alliot, F., \& Pessac, B. (1984). Astrocytic cell clones derived from established cultures of 8-day postnatal mouse cerebella. Brain Res, 306(1-2), 283-291. doi:10.1016/0006-8993(84)90377-9

Almad, A., \& Maragakis, N. J. (2018). A stocked toolbox for understanding the role of astrocytes in disease. Nat Rev Neurol, 14(6), 351-362. doi:10.1038/s41582-018-0010-2

Altelaar, A. F., Munoz, J., \& Heck, A. J. (2013). Next-generation proteomics: towards an integrative view of proteome dynamics. Nat Rev Genet, 14(1), 35-48. doi:10.1038/nrg3356

Alvarez-Castelao, B., Schanzenbacher, C. T., Hanus, C., Glock, C., Tom Dieck, S., Dorrbaum, A. R., ... Schuman, E. M. (2017). Cell-type-specific metabolic labeling of nascent proteomes in vivo. Nat Biotechnol, 35(12), 1196-1201. doi:10.1038/nbt.4016

Amaral, A. I., Meisingset, T. W., Kotter, M. R., \& Sonnewald, U. (2013). Metabolic aspects of neuron-oligodendrocyteastrocyte interactions. Front Endocrinol (Lausanne), 4, 54. doi:10.3389/fendo.2013.00054

Amin, N. D., \& Pasca, S. P. (2018). Building Models of Brain Disorders with Three-Dimensional Organoids. Neuron, 100(2), 389-405. doi:10.1016/j.neuron.2018.10.007

Ang, S. L., Conlon, R. A., Jin, O., \& Rossant, J. (1994). Positive and negative signals from mesoderm regulate the expression of mouse Otx2 in ectoderm explants. Development, 120(10), 2979-2989. 
Araque, A., Parpura, V., Sanzgiri, R. P., \& Haydon, P. G. (1999). Tripartite synapses: glia, the unacknowledged partner. Trends Neurosci, 22(5), 208-215.

Arendt, D., Musser, J. M., Baker, C. V. H., Bergman, A., Cepko, C., Erwin, D. H., . . Wagner, G. P. (2016). The origin and evolution of cell types. Nat Rev Genet, 17(12), 744-757. doi:10.1038/nrg.2016.127

Armstrong, J. J., Larina, I. V., Dickinson, M. E., Zimmer, W. E., \& Hirschi, K. K. (2010). Characterization of bacterial artificial chromosome transgenic mice expressing mCherry fluorescent protein substituted for the murine smooth muscle alpha-actin gene. Genesis, 48(7), 457-463. doi:10.1002/dvg.20638

Arranz, A. M., \& De Strooper, B. (2019). The role of astroglia in Alzheimer's disease: pathophysiology and clinical implications. Lancet Neurol, 18(4), 406-414. doi:10.1016/S1474-4422(18)30490-3

Artegiani, B., Lyubimova, A., Muraro, M., van Es, J. H., van Oudenaarden, A., \& Clevers, H. (2017). A Single-Cell RNA Sequencing Study Reveals Cellular and Molecular Dynamics of the Hippocampal Neurogenic Niche. Cell Rep, 21(11), 3271-3284. doi:10.1016/j.celrep.2017.11.050

Asokan, A., Schaffer, D. V., \& Samulski, R. J. (2012). The AAV vector toolkit: poised at the clinical crossroads. Mol Ther, 20(4), 699-708. doi:10.1038/mt.2011.287

Attwell, D., Mishra, A., Hall, C. N., O'Farrell, F. M., \& Dalkara, T. (2016). What is a pericyte? J Cereb Blood Flow Metab, 36(2), 451-455. doi:10.1177/0271678X15610340

Avey, D., Sankararaman, S., Yim, A. K. Y., Barve, R., Milbrandt, J., \& Mitra, R. D. (2018). Single-Cell RNA-Seq Uncovers a Robust Transcriptional Response to Morphine by Glia. Cell Rep, 24(13), 3619-3629 e3614. doi:10.1016/j.celrep.2018.08.080

Baddeley, D., \& Bewersdorf, J. (2018). Biological Insight from Super-Resolution Microscopy: What We Can Learn from Localization-Based Images. Annu Rev Biochem, 87, 965-989. doi:10.1146/annurev-biochem-060815-014801

Bakken, T. E., Hodge, R. D., Miller, J. A., Yao, Z., Nguyen, T. N., Aevermann, B., . . Tasic, B. (2018). Single-nucleus and single-cell transcriptomes compared in matched cortical cell types. PLoS One, 13(12), e0209648. doi:10.1371/journal.pone.0209648

Baron-Van Evercooren, A., Kleinman, H. K., Ohno, S., Marangos, P., Schwartz, J. P., \& Dubois-Dalcq, M. E. (1982). Nerve growth factor, laminin, and fibronectin promote neurite growth in human fetal sensory ganglia cultures. $J$ Neurosci Res, 8(2-3), 179-193. doi:10.1002/jnr.490080208

Barres, B. A. (2008). The mystery and magic of glia: a perspective on their roles in health and disease. Neuron, 60(3), 430-440. doi:10.1016/j.neuron.2008.10.013

Barres, B. A., Hart, I. K., Coles, H. S., Burne, J. F., Voyvodic, J. T., Richardson, W. D., \& Raff, M. C. (1992). Cell death and control of cell survival in the oligodendrocyte lineage. Cell, 70(1), 31-46.

Barres, B. A., Jacobson, M. D., Schmid, R., Sendtner, M., \& Raff, M. C. (1993). Does oligodendrocyte survival depend on axons? Curr Biol, 3(8), 489-497.

Barres, B. A., Schmid, R., Sendnter, M., \& Raff, M. C. (1993). Multiple extracellular signals are required for long-term oligodendrocyte survival. Development, 118(1), 283-295.

Barry, D. N., Coogan, A. N., \& Commins, S. (2016). The time course of systems consolidation of spatial memory from recent to remote retention: A comparison of the Immediate Early Genes Zif268, c-Fos and Arc. Neurobiol Learn Mem, 128, 46-55. doi:10.1016/j.nlm.2015.12.010

Bartel, D. P., \& Chen, C. Z. (2004). Micromanagers of gene expression: the potentially widespread influence of metazoan microRNAs. Nat Rev Genet, 5(5), 396-400. doi:10.1038/nrg1328

Bartlett, J. S., Samulski, R. J., \& McCown, T. J. (1998). Selective and rapid uptake of adeno-associated virus type 2 in brain. Hum Gene Ther, 9(8), 1181-1186. doi:10.1089/hum.1998.9.8-1181

Bayes, A., \& Grant, S. G. (2009). Neuroproteomics: understanding the molecular organization and complexity of the brain. Nat Rev Neurosci, 10(9), 635-646. doi:10.1038/nrn2701

Bazargani, N., \& Attwell, D. (2016). Astrocyte calcium signaling: the third wave. Nat Neurosci, 19(2), 182-189. doi:10.1038/nn.4201

Belanger, M., Allaman, I., \& Magistretti, P. J. (2011). Brain energy metabolism: focus on astrocyte-neuron metabolic cooperation. Cell Metab, 14(6), 724-738. doi:10.1016/j.cmet.2011.08.016

Ben Haim, L., Ceyzeriat, K., Carrillo-de Sauvage, M. A., Aubry, F., Auregan, G., Guillermier, M., ... Escartin, C. (2015). The JAK/STAT3 pathway is a common inducer of astrocyte reactivity in Alzheimer's and Huntington's diseases. J Neurosci, 35(6), 2817-2829. doi:10.1523/JNEUROSCI.3516-14.2015

Bennett, F. C., Bennett, M. L., Yaqoob, F., Mulinyawe, S. B., Grant, G. A., Hayden Gephart, M., . . Barres, B. A. (2018). A Combination of Ontogeny and CNS Environment Establishes Microglial Identity. Neuron, 98(6), 1170-1183 e1178. doi:10.1016/j.neuron.2018.05.014

Benraiss, A., Wang, S., Herrlinger, S., Li, X., Chandler-Militello, D., Mauceri, J., . . Goldman, S. A. (2016). Human glia can both induce and rescue aspects of disease phenotype in Huntington disease. Nat Commun, 7, 11758. doi:10.1038/ncomms11758

Bergles, D. E., \& Richardson, W. D. (2015). Oligodendrocyte Development and Plasticity. Cold Spring Harb Perspect Biol, 8(2), a020453. doi:10.1101/cshperspect.a020453 
Bergles, D. E., Roberts, J. D., Somogyi, P., \& Jahr, C. E. (2000). Glutamatergic synapses on oligodendrocyte precursor cells in the hippocampus. Nature, 405(6783), 187-191. doi:10.1038/35012083

Berry, G. E., \& Asokan, A. (2016). Cellular transduction mechanisms of adeno-associated viral vectors. Curr Opin Virol, 21, 54-60. doi:10.1016/j.coviro.2016.08.001

Berthiaume, A. A., \& Shih, A. Y. (2019). Sharpening the tools for pericyte research. Nat Neurosci, 22(7), $1041-1043$. doi:10.1038/s41593-019-0437-9

Bindocci, E., Savtchouk, I., Liaudet, N., Becker, D., Carriero, G., \& Volterra, A. (2017). Three-dimensional Ca(2+) imaging advances understanding of astrocyte biology. Science, 356(6339). doi:10.1126/science.aai8185

Björklund, A., Kirik, D., Rosenblad, C., Georgievska, B., Lundberg, C., \& Mandel, R. J. (2000). Towards a neuroprotective gene therapy for Parkinson's disease: use of adenovirus, AAV and lentivirus vectors for gene transfer of GDNF to the nigrostriatal system in the rat Parkinson model(1). Brain Res, 886(1-2), 82-98.

Blank, C. U., Rozeman, E. A., Fanchi, L. F., Sikorska, K., van de Wiel, B., Kvistborg, P., . . Schumacher, T. N. (2018). Neoadjuvant versus adjuvant ipilimumab plus nivolumab in macroscopic stage III melanoma. Nat Med, 24(11), 16551661. doi:10.1038/s41591-018-0198-0

Bodini, B., Veronese, M., Garcia-Lorenzo, D., Battaglini, M., Poirion, E., Chardain, A., . . Stankoff, B. (2016). Dynamic Imaging of Individual Remyelination Profiles in Multiple Sclerosis. Ann Neurol, 79(5), 726-738. doi:10.1002/ana.24620

Bohlen, C. J., Bennett, F. C., Tucker, A. F., Collins, H. Y., Mulinyawe, S. B., \& Barres, B. A. (2017). Diverse Requirements for Microglial Survival, Specification, and Function Revealed by Defined-Medium Cultures. Neuron, 94(4), 759-773 e758. doi:10.1016/j.neuron.2017.04.043

Boisvert, M. M., Erikson, G. A., Shokhirev, M. N., \& Allen, N. J. (2018). The Aging Astrocyte Transcriptome from Multiple Regions of the Mouse Brain. Cell Rep, 22(1), 269-285. doi:10.1016/j.celrep.2017.12.039

Bottcher, C., Schlickeiser, S., Sneeboer, M. A. M., Kunkel, D., Knop, A., Paza, E., . . Priller, J. (2019). Human microglia regional heterogeneity and phenotypes determined by multiplexed single-cell mass cytometry. Nat Neurosci, 22(1), 78-90. doi:10.1038/s41593-018-0290-2

Bottenstein, J. E., \& Sato, G. H. (1979). Growth of a rat neuroblastoma cell line in serum-free supplemented medium. Proc Natl Acad Sci U S A, 76(1), 514-517. doi:10.1073/pnas.76.1.514

Boza-Serrano, A., Yang, Y., Paulus, A., \& Deierborg, T. (2018). Innate immune alterations are elicited in microglial cells before plaque deposition in the Alzheimer's disease mouse model 5xFAD. Sci Rep, 8(1), 1550. doi:10.1038/s41598018-19699-y

Brennand, K. J. (2017). Personalized medicine in a dish: the growing possibility of neuropsychiatric disease drug discovery tailored to patient genetic variants using stem cells. Stem Cell Investig, 4, 91. doi:10.21037/sci.2017.10.05

Brenner, M., Kisseberth, W. C., Su, Y., Besnard, F., \& Messing, A. (1994). GFAP promoter directs astrocyte-specific expression in tansgenic mice. J.Neurosci., 14, 1030-1037.

Brewer, G. J., Espinosa, J., Mcllhaney, M. P., Pencek, T. P., Kesslak, J. P., Cotman, C., . . McManus, D. C. (2001). Culture and regeneration of human neurons after brain surgery. J Neurosci Methods, 107(1-2), 15-23. doi:10.1016/s01650270(01)00342-9

Brodin, P. (2019). The biology of the cell - insights from mass cytometry. FEBS J, 286(8), 1514-1522. doi:10.1111/febs.14693

Brown, B. D., \& Naldini, L. (2009). Exploiting and antagonizing microRNA regulation for therapeutic and experimental applications. Nat Rev Genet, 10(8), 578-585. doi:10.1038/nrg2628

Budnik, B., Levy, E., Harmange, G., \& Slavov, N. (2018). SCoPE-MS: mass spectrometry of single mammalian cells quantifies proteome heterogeneity during cell differentiation. Genome Biol, 19(1), 161. doi:10.1186/s13059-0181547-5

Bull, C., Freitas, K. C., Zou, S., Poland, R. S., Syed, W. A., Urban, D. J., . . Bowers, M. S. (2014). Rat nucleus accumbens core astrocytes modulate reward and the motivation to self-administer ethanol after abstinence. Neuropsychopharmacology, 39(12), 2835-2845. doi:10.1038/npp.2014.135

Cahoy, J. D., Emery, B., Kaushal, A., Foo, L. C., Zamanian, J. L., Christopherson, K. S., . . Barres, B. A. (2008). A transcriptome database for astrocytes, neurons, and oligodendrocytes: a new resource for understanding brain development and function. $J$ Neurosci, 28(1), 264-278. doi:28/1/264 [pii]

10.1523/JNEUROSCI.4178-07.2008

Cannon, J. R., Sew, T., Montero, L., Burton, E. A., \& Greenamyre, J. T. (2011). Pseudotype-dependent lentiviral transduction of astrocytes or neurons in the rat substantia nigra. Exp Neurol, 228(1), 41-52. doi:10.1016/j.expneurol.2010.10.016

Cantor, J. R., Abu-Remaileh, M., Kanarek, N., Freinkman, E., Gao, X., Louissaint, A., Jr., . . Sabatini, D. M. (2017). Physiologic Medium Rewires Cellular Metabolism and Reveals Uric Acid as an Endogenous Inhibitor of UMP Synthase. Cell, 169(2), 258-272 e217. doi:10.1016/j.cell.2017.03.023

Caporale, N., \& Dan, Y. (2008). Spike timing-dependent plasticity: a Hebbian learning rule. Annu Rev Neurosci, 31, 2546. doi:10.1146/annurev.neuro.31.060407.125639 
Carrillo-de Sauvage, M. A., Flament, J., Bramoulle, Y., Ben Haim, L., Guillermier, M., Berniard, A., ... Escartin, C. (2015). The neuroprotective agent CNTF decreases neuronal metabolites in the rat striatum: an in vivo multimodal magnetic resonance imaging study. J Cereb Blood Flow Metab, 35(6), 917-921. doi:10.1038/jcbfm.2015.48

Cartier, N., Hacein-Bey-Abina, S., Bartholomae, C. C., Veres, G., Schmidt, M., Kutschera, I., ... Aubourg, P. (2009). Hematopoietic stem cell gene therapy with a lentiviral vector in X-linked adrenoleukodystrophy. Science, 326(5954), 818-823. doi:10.1126/science.1171242

Cearley, C. N., Vandenberghe, L. H., Parente, M. K., Carnish, E. R., Wilson, J. M., \& Wolfe, J. H. (2008). Expanded repertoire of $A A V$ vector serotypes mediate unique patterns of transduction in mouse brain. Mol Ther, 16(10), 17101718. doi:10.1038/mt.2008.166

Chai, H., Diaz-Castro, B., Shigetomi, E., Monte, E., Octeau, J. C., Yu, X., . . Khakh, B. S. (2017). Neural CircuitSpecialized Astrocytes: Transcriptomic, Proteomic, Morphological, and Functional Evidence. Neuron, 95(3), 531-549 e539. doi:10.1016/j.neuron.2017.06.029

Chambers, S. M., Fasano, C. A., Papapetrou, E. P., Tomishima, M., Sadelain, M., \& Studer, L. (2009). Highly efficient neural conversion of human ES and iPS cells by dual inhibition of SMAD signaling. Nat Biotechnol, 27(3), $275-280$. doi:10.1038/nbt.1529

Chan, K. Y., Jang, M. J., Yoo, B. B., Greenbaum, A., Ravi, N., Wu, W. L., . . Gradinaru, V. (2017). Engineered AAVs for efficient noninvasive gene delivery to the central and peripheral nervous systems. Nat Neurosci, 20(8), 1172-1179. doi:10.1038/nn.4593

Chang, Q., Ornatsky, O. I., Siddiqui, I., Loboda, A., Baranov, V. I., \& Hedley, D. W. (2017). Imaging Mass Cytometry. Cytometry A, 91(2), 160-169. doi:10.1002/cyto.a.23053

Chen, G., Ning, B., \& Shi, T. (2019). Single-Cell RNA-Seq Technologies and Related Computational Data Analysis. Front Genet, 10, 317. doi:10.3389/fgene.2019.00317

Chen, H., McCarty, D. M., Bruce, A. T., Suzuki, K., \& Suzuki, K. (1998). Gene transfer and expression in oligodendrocytes under the control of myelin basic protein transcriptional control region mediated by adenoassociated virus. Gene Ther, 5(1), 50-58. doi:10.1038/sj.gt.3300547

Chen, N., Sugihara, H., Kim, J., Fu, Z., Barak, B., Sur, M., . . Han, W. (2016). Direct modulation of GFAP-expressing glia in the arcuate nucleus bi-directionally regulates feeding. Elife, 5. doi:10.7554/eLife.18716

Chen, R., Wu, X., Jiang, L., \& Zhang, Y. (2017). Single-Cell RNA-Seq Reveals Hypothalamic Cell Diversity. Cell Rep, 18(13), 3227-3241. doi:10.1016/j.celrep.2017.03.004

Chen, Y., Stevens, B., Chang, J., Milbrandt, J., Barres, B. A., \& Hell, J. W. (2008). NS21: re-defined and modified supplement B27 for neuronal cultures. J Neurosci Methods, 171(2), 239-247. doi:10.1016/j.jneumeth.2008.03.013

Cheray, M., \& Joseph, B. (2018). Epigenetics Control Microglia Plasticity. Front Cell Neurosci, 12, 243. doi:10.3389/fncel.2018.00243

Choi, S. H., Kim, Y. H., Hebisch, M., Sliwinski, C., Lee, S., D'Avanzo, C., . . Kim, D. Y. (2014). A three-dimensional human neural cell culture model of Alzheimer's disease. Nature, 515(7526), 274-278. doi:10.1038/nature13800

Choi, S. S., Lee, H. J., Lim, I., Satoh, J., \& Kim, S. U. (2014). Human astrocytes: secretome profiles of cytokines and chemokines. PLoS One, 9(4), e92325. doi:10.1371/journal.pone.0092325

Choudhury, S. R., Fitzpatrick, Z., Harris, A. F., Maitland, S. A., Ferreira, J. S., Zhang, Y., . . Sena-Esteves, M. (2016). In Vivo Selection Yields AAV-B1 Capsid for Central Nervous System and Muscle Gene Therapy. Mol Ther, 24(7), 12471257. doi:10.1038/mt.2016.84

Christopherson, K. S., Ullian, E. M., Stokes, C. C., Mullowney, C. E., Hell, J. W., Agah, A., . . Barres, B. A. (2005). Thrombospondins are astrocyte-secreted proteins that promote CNS synaptogenesis. Cell, 120(3), 421-433.

Clark, B. S., Stein-O'Brien, G. L., Shiau, F., Cannon, G. H., Davis-Marcisak, E., Sherman, T., . . Blackshaw, S. (2019). Single-Cell RNA-Seq Analysis of Retinal Development Identifies NFI Factors as Regulating Mitotic Exit and Late-Born Cell Specification. Neuron, 102(6), 1111-1126 e1115. doi:10.1016/j.neuron.2019.04.010

Clarke, L. E., Liddelow, S. A., Chakraborty, C., Munch, A. E., Heiman, M., \& Barres, B. A. (2018). Normal aging induces A1-like astrocyte reactivity. Proc Natl Acad Sci U S A, 115(8), E1896-E1905. doi:10.1073/pnas.1800165115

Colin, A., Faideau, M., Dufour, N., Auregan, G., Hassig, R., Andrieu, T., . . . Deglon, N. (2009). Engineered lentiviral vector targeting astrocytes in vivo. Glia, 57(6), 667-679. doi:10.1002/glia.20795

Colonna, M., \& Butovsky, O. (2017). Microglia Function in the Central Nervous System During Health and Neurodegeneration. Annu Rev Immunol, 35, 441-468. doi:10.1146/annurev-immunol-051116-052358

Coombs, J., Eccles, J., \& Fatt, P. (1955). The electrical properties of the motoneurone membrane. J Physiol (Lond), 130, 291-325.

Coutinho-Budd, J., \& Freeman, M. R. (2013). Probing the enigma: unraveling glial cell biology in invertebrates. Curr Opin Neurobiol, 23(6), 1073-1079. doi:10.1016/j.conb.2013.07.002

Davalos, D., Grutzendler, J., Yang, G., Kim, J. V., Zuo, Y., Jung, S., . . Gan, W. B. (2005). ATP mediates rapid microglial response to local brain injury in vivo. Nat Neurosci, 8(6), 752-758. 
de Leeuw, B., Su, M., ter Horst, M., Iwata, S., Rodijk, M., Hoeben, R. C., . . Brenner, M. (2006). Increased glia-specific transgene expression with glial fibrillary acidic protein promoters containing multiple enhancer elements. J Neurosci Res, 83(5), 744-753. doi:10.1002/jnr.20776

Deglon, N., Tseng, J. L., Bensadoun, J. C., Zurn, A. D., Arsenijevic, Y., Pereira de Almeida, L., ... Aebischer, P. (2000). Self-inactivating lentiviral vectors with enhanced transgene expression as potential gene transfer system in Parkinson's disease. Hum Gene Ther, 11(1), 179-190. doi:10.1089/10430340050016256

Deiters, O. (1865). Untersuchungen u" ber Gehirn und Ru“" ckenmark des

Menschen und der Sa" ugethiere.: Vieweg.

Denk, F., Crow, M., Didangelos, A., Lopes, D. M., \& McMahon, S. B. (2016). Persistent Alterations in Microglial Enhancers in a Model of Chronic Pain. Cell Rep, 15(8), 1771-1781. doi:10.1016/j.celrep.2016.04.063

Deverman, B. E., Ravina, B. M., Bankiewicz, K. S., Paul, S. M., \& Sah, D. W. Y. (2018). Gene therapy for neurological disorders: progress and prospects. Nat Rev Drug Discov. doi:10.1038/nrd.2018.110

Ditadi, A., Sturgeon, C. M., Tober, J., Awong, G., Kennedy, M., Yzaguirre, A. D., . . Keller, G. (2015). Human definitive haemogenic endothelium and arterial vascular endothelium represent distinct lineages. Nat Cell Biol, $17(5), 580-591$. doi:10.1038/ncb3161

Doerr, A. (2019). Single-cell proteomics. Nat Methods, 16(1), 20. doi:10.1038/s41592-018-0273-y

Douvaras, P., Sun, B., Wang, M., Kruglikov, I., Lallos, G., Zimmer, M., . . Fossati, V. (2017). Directed Differentiation of Human Pluripotent Stem Cells to Microglia. Stem Cell Reports, 8(6), 1516-1524. doi:10.1016/j.stemcr.2017.04.023

Douvaras, P., Wang, J., Zimmer, M., Hanchuk, S., O'Bara, M. A., Sadiq, S., . . Fossati, V. (2014). Efficient generation of myelinating oligodendrocytes from primary progressive multiple sclerosis patients by induced pluripotent stem cells. Stem Cell Reports, 3(2), 250-259. doi:10.1016/j.stemcr.2014.06.012

Dow, L. E., Fisher, J., O'Rourke, K. P., Muley, A., Kastenhuber, E. R., Livshits, G., . . Lowe, S. W. (2015). Inducible in vivo genome editing with CRISPR-Cas9. Nat Biotechnol, 33(4), 390-394. doi:10.1038/nbt.3155

Drinkut, A., Tereshchenko, Y., Schulz, J. B., Bahr, M., \& Kugler, S. (2012). Efficient gene therapy for Parkinson's disease using astrocytes as hosts for localized neurotrophic factor delivery. Mol Ther, 20(3), 534-543. doi:10.1038/mt.2011.249

Drouet, V., Perrin, V., Hassig, R., Dufour, N., Auregan, G., Alves, S., . . Deglon, N. (2009). Sustained effects of nonallele-specific Huntingtin silencing. Ann Neurol, 65(3), 276-285. doi:10.1002/ana.21569

Dubbelaar, M. L., Kracht, L., Eggen, B. J. L., \& Boddeke, E. (2018). The Kaleidoscope of Microglial Phenotypes. Front Immunol, 9, 1753. doi:10.3389/fimmu.2018.01753

Durkee, C. A., \& Araque, A. (2019). Diversity and Specificity of Astrocyte-neuron Communication. Neuroscience, 396, 73-78. doi:10.1016/j.neuroscience.2018.11.010

Durston, A. J., Timmermans, J. P., Hage, W. J., Hendriks, H. F., de Vries, N. J., Heideveld, M., \& Nieuwkoop, P. D. (1989). Retinoic acid causes an anteroposterior transformation in the developing central nervous system. Nature, 340(6229), 140-144. doi:10.1038/340140a0

Dutrochet, H. (Ed.) (1824). Recherches anatomiques et physiologiques sur

la structure intime des animaux et des vegetaux, et sur leur motilite'. Paris: J.B. Baillie ' re, Libraire.

Eagle, H. (1959). Amino acid metabolism in mammalian cell cultures. Science, 130(3373), 432-437. doi:10.1126/science.130.3373.432

Echelard, Y., Epstein, D. J., St-Jacques, B., Shen, L., Mohler, J., McMahon, J. A., \& McMahon, A. P. (1993). Sonic hedgehog, a member of a family of putative signaling molecules, is implicated in the regulation of CNS polarity. Cell, 75(7), 1417-1430. doi:10.1016/0092-8674(93)90627-3

Edison, P., Donat, C. K., \& Sastre, M. (2018). In vivo Imaging of Glial Activation in Alzheimer's Disease. Front Neurol, 9, 625. doi:10.3389/fneur.2018.00625

Eleftheriadou, I., Dieringer, M., Poh, X. Y., Sanchez-Garrido, J., Gao, Y., Sgourou, A., . . Mazarakis, N. D. (2017). Selective transduction of astrocytic and neuronal CNS subpopulations by lentiviral vectors pseudotyped with Chikungunya virus envelope. Biomaterials, 123, 1-14. doi:10.1016/j.biomaterials.2017.01.023

Eng, C. L., Lawson, M., Zhu, Q., Dries, R., Koulena, N., Takei, Y., . . . Cai, L. (2019). Transcriptome-scale super-resolved imaging in tissues by RNA seqFISH. Nature, 568(7751), 235-239. doi:10.1038/s41586-019-1049-y

Escartin, C., Guillemaud, O., \& Carrillo-de Sauvage, M. A. (2019). Questions and (some) answers on reactive astrocytes. Glia. doi:10.1002/glia.23687

Escartin, C., Valette, J., Lebon, V., \& Bonvento, G. (2006). Neuron-astrocyte interactions in the regulation of brain energy metabolism: a focus on NMR spectroscopy. J Neurochem, 99(2), 393-401.

Eulalio, A., Huntzinger, E., \& Izaurralde, E. (2008). Getting to the root of miRNA-mediated gene silencing. Cell, 132(1), 9-14. doi:10.1016/j.cell.2007.12.024

Evans, M. J., \& Kaufman, M. H. (1981). Establishment in culture of pluripotential cells from mouse embryos. Nature, 292(5819), 154-156. doi:10.1038/292154a0 
Falcao, A. M., van Bruggen, D., Marques, S., Meijer, M., Jakel, S., Agirre, E., . . Castelo-Branco, G. (2018). Diseasespecific oligodendrocyte lineage cells arise in multiple sclerosis. Nat Med, 24(12), 1837-1844. doi:10.1038/s41591018-0236-y

Fan, X., \& Agid, Y. (2018). At the Origin of the History of Glia. Neuroscience, 385, 255-271. doi:10.1016/j.neuroscience.2018.05.050

Fan, X., Dong, J., Zhong, S., Wei, Y., Wu, Q., Yan, L., . . Tang, F. (2018). Spatial transcriptomic survey of human embryonic cerebral cortex by single-cell RNA-seq analysis. Cell Res, 28(7), 730-745. doi:10.1038/s41422-018-0053-3

Farrar, M. J., Wise, F. W., Fetcho, J. R., \& Schaffer, C. B. (2011). In vivo imaging of myelin in the vertebrate central nervous system using third harmonic generation microscopy. Biophys J, 100(5), 1362-1371. doi:10.1016/j.bpj.2011.01.031

Fecher, C., Trovo, L., Muller, S. A., Snaidero, N., Wettmarshausen, J., Heink, S., . . Misgeld, T. (2019). Cell-type-specific profiling of brain mitochondria reveals functional and molecular diversity. Nat Neurosci, 22(10), 1731-1742. doi:10.1038/s41593-019-0479-z

Fellmann, C., Hoffmann, T., Sridhar, V., Hopfgartner, B., Muhar, M., Roth, M., . . Zuber, J. (2013). An optimized microRNA backbone for effective single-copy RNAi. Cell Rep, 5(6), 1704-1713. doi:10.1016/j.celrep.2013.11.020

Fenno, L., Yizhar, O., \& Deisseroth, K. (2011). The development and application of optogenetics. Annu Rev Neurosci, 34, 389-412. doi:10.1146/annurev-neuro-061010-113817

Filippi, M., \& Agosta, F. (2010). Imaging biomarkers in multiple sclerosis. J Magn Reson Imaging, 31(4), 770-788. doi:10.1002/jmri.22102

Filippi, M., Bruck, W., Chard, D., Fazekas, F., Geurts, J. J. G., Enzinger, C., . . . workshop, M. R. I. f. i. M. (2019). Association between pathological and MRI findings in multiple sclerosis. Lancet Neurol, 18(2), 198-210. doi:10.1016/S1474-4422(18)30451-4

Foo, L. C., Allen, N. J., Bushong, E. A., Ventura, P. B., Chung, W. S., Zhou, L., . . Barres, B. A. (2011). Development of a method for the purification and culture of rodent astrocytes. Neuron, 71(5), 799-811. doi:S0896-6273(11)00649-0 [pii]

10.1016/j.neuron.2011.07.022

Foust, K. D., Nurre, E., Montgomery, C. L., Hernandez, A., Chan, C. M., \& Kaspar, B. K. (2009). Intravascular AAV9 preferentially targets neonatal neurons and adult astrocytes. Nat Biotechnol, 27(1), 59-65. doi:10.1038/nbt.1515

Fraichard, A., Chassande, O., Bilbaut, G., Dehay, C., Savatier, P., \& Samarut, J. (1995). In vitro differentiation of embryonic stem cells into glial cells and functional neurons. J Cell Sci, 108 ( Pt 10), 3181-3188.

Freeman, M. R. (2015). Drosophila Central Nervous System Glia. Cold Spring Harb Perspect Biol, 7(11). doi:10.1101/cshperspect.a020552

Galatro, T. F., Holtman, I. R., Lerario, A. M., Vainchtein, I. D., Brouwer, N., Sola, P. R., . . Eggen, B. J. L. (2017). Transcriptomic analysis of purified human cortical microglia reveals age-associated changes. Nat Neurosci, 20(8), 1162-1171. doi:10.1038/nn.4597

Garden, G. A., \& Campbell, B. M. (2016). Glial biomarkers in human central nervous system disease. Glia, 64(10), 17551771. doi:10.1002/glia.22998

Geirsdottir, L., David, E., Keren-Shaul, H., Weiner, A., Bohlen, S. C., Neuber, J., . . Prinz, M. (2019). Cross-Species Single-Cell Analysis Reveals Divergence of the Primate Microglia Program. Cell, 179(7), 1609-1622 e1616. doi:10.1016/j.cell.2019.11.010

Gentner, B., \& Naldini, L. (2012). Exploiting microRNA regulation for genetic engineering. Tissue Antigens, 80(5), 393403. doi:10.1111/tan.12002

Ghosh, K. K., Burns, L. D., Cocker, E. D., Nimmerjahn, A., Ziv, Y., Gamal, A. E., \& Schnitzer, M. J. (2011). Miniaturized integration of a fluorescence microscope. Nat Methods, 8(10), 871-878. doi:10.1038/nmeth.1694

Ghosh, R., \& Tabrizi, S. J. (2017). Gene suppression approaches to neurodegeneration. Alzheimers Res Ther, 9(1), 82. doi:10.1186/s13195-017-0307-1

Ginhoux, F., Greter, M., Leboeuf, M., Nandi, S., See, P., Gokhan, S., . . Merad, M. (2010). Fate mapping analysis reveals that adult microglia derive from primitive macrophages. Science, 330(6005), 841-845. doi:10.1126/science.1194637

Giulian, D., \& Baker, T. J. (1986). Characterization of ameboid microglia isolated from developing mammalian brain. J Neurosci, 6(8), 2163-2178.

Gokce, O., Stanley, G. M., Treutlein, B., Neff, N. F., Camp, J. G., Malenka, R. C., . . Quake, S. R. (2016). Cellular Taxonomy of the Mouse Striatum as Revealed by Single-Cell RNA-Seq. Cell Rep, 16(4), 1126-1137. doi:10.1016/j.celrep.2016.06.059

Golgi, C. (1873). Suella struttura della sostanza grigia del cervello (comunicazione preventiva). . Gazzetta Medica Italiana, Lombardia, 33, 244-246.

Golgi, C. (1875). Sulla fina struttura dei bulbi olfattori. . Riv sper Freniatria Med legal, 1, 66-78.

Goshen, I. (2014). The optogenetic revolution in memory research. Trends Neurosci, 37(9), 511-522. doi:10.1016/j.tins.2014.06.002 
Gosselin, D., Skola, D., Coufal, N. G., Holtman, I. R., Schlachetzki, J. C. M., Sajti, E., . . Glass, C. K. (2017). An environment-dependent transcriptional network specifies human microglia identity. Science, 356(6344). doi:10.1126/science.aal3222

Gourine, A. V., Kasymov, V., Marina, N., Tang, F., Figueiredo, M. F., Lane, S., . . Kasparov, S. (2010). Astrocytes control breathing through pH-dependent release of ATP. Science, 329(5991), 571-575. doi:10.1126/science.1190721

Grabert, K., Michoel, T., Karavolos, M. H., Clohisey, S., Baillie, J. K., Stevens, M. P., . . McColl, B. W. (2016). Microglial brain region-dependent diversity and selective regional sensitivities to aging. Nat Neurosci, 19(3), 504-516. doi:10.1038/nn.4222

Gradinaru, V., Mogri, M., Thompson, K. R., Henderson, J. M., \& Deisseroth, K. (2009). Optical deconstruction of parkinsonian neural circuitry. Science, 324(5925), 354-359. doi:10.1126/science.1167093

Graff, J. M., Thies, R. S., Song, J. J., Celeste, A. J., \& Melton, D. A. (1994). Studies with a Xenopus BMP receptor suggest that ventral mesoderm-inducing signals override dorsal signals in vivo. Cell, 79(1), 169-179. doi:10.1016/00928674(94)90409-x

Gray, S. J., Matagne, V., Bachaboina, L., Yadav, S., Ojeda, S. R., \& Samulski, R. J. (2011). Preclinical differences of intravascular AAV9 delivery to neurons and glia: a comparative study of adult mice and nonhuman primates. Mol Ther, 19(6), 1058-1069. doi:10.1038/mt.2011.72

Grienberger, C., \& Konnerth, A. (2012). Imaging calcium in neurons. Neuron, 73(5), 862-885. doi:10.1016/j.neuron.2012.02.011

Grimm, D., Lee, J. S., Wang, L., Desai, T., Akache, B., Storm, T. A., \& Kay, M. A. (2008). In vitro and in vivo gene therapy vector evolution via multispecies interbreeding and retargeting of adeno-associated viruses. $J$ Virol, 82(12), 58875911. doi:10.1128/JVI.00254-08

Grubisic, V., \& Gulbransen, B. D. (2017). Enteric glia: the most alimentary of all glia. J Physiol, 595(2), 557-570. doi:10.1113/JP271021

Grutzendler, J., Kasthuri, N., \& Gan, W. B. (2002). Long-term dendritic spine stability in the adult cortex. Nature, 420(6917), 812-816. doi:10.1038/nature01276

Guneykaya, D., Ivanov, A., Hernandez, D. P., Haage, V., Wojtas, B., Meyer, N., . . Wolf, S. A. (2018). Transcriptional and Translational Differences of Microglia from Male and Female Brains. Cell Rep, 24(10), 2773-2783 e2776. doi:10.1016/j.celrep.2018.08.001

Gunner, G., Cheadle, L., Johnson, K. M., Ayata, P., Badimon, A., Mondo, E., . . Schafer, D. P. (2019). Sensory lesioning induces microglial synapse elimination via ADAM10 and fractalkine signaling. Nat Neurosci, 22(7), 1075-1088. doi:10.1038/s41593-019-0419-y

Guttenplan, K. A., \& Liddelow, S. A. (2019). Astrocytes and microglia: Models and tools. J Exp Med, 216(1), 71-83. doi:10.1084/jem.20180200

Hadaczek, P., Stanek, L., Ciesielska, A., Sudhakar, V., Samaranch, L., Pivirotto, P., . . Shihabuddin, L. S. (2016). Widespread AAV1- and AAV2-mediated transgene expression in the nonhuman primate brain: implications for Huntington's disease. Mol Ther Methods Clin Dev, 3, 16037. doi:10.1038/mtm.2016.37

Haenseler, W., Sansom, S. N., Buchrieser, J., Newey, S. E., Moore, C. S., Nicholls, F. J., . . Cowley, S. A. (2017). A Highly Efficient Human Pluripotent Stem Cell Microglia Model Displays a Neuronal-Co-culture-Specific Expression Profile and Inflammatory Response. Stem Cell Reports, 8(6), 1727-1742. doi:10.1016/j.stemcr.2017.05.017

Haimon, Z., Volaski, A., Orthgiess, J., Boura-Halfon, S., Varol, D., Shemer, A., . . Jung, S. (2018). Re-evaluating microglia expression profiles using RiboTag and cell isolation strategies. Nat Immunol, 19(6), 636-644. doi:10.1038/s41590-018-0110-6

Hamburger, V., \& Levi-Montalcini, R. (1949). Proliferation, differentiation and degeneration in the spinal ganglia of the chick embryo under normal and experimental conditions. J Exp Zool, 111(3), 457-501. doi:10.1002/jez.1401110308

Hamelin, L., Lagarde, J., Dorothee, G., Leroy, C., Labit, M., Comley, R. A., . . Clinical, I. t. (2016). Early and protective microglial activation in Alzheimer's disease: a prospective study using 18F-DPA-714 PET imaging. Brain, 139(Pt 4), 1252-1264. doi:10.1093/brain/aww017

Hammond, S. L., Leek, A. N., Richman, E. H., \& Tjalkens, R. B. (2017). Cellular selectivity of AAV serotypes for gene delivery in neurons and astrocytes by neonatal intracerebroventricular injection. PLoS One, 12(12), e0188830. doi:10.1371/journal.pone.0188830

Hammond, T. R., Dufort, C., Dissing-Olesen, L., Giera, S., Young, A., Wysoker, A., . . Stevens, B. (2019). Single-Cell RNA Sequencing of Microglia throughout the Mouse Lifespan and in the Injured Brain Reveals Complex Cell-State Changes. Immunity, 50(1), 253-271 e256. doi:10.1016/j.immuni.2018.11.004

Hasselmann, J., Coburn, M. A., England, W., Figueroa Velez, D. X., Kiani Shabestari, S., Tu, C. H., ... Blurton-Jones, M. (2019). Development of a Chimeric Model to Study and Manipulate Human Microglia In Vivo. Neuron, 103(6), 10161033 e1010. doi:10.1016/j.neuron.2019.07.002

Haustein, M. D., Kracun, S., Lu, X. H., Shih, T., Jackson-Weaver, O., Tong, X., . . Khakh, B. S. (2014). Conditions and constraints for astrocyte calcium signaling in the hippocampal mossy fiber pathway. Neuron, 82(2), 413-429. doi:10.1016/j.neuron.2014.02.041 
Heath, F., Hurley, S. A., Johansen-Berg, H., \& Sampaio-Baptista, C. (2018). Advances in noninvasive myelin imaging. Dev Neurobiol, 78(2), 136-151. doi:10.1002/dneu.22552

Hedlund, E., \& Deng, Q. (2018). Single-cell RNA sequencing: Technical advancements and biological applications. Mol Aspects Med, 59, 36-46. doi:10.1016/j.mam.2017.07.003

Heng, J. S., Rattner, A., Stein-O'Brien, G. L., Winer, B. L., Jones, B. W., Vernon, H. J., . . Nathans, J. (2019). Hypoxia tolerance in the Norrin-deficient retina and the chronically hypoxic brain studied at single-cell resolution. Proc Natl Acad Sci U S A, 116(18), 9103-9114. doi:10.1073/pnas.1821122116

Hickman, S. E., Kingery, N. D., Ohsumi, T. K., Borowsky, M. L., Wang, L. C., Means, T. K., \& El Khoury, J. (2013). The microglial sensome revealed by direct RNA sequencing. Nat Neurosci, 16(12), 1896-1905. doi:10.1038/nn.3554

Hild, W., Chang, J., \& Tasaki, I. (1958). Electrical responses of astrocytic glia from the mammalian central nervous system cultivated in vitro. Experientia, 14, 220-221.

Hill, R. A., Damisah, E. C., Chen, F., Kwan, A. C., \& Grutzendler, J. (2017). Targeted two-photon chemical apoptotic ablation of defined cell types in vivo. Nat Commun, 8, 15837. doi:10.1038/ncomms15837

Hill, R. A., \& Grutzendler, J. (2019). Uncovering the biology of myelin with optical imaging of the live brain. Glia, 67(11), 2008-2019. doi:10.1002/glia.23635

Hill, R. A., Li, A. M., \& Grutzendler, J. (2018). Lifelong cortical myelin plasticity and age-related degeneration in the live mammalian brain. Nat Neurosci, 21(5), 683-695. doi:10.1038/s41593-018-0120-6

Hill, R. A., Tong, L., Yuan, P., Murikinati, S., Gupta, S., \& Grutzendler, J. (2015). Regional Blood Flow in the Normal and Ischemic Brain Is Controlled by Arteriolar Smooth Muscle Cell Contractility and Not by Capillary Pericytes. Neuron, 87(1), 95-110. doi:10.1016/j.neuron.2015.06.001

Hirbec, H. E., Noristani, H. N., \& Perrin, F. E. (2017). Microglia Responses in Acute and Chronic Neurological Diseases: What Microglia-Specific Transcriptomic Studies Taught (and did Not Teach) Us. Front Aging Neurosci, 9, 227. doi:10.3389/fnagi.2017.00227

His, W. (1888). Zur Geschichte des Gehirns sowie der centralen und peripherischen Nervenbahnen beim menschlichen Embryo. Abh Kgl sachs Ges Wissensch math phys, 1, 339-392.

Hodge, R. D., Bakken, T. E., Miller, J. A., Smith, K. A., Barkan, E. R., Graybuck, L. T., . . Lein, E. S. (2019). Conserved cell types with divergent features in human versus mouse cortex. Nature, 573(7772), 61-68. doi:10.1038/s41586-0191506-7

Horton, N. G., Wang, K., Kobat, D., Clark, C. G., Wise, F. W., Schaffer, C. B., \& Xu, C. (2013). In vivo three-photon microscopy of subcortical structures within an intact mouse brain. Nat Photonics, 7(3). doi:10.1038/nphoton.2012.336

Hrvatin, S., Hochbaum, D. R., Nagy, M. A., Cicconet, M., Robertson, K., Cheadle, L., . . Greenberg, M. E. (2018). Singlecell analysis of experience-dependent transcriptomic states in the mouse visual cortex. Nat Neurosci, 21(1), $120-129$. doi:10.1038/s41593-017-0029-5

Hsueh, Y. P., \& Sheng, M. (1999). Regulated expression and subcellular localization of syndecan heparan sulfate proteoglycans and the syndecan-binding protein CASK/LIN-2 during rat brain development. J Neurosci, 19(17), 74157425.

Hsueh, Y. P., Yang, F. C., Kharazia, V., Naisbitt, S., Cohen, A. R., Weinberg, R. J., \& Sheng, M. (1998). Direct interaction of CASK/LIN-2 and syndecan heparan sulfate proteoglycan and their overlapping distribution in neuronal synapses. $J$ Cell Biol, 142(1), 139-151. doi:10.1083/jcb.142.1.139

Hu, B. Y., Du, Z. W., Li, X. J., Ayala, M., \& Zhang, S. C. (2009). Human oligodendrocytes from embryonic stem cells: conserved SHH signaling networks and divergent FGF effects. Development, 136(9), 1443-1452. doi:10.1242/dev.029447

Hudry, E., \& Vandenberghe, L. H. (2019). Therapeutic AAV Gene Transfer to the Nervous System: A Clinical Reality. Neuron, 101(5), 839-862. doi:10.1016/j.neuron.2019.02.017

Hughes, E. G., Kang, S. H., Fukaya, M., \& Bergles, D. E. (2013). Oligodendrocyte progenitors balance growth with selfrepulsion to achieve homeostasis in the adult brain. Nat Neurosci, 16(6), 668-676. doi:10.1038/nn.3390

Hughes, E. G., Orthmann-Murphy, J. L., Langseth, A. J., \& Bergles, D. E. (2018). Myelin remodeling through experiencedependent oligodendrogenesis in the adult somatosensory cortex. Nat Neurosci, 21(5), 696-706. doi:10.1038/s41593-018-0121-5

ladecola, C. (2017). The Neurovascular Unit Coming of Age: A Journey through Neurovascular Coupling in Health and Disease. Neuron, 96(1), 17-42. doi:10.1016/j.neuron.2017.07.030

ladecola, C., \& Nedergaard, M. (2007). Glial regulation of the cerebral microvasculature. Nat Neurosci, 10(11), 13691376. doi:10.1038/nn2003

Ising, C., \& Heneka, M. T. (2018). Functional and structural damage of neurons by innate immune mechanisms during neurodegeneration. Cell Death Dis, 9(2), 120. doi:10.1038/s41419-017-0153-x

Jafari, M., Schumacher, A. M., Snaidero, N., Neziraj, T., Ullrich Gavilanes, E. M., Jürgens, T., . .. Kerschensteiner, M. (2019). Localized calcium accumulations prime synapses for phagocyte removal in cortical neuroinflammation.

BioRxiv. doi:10.1101/758193 
Jakel, S., Agirre, E., Mendanha Falcao, A., van Bruggen, D., Lee, K. W., Knuesel, I., . . Castelo-Branco, G. (2019). Altered human oligodendrocyte heterogeneity in multiple sclerosis. Nature, 566(7745), 543-547. doi:10.1038/s41586-0190903-2

Jha, M. K., Kim, J. H., Song, G. J., Lee, W. H., Lee, I. K., Lee, H. W., . . Suk, K. (2018). Functional dissection of astrocytesecreted proteins: Implications in brain health and diseases. Prog Neurobiol, 162, 37-69. doi:10.1016/j.pneurobio.2017.12.003

Jha, M. K., Seo, M., Kim, J. H., Kim, B. G., Cho, J. Y., \& Suk, K. (2013). The secretome signature of reactive glial cells and its pathological implications. Biochim Biophys Acta, 1834(11), 2418-2428. doi:10.1016/j.bbapap.2012.12.006

Jiang, T., Zhang, Y. D., Chen, Q., Gao, Q., Zhu, X. C., Zhou, J. S., . . Yu, J. T. (2016). TREM2 modifies microglial phenotype and provides neuroprotection in P301S tau transgenic mice. Neuropharmacology, 105, 196-206. doi:10.1016/j.neuropharm.2016.01.028

Jiang, T., Zhang, Y. D., Gao, Q., Ou, Z., Gong, P. Y., Shi, J. Q., . . Zhou, J. S. (2018). TREM2 Ameliorates Neuronal Tau Pathology Through Suppression of Microglial Inflammatory Response. Inflammation, 41(3), 811-823. doi:10.1007/s10753-018-0735-5

Joglekar, A. V., \& Sandoval, S. (2017). Pseudotyped Lentiviral Vectors: One Vector, Many Guises. Hum Gene Ther Methods, 28(6), 291-301. doi:10.1089/hgtb.2017.084

John Lin, C. C., Yu, K., Hatcher, A., Huang, T. W., Lee, H. K., Carlson, J., . . . Deneen, B. (2017). Identification of diverse astrocyte populations and their malignant analogs. Nat Neurosci, 20(3), 396-405. doi:10.1038/nn.4493

Kalish, B. T., Cheadle, L., Hrvatin, S., Nagy, M. A., Rivera, S., Crow, M., . . Greenberg, M. E. (2018). Single-cell transcriptomics of the developing lateral geniculate nucleus reveals insights into circuit assembly and refinement. Proc Natl Acad Sci U S A, 115(5), E1051-E1060. doi:10.1073/pnas.1717871115

Kastanenka, K. V., Moreno-Bote, R., De Pitta, M., Perea, G., Eraso-Pichot, A., Masgrau, R., . . Galea, E. (2019). A roadmap to integrate astrocytes into Systems Neuroscience. Glia. doi:10.1002/glia.23632

Keren-Shaul, H., Spinrad, A., Weiner, A., Matcovitch-Natan, O., Dvir-Szternfeld, R., Ulland, T. K., . . . Amit, I. (2017). A Unique Microglia Type Associated with Restricting Development of Alzheimer's Disease. Cell, 169(7), 1276-1290 e1217. doi:10.1016/j.cell.2017.05.018

Kim, W. K., Kim, D., Cui, J., Jang, H. H., Kim, K. S., Lee, H. J., . . . Ahn, S. M. (2014). Secretome analysis of human oligodendrocytes derived from neural stem cells. PLoS One, 9(1), e84292. doi:10.1371/journal.pone.0084292

Kirby, B. B., Takada, N., Latimer, A. J., Shin, J., Carney, T. J., Kelsh, R. N., \& Appel, B. (2006). In vivo time-lapse imaging shows dynamic oligodendrocyte progenitor behavior during zebrafish development. Nat Neurosci, 9(12), $1506-1511$. doi:10.1038/nn1803

Kiskinis, E., Kralj, J. M., Zou, P., Weinstein, E. N., Zhang, H., Tsioras, K., . . Cohen, A. E. (2018). All-Optical Electrophysiology for High-Throughput Functional Characterization of a Human iPSC-Derived Motor Neuron Model of ALS. Stem Cell Reports, 10(6), 1991-2004. doi:10.1016/j.stemcr.2018.04.020

Kitchen, R. R., Rozowsky, J. S., Gerstein, M. B., \& Nairn, A. C. (2014). Decoding neuroproteomics: integrating the genome, translatome and functional anatomy. Nat Neurosci, 17(11), 1491-1499. doi:10.1038/nn.3829

Klein, R. L., Dayton, R. D., Leidenheimer, N. J., Jansen, K., Golde, T. E., \& Zweig, R. M. (2006). Efficient neuronal gene transfer with AAV8 leads to neurotoxic levels of tau or green fluorescent proteins. Mol Ther, 13(3), 517-527. doi:10.1016/j.ymthe.2005.10.008

Klein, R. L., Dayton, R. D., Tatom, J. B., Henderson, K. M., \& Henning, P. P. (2008). AAV8, 9, Rh10, Rh43 vector gene transfer in the rat brain: effects of serotype, promoter and purification method. Mol Ther, 16(1), 89-96. doi:10.1038/sj.mt.6300331

Klum, S., Zaouter, C., Alekseenko, Z., Bjorklund, A. K., Hagey, D. W., Ericson, J., . . Bergsland, M. (2018). Sequentially acting SOX proteins orchestrate astrocyte- and oligodendrocyte-specific gene expression. EMBO Rep, 19(11). doi:10.15252/embr.201846635

Ko, M. H., Kim, S., Hwang, D. W., Ko, H. Y., Kim, Y. H., \& Lee, D. S. (2008). Bioimaging of the unbalanced expression of microRNA9 and microRNA9* during the neuronal differentiation of P19 cells. FEBS J, 275(10), 2605-2616. doi:10.1111/j.1742-4658.2008.06408.x

Koelle, G. (1955). The histochemical identification of acetylcholinesterase in cholinergic, adrenergic and sensory neurons. J Pharmacol Exp Ther, 114, 167-184.

Kohro, Y., Sakaguchi, E., Tashima, R., Tozaki-Saitoh, H., Okano, H., Inoue, K., \& Tsuda, M. (2015). A new minimallyinvasive method for microinjection into the mouse spinal dorsal horn. Sci Rep, 5, 14306. doi:10.1038/srep14306

Krencik, R., \& Zhang, S. C. (2011). Directed differentiation of functional astroglial subtypes from human pluripotent stem cells. Nat Protoc, 6(11), 1710-1717. doi:10.1038/nprot.2011.405

Krogager, T. P., Ernst, R. J., Elliott, T. S., Calo, L., Beranek, V., Ciabatti, E., . . Chin, J. W. (2018). Labeling and identifying cell-specific proteomes in the mouse brain. Nat Biotechnol, 36(2), 156-159. doi:10.1038/nbt.4056

Kunze, C., Borner, K., Kienle, E., Orschmann, T., Rusha, E., Schneider, M., . . Brack-Werner, R. (2018). Synthetic AAV/CRISPR vectors for blocking HIV-1 expression in persistently infected astrocytes. Glia, 66(2), 413-427. doi:10.1002/glia.23254 
La Manno, G., Gyllborg, D., Codeluppi, S., Nishimura, K., Salto, C., Zeisel, A., . . Linnarsson, S. (2016). Molecular Diversity of Midbrain Development in Mouse, Human, and Stem Cells. Cell, 167(2), 566-580 e519. doi:10.1016/j.cell.2016.09.027

Lacar, B., Linker, S. B., Jaeger, B. N., Krishnaswami, S. R., Barron, J. J., Kelder, M. J. E., . . Gage, F. H. (2016). Nuclear RNA-seq of single neurons reveals molecular signatures of activation. Nat Commun, 7, 11022. doi:10.1038/ncomms11022

Lake, B. B., Codeluppi, S., Yung, Y. C., Gao, D., Chun, J., Kharchenko, P. V., . . . Zhang, K. (2017). A comparative strategy for single-nucleus and single-cell transcriptomes confirms accuracy in predicted cell-type expression from nuclear RNA. Sci Rep, 7(1), 6031. doi:10.1038/s41598-017-04426-w

Lancaster, M. A., Renner, M., Martin, C. A., Wenzel, D., Bicknell, L. S., Hurles, M. E., . . Knoblich, J. A. (2013). Cerebral organoids model human brain development and microcephaly. Nature, 501(7467), 373-379. doi:10.1038/nature12517

Lavin, Y., Winter, D., Blecher-Gonen, R., David, E., Keren-Shaul, H., Merad, M., . . . Amit, I. (2014). Tissue-resident macrophage enhancer landscapes are shaped by the local microenvironment. Cell, 159(6), 1312-1326. doi:10.1016/j.cell.2014.11.018

Lavisse, S., Guillermier, M., Herard, A. S., Petit, F., Delahaye, M., Van Camp, N., . . Escartin, C. (2012). Reactive Astrocytes Overexpress TSPO and Are Detected by TSPO Positron Emission Tomography Imaging. J Neurosci, 32(32), 10809-10818. doi:32/32/10809 [pii]

10.1523/JNEUROSCI.1487-12.2012

Lawlor, P. A., Bland, R. J., Mouravlev, A., Young, D., \& During, M. J. (2009). Efficient gene delivery and selective transduction of glial cells in the mammalian brain by AAV serotypes isolated from nonhuman primates. Mol Ther, 17(10), 1692-1702. doi:10.1038/mt.2009.170

Lebon, V., Petersen, K. F., Cline, G. W., Shen, J., Mason, G. F., Dufour, S., . . Rothman, D. L. (2002). Astroglial contribution to brain energy metabolism in humans revealed by $13 \mathrm{C}$ nuclear magnetic resonance spectroscopy: elucidation of the dominant pathway for neurotransmitter glutamate repletion and measurement of astrocytic oxidative metabolism. J Neurosci, 22(5), 1523-1531.

Lee, B., Lee, K., Panda, S., Gonzales-Rojas, R., Chong, A., Bugay, V., . . . Lee, H. Y. (2018). Nanoparticle delivery of CRISPR into the brain rescues a mouse model of fragile $X$ syndrome from exaggerated repetitive behaviours. Nat Biomed Eng, 2(7), 497-507. doi:10.1038/s41551-018-0252-8

Lee, C. Z. W., Kozaki, T., \& Ginhoux, F. (2018). Studying tissue macrophages in vitro: are iPSC-derived cells the answer? Nat Rev Immunol, 18(11), 716-725. doi:10.1038/s41577-018-0054-y

Lee, Y., Messing, A., Su, M., \& Brenner, M. (2008). GFAP promoter elements required for region-specific and astrocytespecific expression. Glia, 56(5), 481-493. doi:10.1002/glia.20622

Lee, Y., Morrison, B. M., Li, Y., Lengacher, S., Farah, M. H., Hoffman, P. N., . . Rothstein, J. D. (2012). Oligodendroglia metabolically support axons and contribute to neurodegeneration. Nature, 487(7408), 443-448. doi:10.1038/nature11314

Levy, E., \& Slavov, N. (2018). Single cell protein analysis for systems biology. Essays Biochem, 62(4), 595-605. doi:10.1042/EBC20180014

Li, M., Husic, N., Lin, Y., Christensen, H., Malik, I., Mclver, S., . . Snider, B. J. (2010). Optimal promoter usage for lentiviral vector-mediated transduction of cultured central nervous system cells. J Neurosci Methods, 189(1), 56-64. doi:10.1016/j.jneumeth.2010.03.019

Li, Q., Cheng, Z., Zhou, L., Darmanis, S., Neff, N. F., Okamoto, J., . . Barres, B. A. (2019). Developmental Heterogeneity of Microglia and Brain Myeloid Cells Revealed by Deep Single-Cell RNA Sequencing. Neuron, 101(2), $207-223$ e210. doi:10.1016/j.neuron.2018.12.006

Li, Y., Muffat, J., Omer, A., Bosch, I., Lancaster, M. A., Sur, M., . . . Jaenisch, R. (2017). Induction of Expansion and Folding in Human Cerebral Organoids. Cell Stem Cell, 20(3), 385-396 e383. doi:10.1016/j.stem.2016.11.017

Li, Y., Wang, H., Muffat, J., Cheng, A. W., Orlando, D. A., Loven, J., . . . Jaenisch, R. (2013). Global transcriptional and translational repression in human-embryonic-stem-cell-derived Rett syndrome neurons. Cell Stem Cell, 13(4), 446458. doi:10.1016/j.stem.2013.09.001

Liddelow, S. A., \& Barres, B. A. (2017). Reactive Astrocytes: Production, Function, and Therapeutic Potential. Immunity, 46(6), 957-967. doi:10.1016/j.immuni.2017.06.006

Liddelow, S. A., Guttenplan, K. A., Clarke, L. E., Bennett, F. C., Bohlen, C. J., Schirmer, L., . . Barres, B. A. (2017). Neurotoxic reactive astrocytes are induced by activated microglia. Nature, 541(7638), 481-487. doi:10.1038/nature21029

Ligneul, C., Palombo, M., Hernandez-Garzon, E., Carrillo-de Sauvage, M. A., Flament, J., Hantraye, P., . . . Valette, J. (2019). Diffusion-weighted magnetic resonance spectroscopy enables cell-specific monitoring of astrocyte reactivity in vivo. Neuroimage, 191, 457-469. doi:10.1016/j.neuroimage.2019.02.046

Liu, G., Martins, I. H., Chiorini, J. A., \& Davidson, B. L. (2005). Adeno-associated virus type 4 (AAV4) targets ependyma and astrocytes in the subventricular zone and RMS. Gene Ther, 12(20), 1503-1508. doi:10.1038/sj.gt.3302554 
Liu, Y., Beyer, A., \& Aebersold, R. (2016). On the Dependency of Cellular Protein Levels on mRNA Abundance. Cell, 165(3), 535-550. doi:10.1016/j.cell.2016.03.014

Lukowski, S. W., Lo, C. Y., Sharov, A. A., Nguyen, Q., Fang, L., Hung, S. S., . . Wong, R. C. (2019). A single-cell transcriptome atlas of the adult human retina. $E M B O \mathrm{~J}, 38(18)$, e100811. doi:10.15252/embj.2018100811

Lundberg, C., Bjorklund, T., Carlsson, T., Jakobsson, J., Hantraye, P., Deglon, N., \& Kirik, D. (2008). Applications of lentiviral vectors for biology and gene therapy of neurological disorders. Curr Gene Ther, 8(6), 461-473.

Lyons, D. A., \& Talbot, W. S. (2014). Glial cell development and function in zebrafish. Cold Spring Harb Perspect Biol, 7(2), a020586. doi:10.1101/cshperspect.a020586

Macosko, E. Z., Basu, A., Satija, R., Nemesh, J., Shekhar, K., Goldman, M., . . McCarroll, S. A. (2015). Highly Parallel Genome-wide Expression Profiling of Individual Cells Using Nanoliter Droplets. Cell, 161(5), 1202-1214. doi:10.1016/j.cell.2015.05.002

Madhavan, M., Nevin, Z. S., Shick, H. E., Garrison, E., Clarkson-Paredes, C., Karl, M., .. Tesar, P. J. (2018). Induction of myelinating oligodendrocytes in human cortical spheroids. Nat Methods, 15(9), 700-706. doi:10.1038/s41592-0180081-4

Maes, M. E., Colombo, G., Schulz, R., \& Siegert, S. (2019). Targeting microglia with lentivirus and AAV: Recent advances and remaining challenges. Neurosci Lett, 707, 134310. doi:10.1016/j.neulet.2019.134310

Mallet, V. O., Mitchell, C., Guidotti, J. E., Jaffray, P., Fabre, M., Spencer, D., . . Gilgenkrantz, H. (2002). Conditional cell ablation by tight control of caspase-3 dimerization in transgenic mice. Nat Biotechnol, 20(12), 1234-1239. doi:10.1038/nbt762

Mancuso, R., Van Den Daele, J., Fattorelli, N., Wolfs, L., Balusu, S., Burton, O., . . De Strooper, B. (2019). Stem-cellderived human microglia transplanted in mouse brain to study human disease. Nat Neurosci, 22(12), 2111-2116. doi:10.1038/s41593-019-0525-x

Marques, S., van Bruggen, D., Vanichkina, D. P., Floriddia, E. M., Munguba, H., Varemo, L., . .. Castelo-Branco, G. (2018). Transcriptional Convergence of Oligodendrocyte Lineage Progenitors during Development. Dev Cell, 46(4), 504-517 e507. doi:10.1016/j.devcel.2018.07.005

Marques, S., Zeisel, A., Codeluppi, S., van Bruggen, D., Mendanha Falcao, A., Xiao, L., . . Castelo-Branco, G. (2016). Oligodendrocyte heterogeneity in the mouse juvenile and adult central nervous system. Science, 352(6291), 13261329. doi:10.1126/science.aaf6463

Martin, G. R. (1981). Isolation of a pluripotent cell line from early mouse embryos cultured in medium conditioned by teratocarcinoma stem cells. Proc Natl Acad Sci U S A, 78(12), 7634-7638. doi:10.1073/pnas.78.12.7634

Martin-Fernandez, M., Jamison, S., Robin, L. M., Zhao, Z., Martin, E. D., Aguilar, J., . . Araque, A. (2017). Synapsespecific astrocyte gating of amygdala-related behavior. Nat Neurosci. doi:10.1038/nn.4649

Marton, R. M., Miura, Y., Sloan, S. A., Li, Q., Revah, O., Levy, R. J., . . Pasca, S. P. (2019). Differentiation and maturation of oligodendrocytes in human three-dimensional neural cultures. Nat Neurosci, 22(3), 484-491. doi:10.1038/s41593-018-0316-9

Marvin, J. S., Borghuis, B. G., Tian, L., Cichon, J., Harnett, M. T., Akerboom, J., . . . Looger, L. L. (2013). An optimized fluorescent probe for visualizing glutamate neurotransmission. Nat Methods, 10(2), 162-170. doi:10.1038/nmeth.2333

Masuda, T., Sankowski, R., Staszewski, O., Bottcher, C., Amann, L., Scheiwe, C., .. Prinz, M. (2019). Spatial and temporal heterogeneity of mouse and human microglia at single-cell resolution. Nature, 566(7744), 388-392. doi:10.1038/s41586-019-0924-x

Matcovitch-Natan, O., Winter, D. R., Giladi, A., Vargas Aguilar, S., Spinrad, A., Sarrazin, S., . . Amit, I. (2016). Microglia development follows a stepwise program to regulate brain homeostasis. Science, 353(6301), aad8670. doi:10.1126/science.aad8670

Mathys, H., Adaikkan, C., Gao, F., Young, J. Z., Manet, E., Hemberg, M., . . Tsai, L. H. (2017). Temporal Tracking of Microglia Activation in Neurodegeneration at Single-Cell Resolution. Cell Rep, 21(2), 366-380. doi:10.1016/j.celrep.2017.09.039

Mathys, H., Davila-Velderrain, J., Peng, Z., Gao, F., Mohammadi, S., Young, J. Z., . . Tsai, L. H. (2019). Single-cell transcriptomic analysis of Alzheimer's disease. Nature, 570(7761), 332-337. doi:10.1038/s41586-019-1195-2

Mazuel, L., Blanc, J., Repond, C., Bouchaud, V., Raffard, G., Deglon, N., . . Bouzier-Sore, A. K. (2017). A neuronal MCT2 knockdown in the rat somatosensory cortex reduces both the NMR lactate signal and the BOLD response during whisker stimulation. PLoS One, 12(4), e0174990. doi:10.1371/journal.pone.0174990

McCarthy, K. D., \& de Vellis, J. (1980). Preparation of separate astroglial and oligodendroglial cell cultures from rat cerebral tissue. J Cell Biol, 85(3), 890-902.

McCown, T. J., Xiao, X., Li, J., Breese, G. R., \& Samulski, R. J. (1996). Differential and persistent expression patterns of CNS gene transfer by an adeno-associated virus (AAV) vector. Brain Res, 713(1-2), 99-107. doi:10.1016/00068993(95)01488-8

Mederos, S., Hernandez-Vivanco, A., Ramirez-Franco, J., Martin-Fernandez, M., Navarrete, M., Yang, A., . . Perea, G. (2019). Melanopsin for precise optogenetic activation of astrocyte-neuron networks. Glia. doi:10.1002/glia.23580 
Mendell, J. R., Al-Zaidy, S., Shell, R., Arnold, W. D., Rodino-Klapac, L. R., Prior, T. W., . . Kaspar, B. K. (2017). SingleDose Gene-Replacement Therapy for Spinal Muscular Atrophy. N Engl J Med, 377(18), 1713-1722. doi:10.1056/NEJMoa1706198

Merienne, N., Delzor, A., Viret, A., Dufour, N., Rey, M., Hantraye, P., \& Deglon, N. (2015). Gene transfer engineering for astrocyte-specific silencing in the CNS. Gene Ther, 22(10), 830-839. doi:10.1038/gt.2015.54

Merienne, N., Meunier, C., Schneider, A., Seguin, J., Nair, S. S., Rocher, A. B., . . Deglon, N. (2019). Cell-Type-Specific Gene Expression Profiling in Adult Mouse Brain Reveals Normal and Disease-State Signatures. Cell Rep, 26(9), 24772493 e2479. doi:10.1016/j.celrep.2019.02.003

Merienne, N., Vachey, G., de Longprez, L., Meunier, C., Zimmer, V., Perriard, G., . . . Deglon, N. (2017). The SelfInactivating KamiCas9 System for the Editing of CNS Disease Genes. Cell Rep, 20(12), 2980-2991. doi:10.1016/j.celrep.2017.08.075

Meunier, C., Merienne, N., Jolle, C., Deglon, N., \& Pellerin, L. (2016). Astrocytes are key but indirect contributors to the development of the symptomatology and pathophysiology of Huntington's disease. Glia, 64(11), 1841-1856. doi:10.1002/glia.23022

Meyer-Franke, A., Kaplan, M. R., Pfrieger, F. W., \& Barres, B. A. (1995). Characterization of the signaling interactions that promote the survival and growth of developing retinal ganglion cells in culture. Neuron, 15(4), 805-819. doi:10.1016/0896-6273(95)90172-8

Meyer-Franke, A., Wilkinson, G. A., Kruttgen, A., Hu, M., Munro, E., Hanson, M. G., Jr., . . Barres, B. A. (1998). Depolarization and CAMP elevation rapidly recruit TrkB to the plasma membrane of CNS neurons. Neuron, 21(4), 681-693. doi:10.1016/s0896-6273(00)80586-3

Mishra, A. (2017). Binaural blood flow control by astrocytes: listening to synapses and the vasculature. J Physiol, 595(6), 1885-1902. doi:10.1113/JP270979

Mitrophanous, K., Yoon, S., Rohll, J., Patil, D., Wilkes, F., Kim, V., . . Mazarakis, N. (1999). Stable gene transfer to the nervous system using a non-primate lentiviral vector. Gene Ther, 6(11), 1808-1818. doi:10.1038/sj.gt.3301023

Mizee, M. R., Poel, M. V., \& Huitinga, I. (2018). Purification of cells from fresh human brain tissue: primary human glial cells. Handb Clin Neurol, 150, 273-283. doi:10.1016/B978-0-444-63639-3.00019-0

Moller, T., \& Boddeke, H. W. (2016). Glial cells as drug targets: What does it take? Glia, 64(10), 1742-1754. doi:10.1002/glia.22993

Moolten, F. L. (1986). Tumor chemosensitivity conferred by inserted herpes thymidine kinase genes: paradigm for a prospective cancer control strategy. Cancer Res, 46(10), 5276-5281.

Moyon, S., Dubessy, A. L., Aigrot, M. S., Trotter, M., Huang, J. K., Dauphinot, L., . . Lubetzki, C. (2015). Demyelination causes adult CNS progenitors to revert to an immature state and express immune cues that support their migration. J Neurosci, 35(1), 4-20. doi:10.1523/JNEUROSCI.0849-14.2015

Moyon, S., Liang, J., \& Casaccia, P. (2016). Epigenetics in NG2 glia cells. Brain Res, 1638(Pt B), 183-198. doi:10.1016/j.brainres.2015.06.009

Mrdjen, D., Pavlovic, A., Hartmann, F. J., Schreiner, B., Utz, S. G., Leung, B. P., . . Becher, B. (2018). High-Dimensional Single-Cell Mapping of Central Nervous System Immune Cells Reveals Distinct Myeloid Subsets in Health, Aging, and Disease. Immunity, 48(2), 380-395 e386. doi:10.1016/j.immuni.2018.01.011

Muffat, J., Li, Y., Yuan, B., Mitalipova, M., Omer, A., Corcoran, S., . . Jaenisch, R. (2016). Efficient derivation of microglia-like cells from human pluripotent stem cells. Nat Med, 22(11), 1358-1367. doi:10.1038/nm.4189

Mujtaba, T., Piper, D. R., Kalyani, A., Groves, A. K., Lucero, M. T., \& Rao, M. S. (1999). Lineage-restricted neural precursors can be isolated from both the mouse neural tube and cultured ES cells. Dev Biol, 214(1), 113-127. doi:10.1006/dbio.1999.9418

Murlidharan, G., Samulski, R. J., \& Asokan, A. (2014). Biology of adeno-associated viral vectors in the central nervous system. Front Mol Neurosci, 7, 76. doi:10.3389/fnmol.2014.00076

Nagai, J., Rajbhandari, A. K., Gangwani, M. R., Hachisuka, A., Coppola, G., Masmanidis, S. C., ... Khakh, B. S. (2019). Hyperactivity with Disrupted Attention by Activation of an Astrocyte Synaptogenic Cue. Cell. doi:10.1016/j.cell.2019.03.019

Naldini, L., Blomer, U., Gallay, P., Ory, D., Mulligan, R., Gage, F. H., . . Trono, D. (1996). In vivo gene delivery and stable transduction of nondividing cells by a lentiviral vector. Science, 272(5259), 263-267.

Narayanaswami, V., Dahl, K., Bernard-Gauthier, V., Josephson, L., Cumming, P., \& Vasdev, N. (2018). Emerging PET Radiotracers and Targets for Imaging of Neuroinflammation in Neurodegenerative Diseases: Outlook Beyond TSPO. Mol Imaging, 17, 1536012118792317. doi:10.1177/1536012118792317

Nimmerjahn, A., Kirchhoff, F., \& Helmchen, F. (2005). Resting microglial cells are highly dynamic surveillants of brain parenchyma in vivo. Science, 308(5726), 1314-1318.

Nowakowski, T. J., Bhaduri, A., Pollen, A. A., Alvarado, B., Mostajo-Radji, M. A., Di Lullo, E., ... Kriegstein, A. R. (2017). Spatiotemporal gene expression trajectories reveal developmental hierarchies of the human cortex. Science, 358(6368), 1318-1323. doi:10.1126/science.aap8809 
Nowakowski, T. J., Pollen, A. A., Di Lullo, E., Sandoval-Espinosa, C., Bershteyn, M., \& Kriegstein, A. R. (2016). Expression Analysis Highlights AXL as a Candidate Zika Virus Entry Receptor in Neural Stem Cells. Cell Stem Cell, 18(5), 591-596. doi:10.1016/j.stem.2016.03.012

Nunes, M. C., Roy, N. S., Keyoung, H. M., Goodman, R. R., McKhann, G., 2nd, Jiang, L., . . Goldman, S. A. (2003). Identification and isolation of multipotential neural progenitor cells from the subcortical white matter of the adult human brain. Nat Med, 9(4), 439-447. doi:10.1038/nm837

Oberheim, N. A., Takano, T., Han, X., He, W., Lin, J. H., Wang, F., . . Nedergaard, M. (2009). Uniquely hominid features of adult human astrocytes. J Neurosci, 29(10), 3276-3287. doi:10.1523/JNEUROSCI.4707-08.2009

Octeau, J. C., Gangwani, M. R., Allam, S. L., Tran, D., Huang, S., Hoang-Trong, T. M., . . Khakh, B. S. (2019). Transient, Consequential Increases in Extracellular Potassium Ions Accompany Channelrhodopsin2 Excitation. Cell Rep, 27(8), 2249-2261 e2247. doi:10.1016/j.celrep.2019.04.078

Ogawa, S., Menon, R. S., Tank, D. W., Kim, S. G., Merkle, H., Ellermann, J. M., \& Ugurbil, K. (1993). Functional brain mapping by blood oxygenation level-dependent contrast magnetic resonance imaging. A comparison of signal characteristics with a biophysical model. Biophys J, 64(3), 803-812. doi:10.1016/S0006-3495(93)81441-3

Ohara, P. T., Vit, J. P., Bhargava, A., Romero, M., Sundberg, C., Charles, A. C., \& Jasmin, L. (2009). Gliopathic pain: when satellite glial cells go bad. Neuroscientist, 15(5), 450-463. doi:10.1177/1073858409336094

Okabe, S., Forsberg-Nilsson, K., Spiro, A. C., Segal, M., \& McKay, R. D. (1996). Development of neuronal precursor cells and functional postmitotic neurons from embryonic stem cells in vitro. Mech Dev, 59(1), 89-102. doi:10.1016/09254773(96)00572-2

Okada, Y., Sasaki, T., Oku, Y., Takahashi, N., Seki, M., Ujita, S., . . Ikegaya, Y. (2012). Preinspiratory calcium rise in putative pre-Botzinger complex astrocytes. J Physiol, 590(19), 4933-4944. doi:10.1113/jphysiol.2012.231464

Okaty, B. W., Sugino, K., \& Nelson, S. B. (2011). Cell type-specific transcriptomics in the brain. J Neurosci, 31(19), 69396943. doi:10.1523/JNEUROSCI.0626-11.2011

Olah, M., Patrick, E., Villani, A. C., Xu, J., White, C. C., Ryan, K. J., . . Bradshaw, E. M. (2018). A transcriptomic atlas of aged human microglia. Nat Commun, 9(1), 539. doi:10.1038/s41467-018-02926-5

Olmos-Serrano, J. L., Kang, H. J., Tyler, W. A., Silbereis, J. C., Cheng, F., Zhu, Y., . . Sestan, N. (2016). Down Syndrome Developmental Brain Transcriptome Reveals Defective Oligodendrocyte Differentiation and Myelination. Neuron, 89(6), 1208-1222. doi:10.1016/j.neuron.2016.01.042

Omer Javed, A., Li, Y., Muffat, J., Su, K. C., Cohen, M. A., Lungjangwa, T., . . Jaenisch, R. (2018). Microcephaly Modeling of Kinetochore Mutation Reveals a Brain-Specific Phenotype. Cell Rep, 25(2), 368-382 e365. doi:10.1016/j.celrep.2018.09.032

Onorati, M., Li, Z., Liu, F., Sousa, A. M. M., Nakagawa, N., Li, M., . . Sestan, N. (2016). Zika Virus Disrupts PhosphoTBK1 Localization and Mitosis in Human Neuroepithelial Stem Cells and Radial Glia. Cell Rep, 16(10), $2576-2592$. doi:10.1016/j.celrep.2016.08.038

Orr, A. G., Hsiao, E. C., Wang, M. M., Ho, K., Kim, D. H., Wang, X., . . Mucke, L. (2015). Astrocytic adenosine receptor A2A and Gs-coupled signaling regulate memory. Nat Neurosci, 18(3), 423-434. doi:10.1038/nn.3930

Ortinski, P. I., Dong, J., Mungenast, A., Yue, C., Takano, H., Watson, D. J., . . . Coulter, D. A. (2010). Selective induction of astrocytic gliosis generates deficits in neuronal inhibition. Nat Neurosci, 13(5), 584-591. doi:10.1038/nn.2535

Palfi, S., Gurruchaga, J. M., Lepetit, H., Howard, K., Ralph, G. S., Mason, S., . . Mitrophanous, K. A. (2018). Long-Term Follow-Up of a Phase I/II Study of ProSavin, a Lentiviral Vector Gene Therapy for Parkinson's Disease. Hum Gene Ther Clin Dev, 29(3), 148-155. doi:10.1089/humc.2018.081

Palombo, M., Ligneul, C., Najac, C., Le Douce, J., Flament, J., Escartin, C., . . Valette, J. (2016). New paradigm to assess brain cell morphology by diffusion-weighted MR spectroscopy in vivo. Proc Natl Acad Sci U S A, 113(24), 6671-6676. doi:10.1073/pnas.1504327113

Pandya, H., Shen, M. J., Ichikawa, D. M., Sedlock, A. B., Choi, Y., Johnson, K. R., . . Park, J. K. (2017). Differentiation of human and murine induced pluripotent stem cells to microglia-like cells. Nat Neurosci, 20(5), 753-759. doi:10.1038/nn.4534

Pannasch, U., Freche, D., Dallerac, G., Ghezali, G., Escartin, C., Ezan, P., . . Rouach, N. (2014). Connexin 30 sets synaptic strength by controlling astroglial synapse invasion. Nat Neurosci, 17(4), 549-558. doi:10.1038/nn.3662

Papagiakoumou, E., Anselmi, F., Begue, A., de Sars, V., Gluckstad, J., Isacoff, E. Y., \& Emiliani, V. (2010). Scanless twophoton excitation of channelrhodopsin-2. Nat Methods, 7(10), 848-854. doi:10.1038/nmeth.1505

Park, C., Ponath, G., Levine-Ritterman, M., Bull, E., Swanson, E. C., De Jager, P. L., . . Pitt, D. (2019). The landscape of myeloid and astrocyte phenotypes in acute multiple sclerosis lesions. Acta Neuropathol Commun, 7(1), 130. doi:10.1186/s40478-019-0779-2

Pasca, A. M., Sloan, S. A., Clarke, L. E., Tian, Y., Makinson, C. D., Huber, N., . . Pasca, S. P. (2015). Functional cortical neurons and astrocytes from human pluripotent stem cells in 3D culture. Nat Methods, 12(7), 671-678. doi:10.1038/nmeth.3415

Pasquale, G. D., Davidson, B. L., Stein, C. S., Martins, I., Scudiero, D., Monks, A., \& Chiorini, J. A. (2003). Identification of PDGFR as a receptor for AAV-5 transduction. Nat Med, 9(10), 1306-1312. 
Patriarchi, T., Cho, J. R., Merten, K., Marley, A., Broussard, G. J., Liang, R., . . Tian, L. (2019). Imaging neuromodulators with high spatiotemporal resolution using genetically encoded indicators. Nat Protoc, 14(12), 3471-3505. doi:10.1038/s41596-019-0239-2

Pelluru, D., Konadhode, R. R., Bhat, N. R., \& Shiromani, P. J. (2016). Optogenetic stimulation of astrocytes in the posterior hypothalamus increases sleep at night in C57BL/6J mice. Eur J Neurosci, 43(10), 1298-1306. doi:10.1111/ejn.13074

Perea, G., Yang, A., Boyden, E. S., \& Sur, M. (2014). Optogenetic astrocyte activation modulates response selectivity of visual cortex neurons in vivo. Nat Commun, 5, 3262. doi:10.1038/ncomms4262

Pertusa, M., Garcia-Matas, S., Mammeri, H., Adell, A., Rodrigo, T., Mallet, J., . . Sanfeliu, C. (2008). Expression of GDNF transgene in astrocytes improves cognitive deficits in aged rats. Neurobiol Aging, 29(9), 1366-1379. doi:10.1016/j.neurobiolaging.2007.02.026

Petrelli, F., Dallerac, G., Pucci, L., Cali, C., Zehnder, T., Sultan, S., . . Bezzi, P. (2018). Dysfunction of homeostatic control of dopamine by astrocytes in the developing prefrontal cortex leads to cognitive impairments. Mol Psychiatry. doi:10.1038/s41380-018-0226-y

Pillay, S., Meyer, N. L., Puschnik, A. S., Davulcu, O., Diep, J., Ishikawa, Y., . . Carette, J. E. (2016). An essential receptor for adeno-associated virus infection. Nature, 530(7588), 108-112. doi:10.1038/nature16465

Platt, R. J., Chen, S., Zhou, Y., Yim, M. J., Swiech, L., Kempton, H. R., . . Zhang, F. (2014). CRISPR-Cas9 knockin mice for genome editing and cancer modeling. Cell, 159(2), 440-455. doi:10.1016/j.cell.2014.09.014

Poskanzer, K. E., \& Yuste, R. (2016). Astrocytes regulate cortical state switching in vivo. Proc Natl Acad Sci U S A, 113(19), E2675-2684. doi:10.1073/pnas.1520759113

Poulopoulos, A., Murphy, A. J., Ozkan, A., Davis, P., Hatch, J., Kirchner, R., \& Macklis, J. D. (2019). Subcellular transcriptomes and proteomes of developing axon projections in the cerebral cortex. Nature, 565(7739), 356-360. doi:10.1038/s41586-018-0847-y

Powell, S. K., Gregory, J., Akbarian, S., \& Brennand, K. J. (2017). Application of CRISPR/Cas9 to the study of brain development and neuropsychiatric disease. Mol Cell Neurosci, 82, 157-166. doi:10.1016/j.mcn.2017.05.007

Powell, S. K., Khan, N., Parker, C. L., Samulski, R. J., Matsushima, G., Gray, S. J., \& McCown, T. J. (2016).

Characterization of a novel adeno-associated viral vector with preferential oligodendrocyte tropism. Gene Ther, 23(11), 807-814. doi:10.1038/gt.2016.62

Prevot, V., Dehouck, B., Sharif, A., Ciofi, P., Giacobini, P., \& Clasadonte, J. (2018). The Versatile Tanycyte: A Hypothalamic Integrator of Reproduction and Energy Metabolism. Endocr Rev, 39(3), 333-368. doi:10.1210/er.201700235

Priller, J., \& Prinz, M. (2019). Targeting microglia in brain disorders. Science, 365(6448), 32-33. doi:10.1126/science.aau9100

Prinz, M., Jung, S., \& Priller, J. (2019). Microglia Biology: One Century of Evolving Concepts. Cell, 179(2), $292-311$. doi:10.1016/j.cell.2019.08.053

Qing, K., Mah, C., Hansen, J., Zhou, S., Dwarki, V., \& Srivastava, A. (1999). Human fibroblast growth factor receptor 1 is a co-receptor for infection by adeno-associated virus 2. Nat Med, 5, 71-77.

Rabinowitz, J. E., \& Samulski, J. (1998). Adeno-associated virus expression systems for gene transfer. Curr Opin Biotechnol, 9(5), 470-475.

Raff, M. C., Abney, E. R., Cohen, J., Lindsay, R., \& Noble, M. (1983). Two types of astrocytes in cultures of developing rat white matter: differences in morphology, surface gangliosides, and growth characteristics. J Neurosci, 3(6), 12891300.

Raff, M. C., Brockes, J. P., Fields, K. L., \& Mirsky, R. (1979). Neural cell markers: the end of the beginning. Prog Brain Res, 51, 17-22. doi:10.1016/S0079-6123(08)61290-X

Raikwar, S. P., Thangavel, R., Dubova, I., Selvakumar, G. P., Ahmed, M. E., Kempuraj, D., . . Zaheer, A. (2019). Targeted Gene Editing of Glia Maturation Factor in Microglia: a Novel Alzheimer's Disease Therapeutic Target. Mol Neurobiol, 56(1), 378-393. doi:10.1007/s12035-018-1068-y

Ramon y Cajal, S. (1888). Estructura de los centros nerviosos de las aves. . Rev Trimest Histol Norm Patol, 1, 305-315.

Rangaraju, S., Dammer, E. B., Raza, S. A., Gao, T., Xiao, H., Betarbet, R., . . Seyfried, N. T. (2018). Quantitative proteomics of acutely-isolated mouse microglia identifies novel immune Alzheimer's disease-related proteins. Mol Neurodegener, 13(1), 34. doi:10.1186/s13024-018-0266-4

Reubinoff, B. E., Itsykson, P., Turetsky, T., Pera, M. F., Reinhartz, E., Itzik, A., \& Ben-Hur, T. (2001). Neural progenitors from human embryonic stem cells. Nat Biotechnol, 19(12), 1134-1140. doi:10.1038/nbt1201-1134

Riddle, R. D., Johnson, R. L., Laufer, E., \& Tabin, C. (1993). Sonic hedgehog mediates the polarizing activity of the ZPA. Cell, 75(7), 1401-1416. doi:10.1016/0092-8674(93)90626-2

Roberts, B., Haupt, A., Tucker, A., Grancharova, T., Arakaki, J., Fuqua, M. A., . . Gunawardane, R. N. (2017). Systematic gene tagging using CRISPR/Cas9 in human stem cells to illuminate cell organization. Mol Biol Cell, 28(21), 2854-2874. doi:10.1091/mbc.E17-03-0209 
Roberts, K. M., Rosen, A., \& Casciola-Rosen, L. A. (2004). Methods for inducing apoptosis. Methods Mol Med, 102, 115-128. doi:10.1385/1-59259-805-6:115

Roe, T., Reynolds, T. C., Yu, G., \& Brown, P. O. (1993). Integration of murine leukemia virus DNA depends on mitosis. $E M B O$ J, 12(5), 2099-2108.

Ronning, K. E., Karlen, S. J., Miller, E. B., \& Burns, M. E. (2019). Molecular profiling of resident and infiltrating mononuclear phagocytes during rapid adult retinal degeneration using single-cell RNA sequencing. Sci Rep, 9(1), 4858. doi:10.1038/s41598-019-41141-0

Rosario, A. M., Cruz, P. E., Ceballos-Diaz, C., Strickland, M. R., Siemienski, Z., Pardo, M., . . Chakrabarty, P. (2016). Microglia-specific targeting by novel capsid-modified AAV6 vectors. Mol Ther Methods Clin Dev, 3, 16026. doi:10.1038/mtm.2016.26

Roth, B. L. (2016). DREADDs for Neuroscientists. Neuron, 89(4), 683-694. doi:10.1016/j.neuron.2016.01.040

Rothhammer, V., Borucki, D. M., Tjon, E. C., Takenaka, M. C., Chao, C. C., Ardura-Fabregat, A., ... Quintana, F. J. (2018). Microglial control of astrocytes in response to microbial metabolites. Nature, 557(7707), 724-728. doi:10.1038/s41586-018-0119-x

Rouget, C. (1874). Note on the development of the contractile walls of blood vessels. C R Acad Sci, 79, 559-562.

Saito, M., Iwawaki, T., Taya, C., Yonekawa, H., Noda, M., Inui, Y., . . Kohno, K. (2001). Diphtheria toxin receptormediated conditional and targeted cell ablation in transgenic mice. Nat Biotechnol, 19(8), 746-750. doi:10.1038/90795

Sakuma, T., Barry, M. A., \& Ikeda, Y. (2012). Lentiviral vectors: basic to translational. Biochem J, 443(3), 603-618. doi:10.1042/BJ20120146

Sala Frigerio, C., Wolfs, L., Fattorelli, N., Thrupp, N., Voytyuk, I., Schmidt, I., . . De Strooper, B. (2019). The Major Risk Factors for Alzheimer's Disease: Age, Sex, and Genes Modulate the Microglia Response to Abeta Plaques. Cell Rep, 27(4), 1293-1306 e1296. doi:10.1016/j.celrep.2019.03.099

Salganik, M., Hirsch, M. L., \& Samulski, R. J. (2015). Adeno-associated Virus as a Mammalian DNA Vector. Microbiol Spectr, 3(4). doi:10.1128/microbiolspec.MDNA3-0052-2014

Samaranch, L., Salegio, E. A., San Sebastian, W., Kells, A. P., Bringas, J. R., Forsayeth, J., \& Bankiewicz, K. S. (2013). Strong cortical and spinal cord transduction after AAV7 and AAV9 delivery into the cerebrospinal fluid of nonhuman primates. Hum Gene Ther, 24(5), 526-532. doi:10.1089/hum.2013.005

Sanz, E., Yang, L., Su, T., Morris, D. R., McKnight, G. S., \& Amieux, P. S. (2009). Cell-type-specific isolation of ribosomeassociated mRNA from complex tissues. Proc Natl Acad Sci U S A, 106(33), 13939-13944. doi:10.1073/pnas.0907143106

Saraiva, J., Nobre, R. J., \& Pereira de Almeida, L. (2016). Gene therapy for the CNS using AAVs: The impact of systemic delivery by AAV9. J Control Release, 241, 94-109. doi:10.1016/j.jconrel.2016.09.011

Sasaki, T., Beppu, K., Tanaka, K. F., Fukazawa, Y., Shigemoto, R., \& Matsui, K. (2012). Application of an optogenetic byway for perturbing neuronal activity via glial photostimulation. Proc Natl Acad Sci U S A, 109(50), 20720-20725. doi:10.1073/pnas.1213458109

Saunders, A., Macosko, E. Z., Wysoker, A., Goldman, M., Krienen, F. M., de Rivera, H., . . McCarroll, S. A. (2018). Molecular Diversity and Specializations among the Cells of the Adult Mouse Brain. Cell, 174(4), 1015-1030 e1016. doi:10.1016/j.cell.2018.07.028

Savell, K. E., Bach, S. V., Zipperly, M. E., Revanna, J. S., Goska, N. A., Tuscher, J. J., . . Day, J. J. (2019). A NeuronOptimized CRISPR/dCas9 Activation System for Robust and Specific Gene Regulation. eNeuro, 6(1). doi:10.1523/ENEURO.0495-18.2019

Schachner, M. (1982). Cell type-specific surface antigens in the mammalian nervous system. J Neurochem, 39(1), 1-8. doi:10.1111/j.1471-4159.1982.tb04694.x

Schain, A. J., Hill, R. A., \& Grutzendler, J. (2014). Label-free in vivo imaging of myelinated axons in health and disease with spectral confocal reflectance microscopy. Nat Med, 20(4), 443-449. doi:10.1038/nm.3495

Schirmer, L., Velmeshev, D., Holmqvist, S., Kaufmann, M., Werneburg, S., Jung, D., . . Rowitch, D. H. (2019). Neuronal vulnerability and multilineage diversity in multiple sclerosis. Nature, 573(7772), 75-82. doi:10.1038/s41586-0191404-z

Schnodt, M., \& Buning, H. (2017). Improving the Quality of Adeno-Associated Viral Vector Preparations: The Challenge of Product-Related Impurities. Hum Gene Ther Methods, 28(3), 101-108. doi:10.1089/hgtb.2016.188

Schober, A. L., Gagarkin, D. A., Chen, Y., Gao, G., Jacobson, L., \& Mongin, A. A. (2016). Recombinant Adeno-Associated Virus Serotype 6 (rAAV6) Potently and Preferentially Transduces Rat Astrocytes In vitro and In vivo. Front Cell Neurosci, 10, 262. doi:10.3389/fncel.2016.00262

Scholze, A. R., Foo, L. C., Mulinyawe, S., \& Barres, B. A. (2014). BMP signaling in astrocytes downregulates EGFR to modulate survival and maturation. PLoS One, 9(10), e110668. doi:10.1371/journal.pone.0110668

Scofield, M. D., Boger, H. A., Smith, R. J., Li, H., Haydon, P. G., \& Kalivas, P. W. (2015). Gq-DREADD Selectively Initiates Glial Glutamate Release and Inhibits Cue-induced Cocaine Seeking. Biol Psychiatry, 78(7), 441-451.

doi:10.1016/j.biopsych.2015.02.016 
Severino, V., Farina, A., \& Chambery, A. (2013). Analysis of secreted proteins. Methods Mol Biol, 1002, 37-60. doi:10.1007/978-1-62703-360-2_4

Shaham, S. (2015). Glial development and function in the nervous system of Caenorhabditis elegans. Cold Spring Harb Perspect Biol, 7(4), a020578. doi:10.1101/cshperspect.a020578

Sharma, K., Schmitt, S., Bergner, C. G., Tyanova, S., Kannaiyan, N., Manrique-Hoyos, N., . . Simons, M. (2015). Cell type- and brain region-resolved mouse brain proteome. Nat Neurosci, 18(12), 1819-1831. doi:10.1038/nn.4160

Shen, S., Bryant, K. D., Brown, S. M., Randell, S. H., \& Asokan, A. (2011). Terminal N-linked galactose is the primary receptor for adeno-associated virus 9. J Biol Chem, 286(15), 13532-13540. doi:10.1074/jbc.M110.210922

Sim, F. J., McClain, C. R., Schanz, S. J., Protack, T. L., Windrem, M. S., \& Goldman, S. A. (2011). CD140a identifies a population of highly myelinogenic, migration-competent and efficiently engrafting human oligodendrocyte progenitor cells. Nat Biotechnol, 29(10), 934-941. doi:10.1038/nbt.1972

Simons, M., \& Nave, K. A. (2015). Oligodendrocytes: Myelination and Axonal Support. Cold Spring Harb Perspect Biol, 8(1), a020479. doi:10.1101/cshperspect.a020479

Sive, H. L., Draper, B. W., Harland, R. M., \& Weintraub, H. (1990). Identification of a retinoic acid-sensitive period during primary axis formation in Xenopus laevis. Genes Dev, 4(6), 932-942. doi:10.1101/gad.4.6.932

Slezak, M., Goritz, C., Niemiec, A., Frisen, J., Chambon, P., Metzger, D., \& Pfrieger, F. W. (2007). Transgenic mice for conditional gene manipulation in astroglial cells. Glia, 55(15), 1565-1576.

Sloan, S. A., Darmanis, S., Huber, N., Khan, T. A., Birey, F., Caneda, C., . . Pasca, S. P. (2017). Human Astrocyte Maturation Captured in 3D Cerebral Cortical Spheroids Derived from Pluripotent Stem Cells. Neuron, 95(4), 779-790 e776. doi:10.1016/j.neuron.2017.07.035

Smith, W. C., \& Harland, R. M. (1992). Expression cloning of noggin, a new dorsalizing factor localized to the Spemann organizer in Xenopus embryos. Cell, 70(5), 829-840. doi:10.1016/0092-8674(92)90316-5

Soldner, F., Hockemeyer, D., Beard, C., Gao, Q., Bell, G. W., Cook, E. G., . . Jaenisch, R. (2009). Parkinson's disease patient-derived induced pluripotent stem cells free of viral reprogramming factors. Cell, 136(5), 964-977. doi:10.1016/j.cell.2009.02.013

Sousa, C., Golebiewska, A., Poovathingal, S. K., Kaoma, T., Pires-Afonso, Y., Martina, S., . . Michelucci, A. (2018). Single-cell transcriptomics reveals distinct inflammation-induced microglia signatures. EMBO Rep, 19(11). doi:10.15252/embr.201846171

Srinivasan, R., Huang, B. S., Venugopal, S., Johnston, A. D., Chai, H., Zeng, H., . . Khakh, B. S. (2015). Ca(2+) signaling in astrocytes from Ip3r2(-/-) mice in brain slices and during startle responses in vivo. Nat Neurosci, 18(5), 708-717. doi:10.1038/nn.4001

Stahl, P. L., Salmen, F., Vickovic, S., Lundmark, A., Navarro, J. F., Magnusson, J., . . Frisen, J. (2016). Visualization and analysis of gene expression in tissue sections by spatial transcriptomics. Science, 353(6294), 78-82. doi:10.1126/science.aaf2403

Stanek, L. M., Bu, J., \& Shihabuddin, L. S. (2019). Astrocyte transduction is required for rescue of behavioral phenotypes in the YAC128 mouse model with AAV-RNAi mediated HTT lowering therapeutics. Neurobiol Dis, 129, 29-37. doi:10.1016/j.nbd.2019.04.015

Strell, C., Hilscher, M. M., Laxman, N., Svedlund, J., Wu, C., Yokota, C., \& Nilsson, M. (2019). Placing RNA in context and space - methods for spatially resolved transcriptomics. FEBS J, 286(8), 1468-1481. doi:10.1111/febs.14435

Sturgeon, C. M., Ditadi, A., Awong, G., Kennedy, M., \& Keller, G. (2014). Wnt signaling controls the specification of definitive and primitive hematopoiesis from human pluripotent stem cells. Nat Biotechnol, 32(6), 554-561. doi:10.1038/nbt.2915

Suk, K. (2010). Combined analysis of the glia secretome and the CSF proteome: neuroinflammation and novel biomarkers. Expert Rev Proteomics, 7(2), 263-274. doi:10.1586/epr.10.6

Sweeney, P., Qi, Y., Xu, Z., \& Yang, Y. (2016). Activation of hypothalamic astrocytes suppresses feeding without altering emotional states. Glia, 64(12), 2263-2273. doi:10.1002/glia.23073

Tabula Muris, C., Overall, c., Logistical, c., Organ, c., processing, Library, p., . . Principal, i. (2018). Single-cell transcriptomics of 20 mouse organs creates a Tabula Muris. Nature, 562(7727), 367-372. doi:10.1038/s41586-0180590-4

Tai, Y. F., Pavese, N., Gerhard, A., Tabrizi, S. J., Barker, R. A., Brooks, D. J., \& Piccini, P. (2007). Microglial activation in presymptomatic Huntington's disease gene carriers. Brain, 130(Pt 7), 1759-1766. doi:10.1093/brain/awm044

Takata, K., Kozaki, T., Lee, C. Z. W., Thion, M. S., Otsuka, M., Lim, S., . . Ginhoux, F. (2017). Induced-Pluripotent-StemCell-Derived Primitive Macrophages Provide a Platform for Modeling Tissue-Resident Macrophage Differentiation and Function. Immunity, 47(1), 183-198 e186. doi:10.1016/j.immuni.2017.06.017

Taschenberger, G., Tereshchenko, J., \& Kugler, S. (2017). A MicroRNA124 Target Sequence Restores Astrocyte Specificity of gfaABC1D-Driven Transgene Expression in AAV-Mediated Gene Transfer. Mol Ther Nucleic Acids, 8, 1325. doi:10.1016/j.omtn.2017.03.009 
Tay, T. L., Sagar, Dautzenberg, J., Grun, D., \& Prinz, M. (2018). Unique microglia recovery population revealed by single-cell RNAseq following neurodegeneration. Acta Neuropathol Commun, 6(1), 87. doi:10.1186/s40478-0180584-3

Thion, M. S., Ginhoux, F., \& Garel, S. (2018). Microglia and early brain development: An intimate journey. Science, 362(6411), 185-189. doi:10.1126/science.aat0474

Todd, L., Palazzo, I., Suarez, L., Liu, X., Volkov, L., Hoang, T. V., . . Fischer, A. J. (2019). Reactive microglia and IL1beta/IL-1R1-signaling mediate neuroprotection in excitotoxin-damaged mouse retina. J Neuroinflammation, 16(1), 118. doi:10.1186/s12974-019-1505-5

Tomassy, G. S., Berger, D. R., Chen, H. H., Kasthuri, N., Hayworth, K. J., Vercelli, A., . . Arlotta, P. (2014). Distinct profiles of myelin distribution along single axons of pyramidal neurons in the neocortex. Science, 344(6181), 319324. doi:10.1126/science.1249766

Toro Cabrera, G., \& Mueller, C. (2016). Design of shRNA and miRNA for Delivery to the CNS. Methods Mol Biol, 1382, 67-80. doi:10.1007/978-1-4939-3271-9_5

Uezu, A., Kanak, D. J., Bradshaw, T. W., Soderblom, E. J., Catavero, C. M., Burette, A. C., ... Soderling, S. H. (2016). Identification of an elaborate complex mediating postsynaptic inhibition. Science, 353(6304), 1123-1129. doi:10.1126/science.aag0821

van Bruggen, D., Agirre, E., \& Castelo-Branco, G. (2017). Single-cell transcriptomic analysis of oligodendrocyte lineage cells. Curr Opin Neurobiol, 47, 168-175. doi:10.1016/j.conb.2017.10.005

Vavasour, I. M., Laule, C., Li, D. K., Traboulsee, A. L., \& MacKay, A. L. (2011). Is the magnetization transfer ratio a marker for myelin in multiple sclerosis? J Magn Reson Imaging, 33(3), 713-718. doi:10.1002/jmri.22441

Velmeshev, D., Schirmer, L., Jung, D., Haeussler, M., Perez, Y., Mayer, S., . . Kriegstein, A. R. (2019). Single-cell genomics identifies cell type-specific molecular changes in autism. Science, 364(6441), 685-689. doi:10.1126/science.aav8130

Verheijen, J., \& Sleegers, K. (2018). Understanding Alzheimer Disease at the Interface between Genetics and Transcriptomics. Trends Genet, 34(6), 434-447. doi:10.1016/j.tig.2018.02.007

Verkhratsky, A., Ho, M. S., Zorec, R., \& Parpura, V. (2019). The Concept of Neuroglia. Adv Exp Med Biol, 1175, 1-13. doi:10.1007/978-981-13-9913-8_1

Verkhratsky, A., \& Nedergaard, M. (2018). Physiology of Astroglia. Physiol Rev, 98(1), 239-389. doi:10.1152/physrev.00042.2016

Vitry, S., Bertrand, J. Y., Cumano, A., \& Dubois-Dalcq, M. (2003). Primordial hematopoietic stem cells generate microglia but not myelin-forming cells in a neural environment. J Neurosci, 23(33), 10724-10731.

von Jonquieres, G., Frohlich, D., Klugmann, C. B., Wen, X., Harasta, A. E., Ramkumar, R., . . Klugmann, M. (2016). Recombinant Human Myelin-Associated Glycoprotein Promoter Drives Selective AAV-Mediated Transgene Expression in Oligodendrocytes. Front Mol Neurosci, 9, 13. doi:10.3389/fnmol.2016.00013

Wang, D., Tai, P. W. L., \& Gao, G. (2019). Adeno-associated virus vector as a platform for gene therapy delivery. Nat Rev Drug Discov. doi:10.1038/s41573-019-0012-9

Wang, H., Fu, Y., Zickmund, P., Shi, R., \& Cheng, J. X. (2005). Coherent anti-stokes Raman scattering imaging of axonal myelin in live spinal tissues. Biophys J, 89(1), 581-591. doi:10.1529/biophysj.105.061911

Wang, X., Allen, W. E., Wright, M. A., Sylwestrak, E. L., Samusik, N., Vesuna, S., . . Deisseroth, K. (2018). Threedimensional intact-tissue sequencing of single-cell transcriptional states. Science, 361(6400). doi:10.1126/science.aat5691

Wang, Y., DelRosso, N. V., Vaidyanathan, T. V., Cahill, M. K., Reitman, M. E., Pittolo, S., .. Poskanzer, K. E. (2019). Accurate quantification of astrocyte and neurotransmitter fluorescence dynamics for single-cell and population-level physiology. Nat Neurosci. doi:10.1038/s41593-019-0492-2

Watkins, T. A., Emery, B., Mulinyawe, S., \& Barres, B. A. (2008). Distinct stages of myelination regulated by gammasecretase and astrocytes in a rapidly myelinating CNS coculture system. Neuron, 60(4), 555-569. doi:S08966273(08)00759-9 [pii]

10.1016/j.neuron.2008.09.011

Weick, J. P., Johnson, M. A., Skroch, S. P., Williams, J. C., Deisseroth, K., \& Zhang, S. C. (2010). Functional control of transplantable human ESC-derived neurons via optogenetic targeting. Stem Cells, 28(11), 2008-2016. doi:10.1002/stem.514

Wendeln, A. C., Degenhardt, K., Kaurani, L., Gertig, M., Ulas, T., Jain, G., . . Neher, J. J. (2018). Innate immune memory in the brain shapes neurological disease hallmarks. Nature, 556(7701), 332-338. doi:10.1038/s41586-018-0023-4

Wheeler, M. A., Jaronen, M., Covacu, R., Zandee, S. E. J., Scalisi, G., Rothhammer, V., . . Quintana, F. J. (2019). Environmental Control of Astrocyte Pathogenic Activities in CNS Inflammation. Cell, 176(3), 581-596 e518. doi:10.1016/j.cell.2018.12.012

Wieghofer, P., Knobeloch, K. P., \& Prinz, M. (2015). Genetic targeting of microglia. Glia, 63(1), 1-22. doi:10.1002/glia.22727 
Wilson, R. S., \& Nairn, A. C. (2018). Cell-Type-Specific Proteomics: A Neuroscience Perspective. Proteomes, 6(4). doi:10.3390/proteomes6040051

Windrem, M. S., Nunes, M. C., Rashbaum, W. K., Schwartz, T. H., Goodman, R. A., McKhann, G., 2nd, . . Goldman, S. A. (2004). Fetal and adult human oligodendrocyte progenitor cell isolates myelinate the congenitally dysmyelinated brain. Nat Med, 10(1), 93-97. doi:10.1038/nm974

Wright, A. P., Fitzgerald, J. J., \& Colello, R. J. (1997). Rapid purification of glial cells using immunomagnetic separation. J Neurosci Methods, 74(1), 37-44. doi:10.1016/s0165-0270(97)22400-3

Wu, Y. E., Pan, L., Zuo, Y., Li, X., \& Hong, W. (2017). Detecting Activated Cell Populations Using Single-Cell RNA-Seq. Neuron, 96(2), 313-329 e316. doi:10.1016/j.neuron.2017.09.026

Wu, Z., Asokan, A., \& Samulski, R. J. (2006). Adeno-associated virus serotypes: vector toolkit for human gene therapy. Mol Ther, 14(3), 316-327. doi:10.1016/j.ymthe.2006.05.009

Wysocki, L. J., \& Sato, V. L. (1978). "Panning" for lymphocytes: a method for cell selection. Proc Natl Acad Sci U S A, 75(6), 2844-2848. doi:10.1073/pnas.75.6.2844

Ximerakis, M., Lipnick, S. L., Innes, B. T., Simmons, S. K., Adiconis, X., Dionne, D., . . Rubin, L. L. (2019). Single-cell transcriptomic profiling of the aging mouse brain. Nat Neurosci, 22(10), 1696-1708. doi:10.1038/s41593-019-0491-3

Yamashita, A., Hamada, A., Suhara, Y., Kawabe, R., Yanase, M., Kuzumaki, N., . . Okano, H. (2014). Astrocytic activation in the anterior cingulate cortex is critical for sleep disorder under neuropathic pain. Synapse, 68(6), 235247. doi:10.1002/syn.21733

Yang, L., Qi, Y., \& Yang, Y. (2015). Astrocytes control food intake by inhibiting AGRP neuron activity via adenosine A1 receptors. Cell Rep, 11(5), 798-807. doi:10.1016/j.celrep.2015.04.002

Yao, S., Yuan, P., Ouellette, B., Zhou, T., Mortrud, M., Balaram, P., . . Cetin, A. (2019). RecV recombinasesystemfor in vivotargeted optogenomic modifications ofsingle cells or cell populations. BioRxiv. doi:10.1101/553271

Zamanian, J. L., Xu, L., Foo, L. C., Nouri, N., Zhou, L., Giffard, R. G., \& Barres, B. A. (2012). Genomic analysis of reactive astrogliosis. J Neurosci, 32(18), 6391-6410. doi:32/18/6391 [pii]

10.1523/JNEUROSCI.6221-11.2012

Zeisel, A., Hochgerner, H., Lonnerberg, P., Johnsson, A., Memic, F., van der Zwan, J., . . Linnarsson, S. (2018). Molecular Architecture of the Mouse Nervous System. Cell, 174(4), 999-1014 e1022. doi:10.1016/j.cell.2018.06.021

Zeisel, A., Munoz-Manchado, A. B., Codeluppi, S., Lonnerberg, P., La Manno, G., Jureus, A., . . Linnarsson, S. (2015). Brain structure. Cell types in the mouse cortex and hippocampus revealed by single-cell RNA-seq. Science, 347(6226), 1138-1142. doi:10.1126/science.aaa1934

Zeng, H., \& Sanes, J. R. (2017). Neuronal cell-type classification: challenges, opportunities and the path forward. Nat Rev Neurosci, 18(9), 530-546. doi:10.1038/nrn.2017.85

Zhang, S. C., Wernig, M., Duncan, I. D., Brustle, O., \& Thomson, J. A. (2001). In vitro differentiation of transplantable neural precursors from human embryonic stem cells. Nat Biotechnol, 19(12), 1129-1133. doi:10.1038/nbt1201-1129

Zhang, Y., Chen, K., Sloan, S. A., Bennett, M. L., Scholze, A. R., O'Keeffe, S., . . Wu, J. Q. (2014). An RNA-sequencing transcriptome and splicing database of glia, neurons, and vascular cells of the cerebral cortex. J Neurosci, 34(36), 11929-11947. doi:10.1523/JNEUROSCI.1860-14.2014

Zhang, Y., Fonslow, B. R., Shan, B., Baek, M. C., \& Yates, J. R., 3rd. (2013). Protein analysis by shotgun/bottom-up proteomics. Chem Rev, 113(4), 2343-2394. doi:10.1021/cr3003533

Zhang, Y., Sloan, S. A., Clarke, L. E., Caneda, C., Plaza, C. A., Blumenthal, P. D., . . Barres, B. A. (2016). Purification and Characterization of Progenitor and Mature Human Astrocytes Reveals Transcriptional and Functional Differences with Mouse. Neuron, 89(1), 37-53. doi:10.1016/j.neuron.2015.11.013

Zheng, Y., Shen, W., Zhang, J., Yang, B., Liu, Y. N., Qi, H., . . Yao, J. (2018). CRISPR interference-based specific and efficient gene inactivation in the brain. Nat Neurosci, 21(3), 447-454. doi:10.1038/s41593-018-0077-5

Zhou, H., Liu, J., Zhou, C., Gao, N., Rao, Z., Li, H., . . Yang, H. (2018). In vivo simultaneous transcriptional activation of multiple genes in the brain using CRISPR-dCas9-activator transgenic mice. Nat Neurosci, 21(3), 440-446. doi:10.1038/s41593-017-0060-6

Ziegenhain, C., Vieth, B., Parekh, S., Reinius, B., Guillaumet-Adkins, A., Smets, M., . . Enard, W. (2017). Comparative Analysis of Single-Cell RNA Sequencing Methods. Mol Cell, 65(4), 631-643 e634. doi:10.1016/j.molcel.2017.01.023

Zinn, E., Pacouret, S., Khaychuk, V., Turunen, H. T., Carvalho, L. S., Andres-Mateos, E., . . Vandenberghe, L. H. (2015). In Silico Reconstruction of the Viral Evolutionary Lineage Yields a Potent Gene Therapy Vector. Cell Rep, 12(6), 10561068. doi:10.1016/j.celrep.2015.07.019

Zuchero, J. B., \& Barres, B. A. (2015). Glia in mammalian development and disease. Development, 142(22), 3805-3809. doi:10.1242/dev.129304 


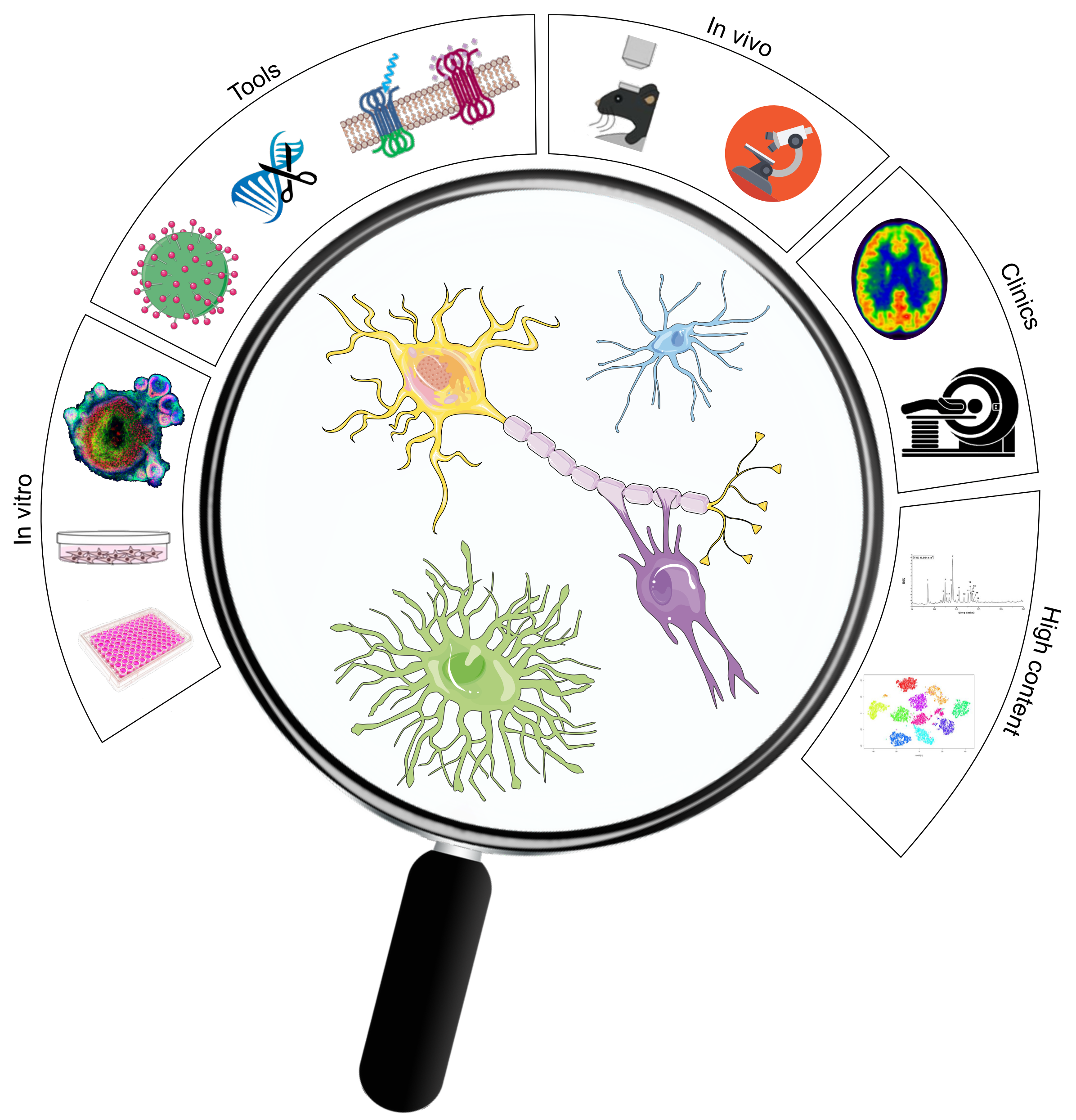



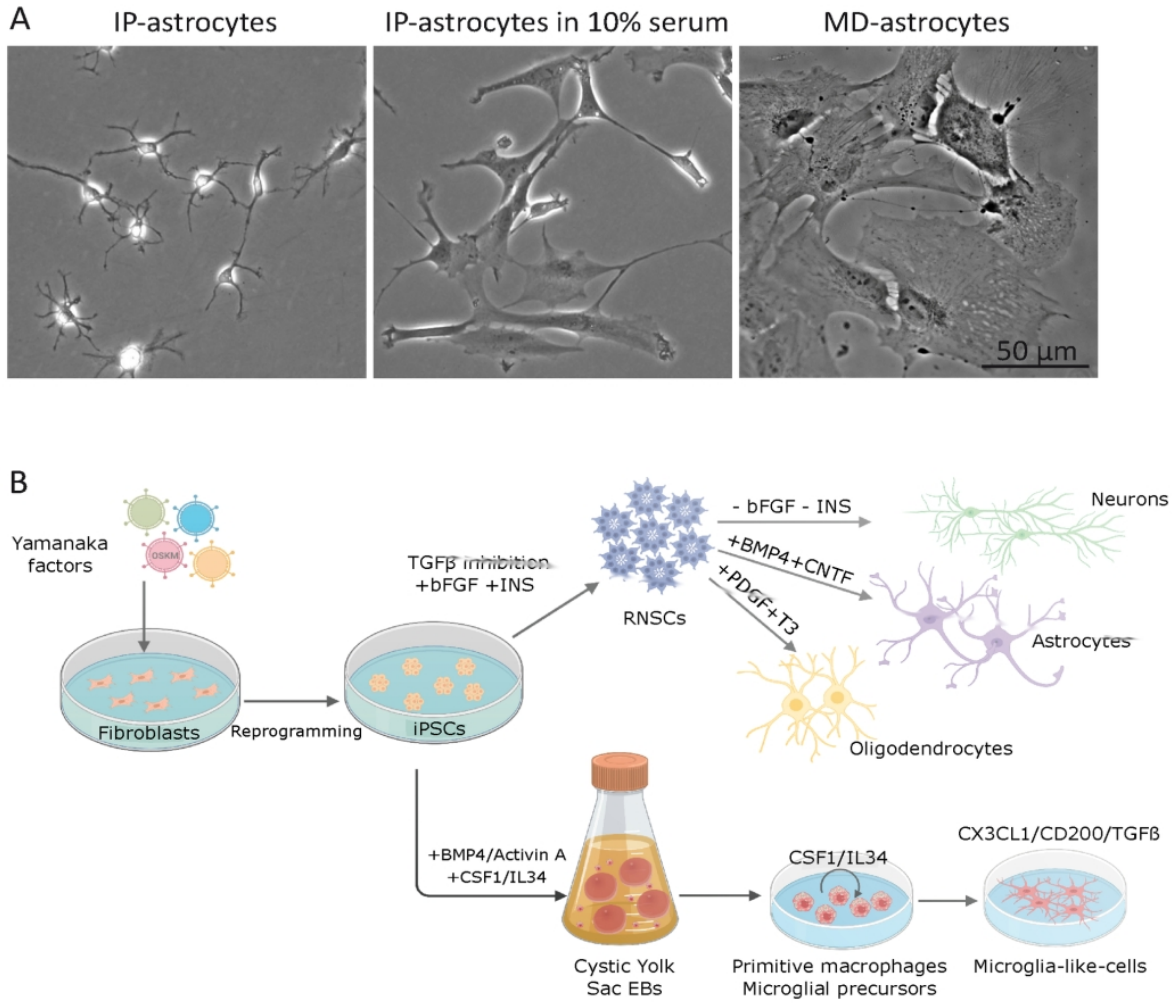

C

All-human co-cultures

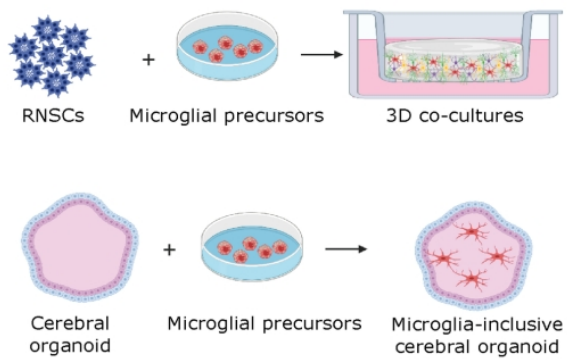

Human/mouse chimeric system
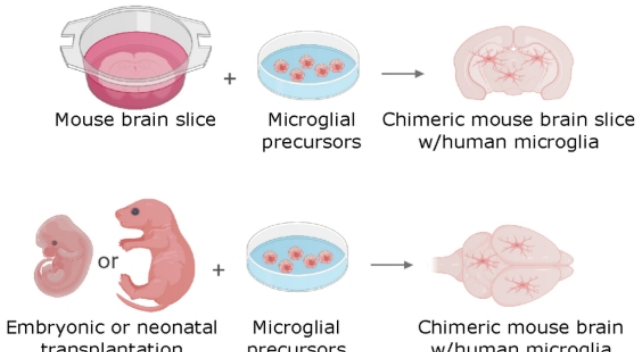

Methods to culture glial cells

$190 \times 234 \mathrm{~mm}(300 \times 300 \mathrm{DPI})$ 
A

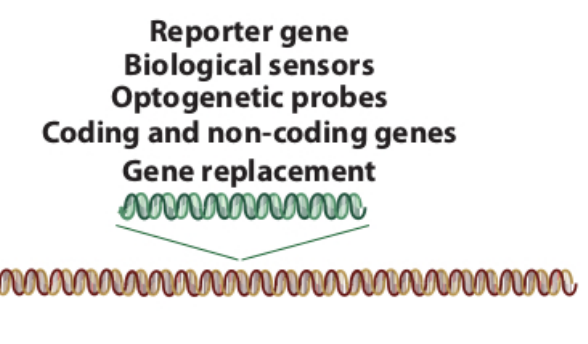

gene silencing

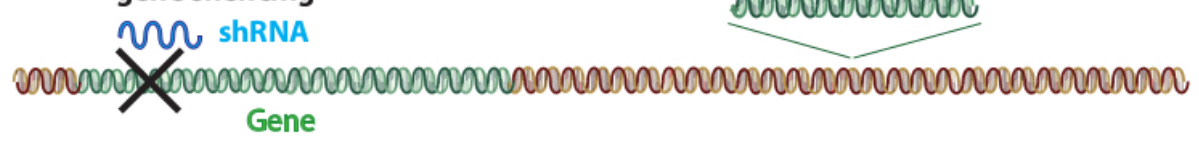

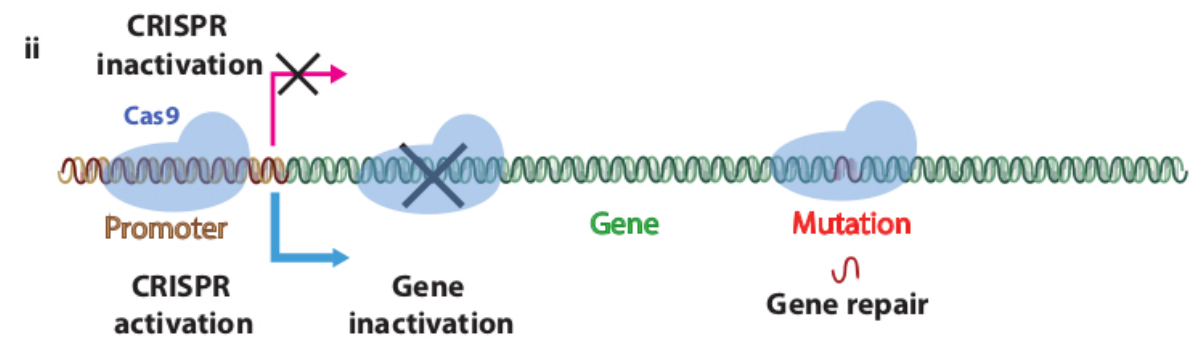

B

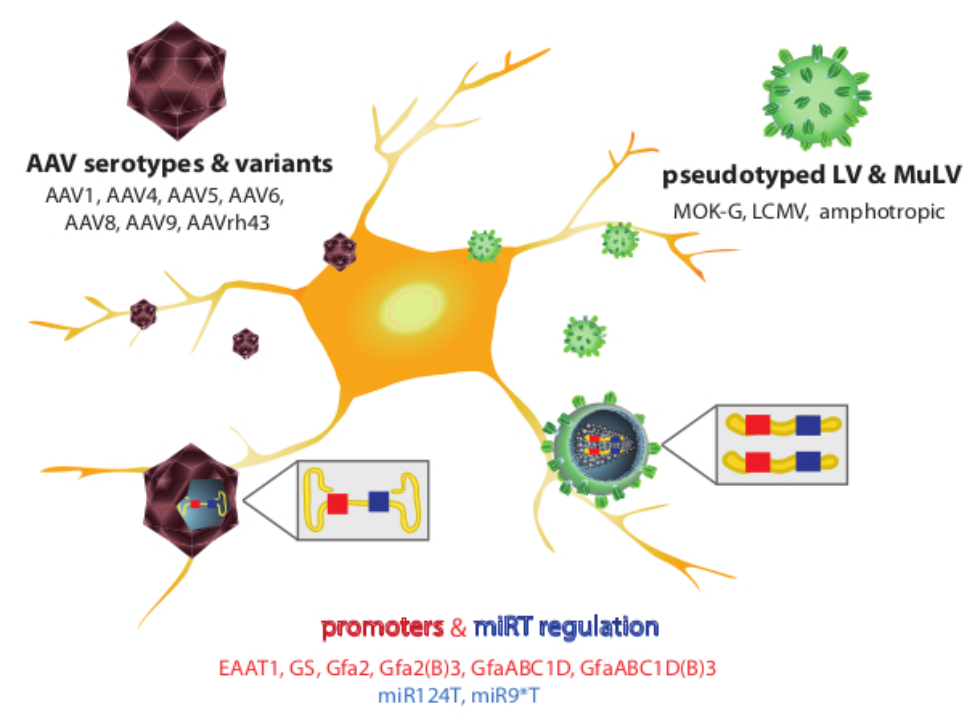

Gene transfer methods for biological and therapeutic applications and improvement of astrocyte tropism $201 \times 246 \mathrm{~mm}(100 \times 100 \mathrm{DPI})$ 

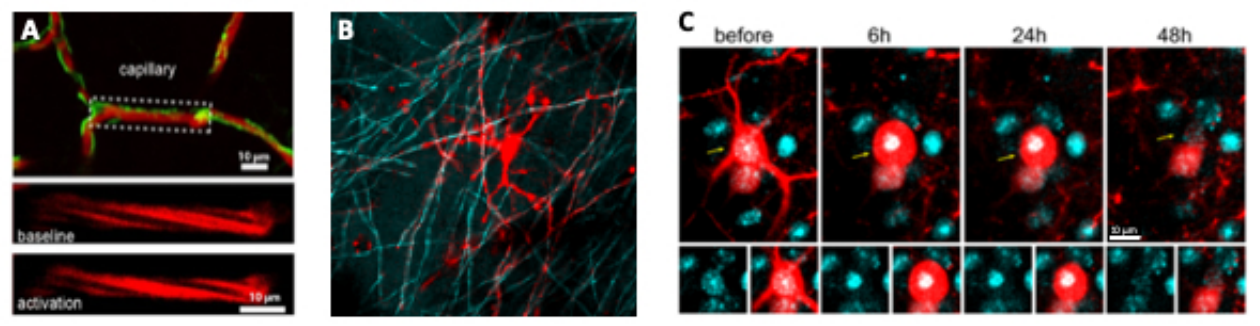

Methods to image and manipulate glial cells

$286 \times 82 \mathrm{~mm}(54 \times 54 \mathrm{DPI})$

John Wiley \& Sons, Inc. 


\section{A. Astrocyte-Specific Modulation}

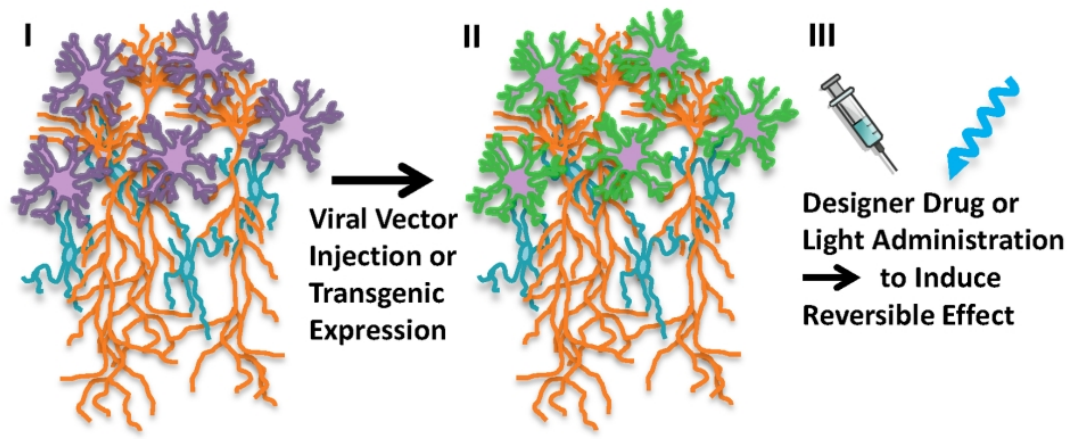

\section{B. Chemogenetic Tools}

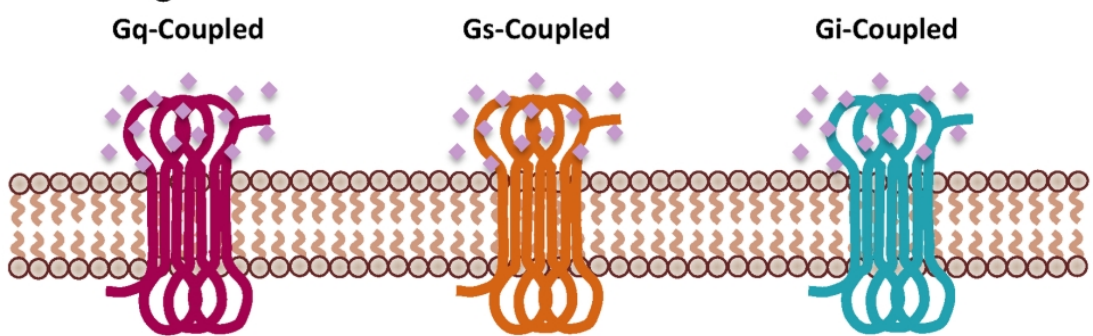

For Example: hM3Dq (Ligand- CNO) MrgA1R (Ligand- FMRF)

\section{Optogenetic Tools}

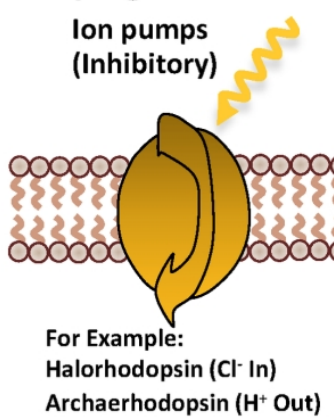

For Example: GsD (Ligand- CNO) Rs1 (Ligand- GR-125487)
For Example: hM4Di (Ligand- CNO) KORD (Ligand-SALB)

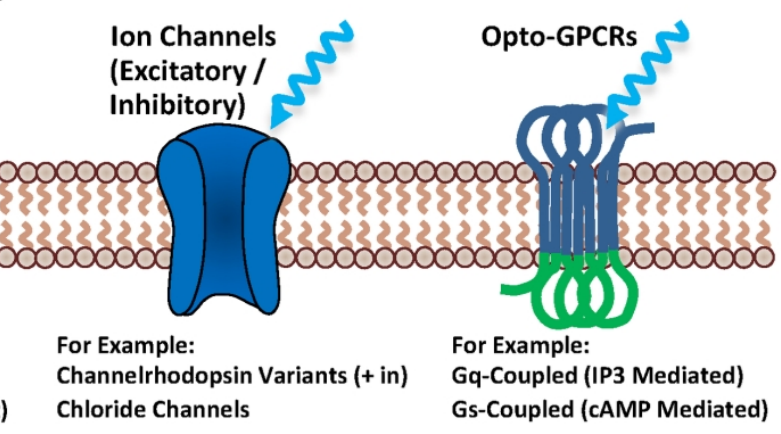

Chemogenetic and optogenetic tools for astrocytic manipulation $158 \times 213 \mathrm{~mm}(300 \times 300 \mathrm{DPI})$ 

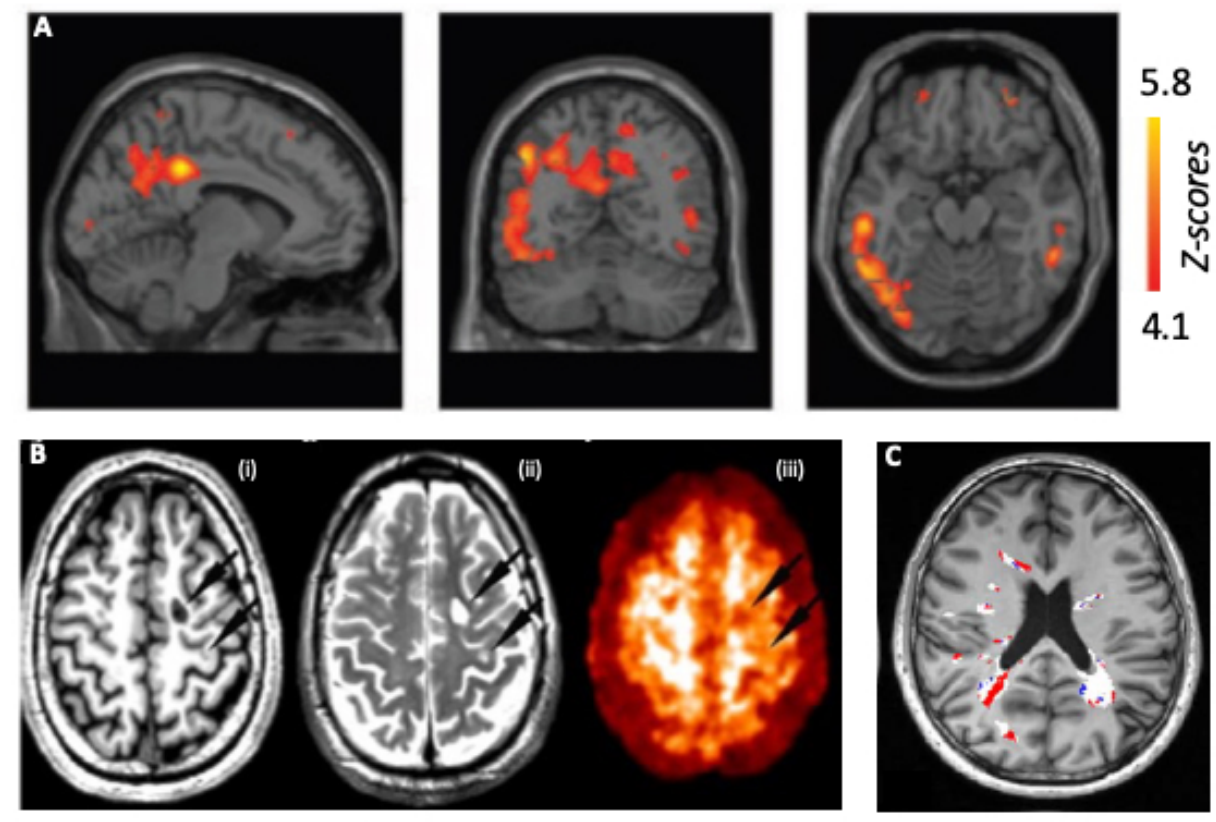

Non-invasive imaging of glial cells in patients $158 \times 107 \mathrm{~mm}(96 \times 96 \mathrm{DPI})$ 


\begin{tabular}{|c|c|}
\hline Lentiviral Vectors & Adeno-associated viral Vectors \\
\hline \multicolumn{2}{|c|}{ Infect both dividing and non-dividing cells } \\
\hline \multicolumn{2}{|c|}{ Long-term gene expression } \\
\hline $\begin{array}{l}\text { Integrating virus } \\
\text { Integration-deficient LV }\end{array}$ & Non-integrating virus \\
\hline Single stranded RNA viruses & Single stranded DNA viruses \\
\hline $8 \mathrm{~kb}$ of capacity & $\begin{array}{l}\text { 4.5kb of capacity for single strand AAV } \\
2.2 \mathrm{~kb} \text { of capacity for self-complentary AAV }\end{array}$ \\
\hline Retroviridae & Dependovirus genus of the Parvoviridae \\
\hline Enveloped & Not enveloped \\
\hline No pre-immunity & Pre-existing neutralizing antibodies \\
\hline Low to medium diffusion & High diffusion \\
\hline
\end{tabular}




\begin{tabular}{|c|c|c|c|c|c|c|c|}
\hline Reference & CNS cells analyzed & Species & Tissue & Condition & Stage & Number of cells & Accession number \\
\hline \multicolumn{8}{|l|}{$\begin{array}{l}\text { Sc-RNASeq studies } \\
\text { Microglia }\end{array}$} \\
\hline Matcovitch-Natan et al., 2016 & Micro & Mouse & WB & Control & E12.5 / E18.5 / Adult & 2,831 & GSE79819 \\
\hline Keren-Shaul et al., 2017 & Micro & Mouse & WB & $A D$ & $1 / 3 / 6 / 8 \mathrm{mo}$ & 8,016 & GSE98969 \\
\hline Mathys et al., 2017 & Micro & Mouse & Hpp & Neurodegeneration & Adults, 0 / 1 / 2 / 6 w post-induction & 1,685 & GSE103334 \\
\hline Tay et al., 2018 & Micro & Mouse & $\mathrm{FN}$ & FNX & $2 \mathrm{mo}, 0 / 7 / 30 \mathrm{~d}$ post-axotomy & 944 & GSE90975 \\
\hline Sousa et al., 2018 & Micro & Mouse & WB & LPS (4 mg/kg i.p.) & $24 \mathrm{~h}$ post treatment & 1,247 & GSE115571 \\
\hline Hammond et al., 2019 & Micro & Mouse & WB & Physio \& Demyelination & E14.5 / P4-5 / P30 / P100 / P540 & 76,149 & GSE121654 \\
\hline Li et al., 2019 & Micro/Monocytes & Mouse & WB - Ctx/CB/Hpp/St/OB/CP & Control & $\mathrm{E} 14.5-\mathrm{P} 7$ / $8 \mathrm{mo}$ & 1,816 & GSE123030 \\
\hline Ronning et al., 2019 & Micro/Monocytes & Mouse & Retina & Retinal degeneration & $48 \mathrm{~h}$ after light exposure & NS & GSE121081 \\
\hline Masuda et al., 2019 & Micro & Mouse & 10 brain regions & Physio/Cuprizone/FNX & E16.5 - P21 / 4 mo & 3,826 & GSE120629 \& GSE120747 \\
\hline Masuda et al., 2019 & Micro & Human & Surgical resections & Control \& MS & NS & 1,180 & GSE124335 \\
\hline Sala Frigerio et al., 2019 & Micro & Mouse & $\mathrm{Ctx} / \mathrm{Hpp}$ & $A D$ & $3 / 6 / 12 / 21 \mathrm{mo}$ & 10,801 & GSE127893 \\
\hline \multicolumn{8}{|l|}{ Oligodendrocyte } \\
\hline Marques et al., 2016 & Oligo & Mouse & 10 brain regions & Control & $\mathrm{P} 21-30 / 2 \mathrm{mo}$ & 5,072 & GSE75330 \\
\hline Marques et al., 2018 & Oligo & Mouse & Brain \& SC & Physio & E13.5 / P7 & $\begin{array}{l}1,514 \text { (+ cells from } \\
\text { Marques 2016) }\end{array}$ & GSE95194 \\
\hline Falcao et al., 2018 & Oligo & Mouse & SC & MS (EAE model) & 15-20 d post induction & 1,765 & GSE113973 \\
\hline \multicolumn{8}{|c|}{ All brain cells but significant findings on glial cells } \\
\hline Zeisel et al., 2015 & All & Mouse & Hpp (CA1) \& sCtx & Control & P20-30 & 3005 & GSE60361 \\
\hline La Manno et al.. 2016 & All & Mouse & VMB & Development & E11.5-18.5 / P19-27/ P28-57 & 1,907 & GSE76381 \\
\hline & All & Human & VMB & Development & $6 \mathrm{w}$ gestation & 1,977 & GSE76381 \\
\hline Gocke et al., 2016 & All & Mouse & St & Control & 5-7 wo & 1,208 & GSE82187 \\
\hline Onorati et al., 2016 & All & Human & $\mathrm{Cx}$ & Control & 5-20 gestation week & 255 & GSE81475 \\
\hline Chen et al., 2017 & All & Mouse & Нур & Control & 8-10 wo & 3,319 & GSE87544 \\
\hline Wu et al. 2017 & All & Mouse & Medial Amy & Physio \& Seizure & 8-10 wo & 20.679 & GSE103976 \\
\hline Artegiani et al., 2017 & NSC \& niche cells & Mouse & $\mathrm{Hpp}(\mathrm{DG})$ & Control & $6-10$ wo & 1,109 & GSE106447 \\
\hline Nowakowski et al., 2017 & All & Human & PFC, V1 Ctx \& MGE & Embryonic development & $6-36$ w gestation & 4.261 & NS \\
\hline Kalish et al., 2017 & All & Mouse & LGN & Control & P5 / P10 / P16 / P21 & 35,326 & GSE108761 \\
\hline Avey et al., 2018 & All & Mouse & ACC & Morphine treatment & 6-12 wo & 23,276 & GSE118918 \\
\hline Fan et al., 2018 & All & Human & 22 brain regions & Control & $22-23$ w gestation & 4,233 & GSE103723 \\
\hline Hrvatin et al., 2018 & All & Mouse & Visual Ctx & Visual stim. & $7-8$ wo & 114.601 & GSE102827 \\
\hline Saunders et al., 2018 & All & Mouse & 9 brain regions & Control & 8-10 wo & 690.000 & GSE116470 \\
\hline Zeisel et al., 2018 & All & Mouse & $\begin{array}{l}19 \text { regions (incl. SC, sensory, } \\
\text { sympathic, enteric nervous system) }\end{array}$ & Control & P12-30 / 6-8 wo & 160.796 & Acc\# SRP135960 \\
\hline Klum et al., 2018 & Precursor cells & Mouse & SC & Control & E11.5 / E15.5 & 350 & GSE117997 \\
\hline Lukowskiet al., 2019 & All & Human & Retina & Control & $53-80$ yo & 20,009 & NS \\
\hline Heng et al., 2019 & All & Mouse & Retina \& Ctx & Control \& hypoxia & Adult & 31,692 & GSE125708 \\
\hline Clark et al., 2019 & All & Mouse & Retina & Control & 10 stages (E11->P14) & $\simeq 32,000$ & GSE118614 \\
\hline Todd et al., 2019 & All & Mouse & Retina & NMDA injections & $6-14$ wo & 49,860 & Available on request \\
\hline Gunner et al., 2019 & All & Mouse & sCtx & Whisker deprivation & P5, 24h post deprivation & $\simeq 48,000$ & GSE129150 \\
\hline Ximerakis et al., 2019 & All & Mouse & Hindbrain & Aging & $2-3 \mathrm{mo} / 21-23 \mathrm{mo}$ & 37069 & GSE129788 \\
\hline \multicolumn{8}{|l|}{ Sn-RNASeq studies } \\
\hline Lake et al., 2017 & & Human & Visual \& frontal Ctx / Lateral Cb & Control & Adult & 35,289 & GSE97942 \\
\hline Mathys et al., 2019 & & Human & PFC & $A D$ & Control, early and late onset $A D$ & 75,060 & https://www.synapse.org/\#!ISynapse: \\
\hline Velmeshev et al., 2019 & & Human & PFC \& ACC & Autism & $2-22$ yo & 101,559 & PRJNA34002 \\
\hline Jarkel et al., 2019 & & Human & WM & MS & Adult & 35,753 & GSE118257 \\
\hline Schirmer et al., 2019 & & Human & Cortical GM \& subcortical WM & MS & Adult & 48,919 & PRJNA544731 \\
\hline
\end{tabular}




\begin{tabular}{|c|c|c|c|}
\hline Reference & CNS cells analyzed & Species & Mouse line \\
\hline \multicolumn{4}{|l|}{ Microglia } \\
\hline Matcovitch-Natan et al., 2016 & Micro & Mouse & $\mathrm{CX} 3 \mathrm{CR} 1^{+} / \mathrm{gfp}$ \\
\hline Keren-Shaul et al., 2017 & Micro & Mouse & $5 x F A D$ \\
\hline Mathys et al., 2017 & Micro & Mouse & CK-p25 \\
\hline Tay et al., 2018 & Micro & Mouse & $\mathrm{CX} 3 \mathrm{CR} 1^{+} / \mathrm{gfp}$ \\
\hline Sousa et al., 2018 & Micro & Mouse & C57BL/6N \\
\hline Hammond et al., 2019 & Micro & Mouse & C57BL/6J \\
\hline Li et al., 2019 & Micro/Monocytes & Mouse & $\mathrm{C} 57 \mathrm{BL} / 6$ \\
\hline Ronning et al., 2019 & Micro/Monocytes & Mouse & $\operatorname{Arr}^{-1-}$ \\
\hline Masuda et al., 2019 & Micro & Mouse & $\mathrm{CD} 1$ \\
\hline Masuda et al., 2019 & Micro & Human & - \\
\hline Sala Frigerio et al., 2019 & Micro & Mouse & APPNL-G-F \\
\hline \multicolumn{4}{|l|}{ Oligodendrocyte } \\
\hline Marques et al., 2016 & Oligo & Mouse & Reporter mice \\
\hline Marques et al., 2018 & Oligo & Mouse & Pdgfra reporter mice \\
\hline Falcao et al., 2018 & Oligo & Mouse & Pdgfra reporter mice \\
\hline \multicolumn{4}{|c|}{ All brain cells but significant findings on glial cells } \\
\hline Zeisel et al., 2015 & All & Mouse & CD-1 \\
\hline La Manno et al., 2016 & All & Mouse & $C D-1$ \\
\hline La Manno et al., 2016 & All & Human & - \\
\hline Gocke et al., 2016 & All & Mouse & C57BL/6J \\
\hline Onorati et al., 2016 & All & Human & - \\
\hline Chen et al., 2017 & All & Mouse & $\mathrm{B} 6 \mathrm{D} 2 \mathrm{~F} 1$ \\
\hline Wu et al. 2017 & All & Mouse & C57BL/6J \\
\hline Artegiani et al., 2017 & NSC \& niche cells & Mouse & C57BL/6 \\
\hline Nowakowski et al., 2017 & All & Human & - \\
\hline Kalish et al., 2017 & All & Mouse & C57BL/6J \\
\hline Avey et al., 2018 & All & Mouse & C57BL/6 \\
\hline Fan et al., 2018 & All & Human & - \\
\hline Hrvatin et al., 2018 & All & Mouse & C57BL/6 \\
\hline Saunders et al., 2018 & All & Mouse & C57BL/6N \\
\hline Zeisel et al., 2018 & All & Mouse & CD-1 \\
\hline Klum et al., 2018 & Precursor cells & Mouse & NS \\
\hline Lukowskiet al., 2019 & All & Human & - \\
\hline Heng et al., 2019 & All & Mouse & WT \& Ndp ${ }^{-/-}$ \\
\hline Clark et al., 2019 & All & Mouse & Chox10-Cre-GFP \\
\hline Todd et al., 2019 & All & Mouse & C57BL/6 \\
\hline Gunner et al., 2019 & All & Mouse & CX3CR1gfp \\
\hline Ximerakis et al., 2019 & All & Mouse & C57BL/6J \\
\hline \multicolumn{4}{|l|}{ Sn-RNASeq studies } \\
\hline Lake et al., 2017 & & Human & - \\
\hline Mathys et al., 2019 & & Human & - \\
\hline Velmeshev et al., 2019 & & Human & - \\
\hline Jarkel et al., 2019 & & Human & - \\
\hline Schirmer et al., 2019 & & Human & - \\
\hline
\end{tabular}


Tissue

WB

WB

Hpp

FN

WB

WB

WB - Ctx/CB/Hpp/St/OB/CP

Retina

10 brain regions

Surgical resections

$\mathrm{Ctx} / \mathrm{Hpp}$
Condition

Control

$A D$

Neurodegeneration

FNX

LPS (4 mg/kg i.p.)

Physio \& Demyelination

Control

Retinal degeneration

Physio/Cuprizone/FNX

Control \& MS

$A D$
Stage

E12.5 / E18.5 / Adult

$1 / 3 / 6 / 8$ mo

Adults, 0 / 1 / 2 / 6 w post-induction

2mo, 0 / 7 / 30 d post-axotomy

$24 \mathrm{~h}$ post treatment

E14.5 / P4-5 / P30 / P100 / P540

E14.5 - P7 / 8 mo

$48 \mathrm{~h}$ after light exposure

E16.5 - P21 / 4 mo

NS

$3 / 6 / 12 / 21 \mathrm{mo}$

\begin{tabular}{|c|c|c|}
\hline 10 brain regions & Control & P21-30 / 2 mo \\
\hline Brain \& SC & Physio & $\mathrm{E} 13.5 / \mathrm{P} 7$ \\
\hline SC & MS (EAE model) & 15-20 d post induction \\
\hline Hpp (CA1) \& sCtx & Control & P20-30 \\
\hline vMB & Development & E11.5-18.5 / P19-27/ P28-57 \\
\hline vMB & Development & $6 \mathrm{w}$ gestation \\
\hline St & Control & $5-7$ wo \\
\hline$C x$ & Control & 5-20 gestation week \\
\hline Hyp & Control & 8-10 wo \\
\hline Medial Amy & Physio \& Seizure & $8-10$ wo \\
\hline $\mathrm{Hpp}(\mathrm{DG})$ & Control & $6-10$ wo \\
\hline PFC, V1 Ctx \& MGE & Embryonic development & 6-36 gestation week \\
\hline LGN & Control & P5 / P10 / P16 / P21 \\
\hline ACC & Morphine treatment & 6-12 wo \\
\hline 22 brain regions & Control & $22-23$ w gestation \\
\hline Visual Ctx & Visual stim. & 7-8 wo \\
\hline 9 brain regions & Control & $8-10$ wo \\
\hline $\begin{array}{c}19 \text { regions (incl. SC, sensory, sympathic, } \\
\text { enteric nervous system) }\end{array}$ & Control & P12-30 / 6-8 wo \\
\hline SC & Control & E11.5 / E15.5 \\
\hline Retina & Control & $53-80$ yo \\
\hline Retina \& Ctx & Control \& hypoxia & Adult \\
\hline Retina & Control & 10 stages (E11->P14) \\
\hline Retina & NMDA injections & 6-14 wo \\
\hline $\mathrm{sCtx}$ & Whisker deprivation & P5, 24h post deprivation \\
\hline Hindbrain & Aging & $2-3 \mathrm{mo} / 21-23 \mathrm{mo}$ \\
\hline Visual \& frontal Ctx / Lateral Cb & Control & Adult \\
\hline PFC & $A D$ & Control, early and late onset $A D$ \\
\hline PFC \& ACC & Autism & $2-22$ yo \\
\hline WM & MS & Adult \\
\hline Cortical GM \& subcortical WM & MS & Adult \\
\hline
\end{tabular}




\begin{tabular}{|c|c|c|}
\hline Sex & Isolation strategy & Sequencing strategy \\
\hline NS & $\mathrm{CD} 11 \mathrm{~b}^{+} / \mathrm{CD} 45^{+} / \mathrm{CX} 3 \mathrm{CR} 1-\mathrm{GFP}^{+}$ & MARS-Seq \\
\hline NS & $\mathrm{CD}_{4} 5^{+}$ & MARS-Seq \\
\hline$\hat{\jmath}$ & 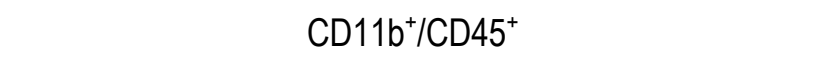 & SMART-Seq2 \\
\hline q & $\mathrm{GFP}^{+} / \mathrm{CD} 11 \mathrm{~b}^{+} / \mathrm{CD} 45^{10}$ & CEL-Seq2 \\
\hline$\widehat{O} \& q$ & $\mathrm{CD} 11 \mathrm{~b}^{+} / \mathrm{CD} 45^{10}$ & Drop-seq \\
\hline$\hat{o} \& / o r$ & $\mathrm{CD} 11 \mathrm{~b}^{+} / \mathrm{CD} 45^{\mathrm{lo}}$ & Drop-Seq (10xgenomics) \\
\hline NS & $\mathrm{cKit} / \mathrm{CD} 45^{+} ; \mathrm{CD} 11 \mathrm{~b}^{+} / \mathrm{CD} 45^{10} ; \mathrm{CD} 11 \mathrm{~b} / \mathrm{CD} 45^{\mathrm{hi}}$ & SMART-Seq2 \\
\hline$q$ & Live cells/CD11 $\mathrm{b}^{+} / \mathrm{CD} 45^{+}$ & Drop-Seq (10xgenomics) \\
\hline q & $\mathrm{CD} 11 \mathrm{~b}^{+} / \mathrm{CD} 45^{10} / \mathrm{Ly} 6 \mathrm{C}^{-} / \mathrm{Ly} 6 \mathrm{G}^{-} / \mathrm{CD}^{2} 26^{-}$ & SMART-Seq2 \\
\hline NS & $\mathrm{CD}_{4} 5^{+}$ & CEL-Seq2 \\
\hline$\widehat{\delta} \& q$ & $\mathrm{CD} 11 \mathrm{~b}^{+}$ & SMART-Seq2 \\
\hline $0 \&$ \& & $\mathrm{GFP}^{+} / \mathrm{RFP}^{+}$or no sorting depending on the brain area & STRT-seq \\
\hline$\widehat{O} \& q$ & $\mathrm{GFP}^{+}$ & STRT-seq \\
\hline$\hat{0} \& q$ & $\mathrm{GFP}^{+}$ & SMART-Seq2 \\
\hline$\widehat{\delta} \& q$ & No purification & STRT-Seq \\
\hline NS & No purification & STRT-Seq \\
\hline NS & No purification & STRT-Seq \\
\hline$\hat{0}$ & No purif \& FACS sorting (Aldh1l1-GFP \& D1-tdTomato ${ }^{+}$) & C1/SMART-Seq2 \\
\hline NS & No purification & C1/SMART-Seq2 \\
\hline$q$ & No purification & Drop-Seq \\
\hline$\hat{\sigma}$ & No purification & Drop-Seq \\
\hline NS & GluR1-/CD24- & SORT-Seq \\
\hline NS & No purification & Fluidigm-C1 \\
\hline NS & No purification & inDrops \\
\hline$\hat{0}$ & No purification & Drop-Seq \\
\hline$\hat{O} \& q$ & No purification (Manual selection) & STRT-seq \\
\hline$\hat{0}$ & No purification & Drop-Seq \\
\hline $0^{\pi}$ & No purification & Drop-Seq (10xgenomics) \\
\hline$\widehat{O} \& q$ & No purification (except enteric nervous system) & Drop-Seq \\
\hline NS & $\mathrm{CD} 133^{+}$ & SMART-Seq2 \\
\hline$\delta \& q$ & No purification & Drop-Seq (10x genomics) \\
\hline$\hat{\jmath}$ & No purification & Drop-Seq (10x genomics) \\
\hline$\delta \& q$ & Chx10-GFP ${ }^{+}$ & SMART-Seq2 \\
\hline NS & No purification & Drop-Seq (10x genomics) \\
\hline NS & No purification & inDrops \\
\hline$\hat{0}$ & No purification & Drop-Seq (10x genomics) \\
\hline NS & $\mathrm{DAPI}^{+}$nuclei & snDrop-seq \\
\hline$\delta \& q$ & No purification & SnDrop-seq (10xgenomics) \\
\hline NS & No purification & snDrop-seq (10xgenomics) \\
\hline$\widehat{0} \& q$ & No purification & snDrop-seq (10xgenomics) \\
\hline$\widehat{O} \& q$ & No purification & snDrop-seq (10xgenomics) \\
\hline
\end{tabular}




\begin{tabular}{|c|c|c|}
\hline Number of cells & Accession number & PMID \\
\hline 2,831 & GSE79819 & 27338705 \\
\hline 8,016 & GSE98969 & 28602351 \\
\hline 1,685 & GSE103334 & 29020624 \\
\hline 944 & GSE90975 & 30185219 \\
\hline 1,247 & GSE115571 & 30206190 \\
\hline 76,149 & GSE121654 & 30471926 \\
\hline 1,816 & GSE123030 & 30606613 \\
\hline NS & GSE121081 & 30890724 \\
\hline 3,826 & GSE120629 \& GSE120747 & 30760920 \\
\hline 1,180 & GSE124335 & 30100929 \\
\hline 10,801 & GSE127893 & 31018141 \\
\hline 5,072 & GSE75330 & 27284195 \\
\hline 1,514 (+ cells from & GSE95194 & 30078729 \\
\hline 1,765 & GSE113973 & 30420755 \\
\hline 3005 & GSE60361 & 25700174 \\
\hline 1,907 & GSE76381 & 27716510 \\
\hline 1,977 & GSE76381 & 27716510 \\
\hline 1,208 & GSE82187 & 27425622 \\
\hline 255 & GSE81475 & 27568284 \\
\hline 3,319 & GSE87544 & 28355573 \\
\hline 20.679 & GSE103976 & 29024657 \\
\hline 1,109 & GSE106447 & 29241552 \\
\hline 4.261 & NS & 29217575 \\
\hline 35,326 & GSE108761 & 29343640 \\
\hline 23,276 & GSE118918 & 30257220 \\
\hline 4,233 & GSE103723 & 29867213 \\
\hline 114.601 & GSE102827 & 29230054 \\
\hline 690.000 & GSE116470 & 30096299 \\
\hline 160.796 & Acc\# SRP135960 & 30096314 \\
\hline 350 & GSE117997 & 30166336 \\
\hline 20,009 & NS & 31436334 \\
\hline 31,692 & GSE125708 & 30988181 \\
\hline$\simeq 32,000$ & GSE118614 & 31128945 \\
\hline 49,860 & Available on request & 31170999 \\
\hline$\simeq 48,000$ & GSE129150 & 31209379 \\
\hline 37069 & GSE129788 & 31551601 \\
\hline 35,289 & GSE97942 & 28729663 \\
\hline 75,060 & wW.synapse.org/\#!Synapse:syn1 & 31042697 \\
\hline 101,559 & PRJNA34002 & 31097668 \\
\hline 35,753 & GSE118257 & 30747918 \\
\hline 48,919 & PRJNA544731 & 31316211 \\
\hline
\end{tabular}




\section{Main findings related to glial cells}

Stepwise Micro developmental program. 16 cells clusters across development. Micro diversity higher at embryonic \& early $\mathrm{F}$ Identif. of DAM. DAM program activated in a two-step process, the $2^{\text {nd }}$ is TREM2-dependent

Early- \& late-response states of reactive Micro in neurodegeneration (trajectory of cellular reprogramming)

Identif. of Micro subtype associated with neurodegeneration due to nerve injury in WT mice. Similar profile compared to sub Identif. of inflammation-specific subtypes of reactive micro, different from those identified in neurodegeneration. Emergence Identif. of $>9$ Micro states. Greatest heterogeneity in young \& aged micro. Distinct Micro subtypes in MS mice Identif. of 6 Micro states. Early postnatal micro are more heterogeneous. Identif. of a DAM-like Micro subtype in developpins Identif. of 5 Micro \& 5 monocytes/macrophages subtypes in degenerating retina. High degree of molecular heterogeneity Identif. of time- \& region-dependent micro subtypes. Different Micro subtypes between demyelinating \& neurodegenerative । Matching of human \& mouse Micro clusters, in healthy \& MS brains Identif. of 2 subtypes of reactive Micro in physiology (ARMs \& IRMs). Amyloid accumulation increases IRM \& ARM proporti Identif. of 13 distinct subtypes in the Oligo lineage, 12 forming a continuum from Pdgfra ${ }^{+}$OPCs to mature Oligo. A distinct sı OPCs from different CNS regions are similar; E13.5 Pdgfra ${ }^{+}$cells give rise mainly to OPCs but also to pericyte lineage cells Identif. of unique subtypes of Oligo \& OPCs in EAE, with unconventionnal immunomodulatory functions

Identif. of 2 Astro, 1 Micro, 6 Oligo subtypes \& some subtype-specific transcription factors Identif. 2 radial glia-like cell, 1 progenitor, 1 ependymal cell subtypes in developing mouse VZ Identif. 5 radial glia-like cell, 5 early progenitor, 1 OPC subtypes in developing human VZ Identif. of 2 oligo subtypes (Newly formed \& Mature). Continuous transcriptional gradient for Astro, with no clear demarcatio Cortical \& SC neuroepithelial stem cells are in vitro models for neural stem/progenitor cells, in early human neurodevelopm Identif. of 11 non-neuronal cell clusters in Hyp, incl. tanicytes, which are disctinct from ependymal cells Identif. of 3 Astro subpopulations, immediate early gene induction following seizures. Improved cell preparation to reduce tr: Gene signatures of non-neuronal cell types (incl. Astro, Micro, Oligo) in the Hpp niche

Radial glia differenciate through topographical, typological \& temporal cues

Genome-wide map of gene expression within neurons, glia, \& vascular cells at 4 stages of postnatal development of the mo Morphine-dependent transcriptional changes in Oligo \& Astro

At this development stage, glial cells account for only $8 \%$ of cells. Micro development is not synchronized across different bi Astro, oligo, endothelial cells highly responsive to visual stimulus

Molecular definition of mural cells at the BBB

7 regionally restricted Astro types. Oligo converge to a single state at early lineage stage, then diversify

Roles of Sox proteins in Astro \& Oligo development. Astro- \& oligo-specific gene expression defined in the dev Transcriptional landscape of human retinal cells, incl. Müller Glia Identif. of 12 cell clusters in retina. Transcriptional changes in mouse Müller glia after hypoxia

NFI transcription factors control bipolar interneurons \& Müller glia cell fate specification

Reactive micro provide neuroprotection in excitotoxin-damaged retina

Neuron-to-micro signaling for cortical synaptic remodeling. Context-dependent immune mechanisms to remodel synapses ir Cell identity preserved with aging. Some gene expression changes common across cell types, some cell-type specific (ever

OPCs \& Astro are different between $\mathrm{Cb} \& \mathrm{Ctx}$

Complexity of neuron-glia interactions in $A D$

Molecular state of Micro is affected in Autism

Heterogeneity of Oligo in healthy brains. Relative abondance of some clusters changes in MS patients (both active lesions \{ Transcriptomic changes in Oligo, Micro, Astro in rim areas of chronically active subcortical lesions 